\title{
Temporary versus Permanent Shocks: Explaining Corporate Financial Policies*
}

\author{
Alexander S. Gorbenko \\ Graduate School of Business \\ Stanford University
}

\author{
Ilya A. Strebulaev \\ Graduate School of Business \\ Stanford University
}

First version: September 2006

This version: September 2009

${ }^{*}$ We are grateful to Anat Admati, Harjoat Bhamra, Hui Chen, Sergei Davydenko, Darrell Duffie, Steven Grenadier, Dirk Hackbarth, Mike Harrison, Sunil Kumar, Dmitry Livdan, Amiyatosh Purnanandam, Ajay Subramanian, Alex Triantis, Neng Wang, Toni Whited, Jeff Zwiebel, and the participants of the Chicago GSB, MIT Sloan, Stanford GSB, and University of Toronto seminars, as well as of the Western Finance Association meeting in Big Sky (2007), the 13th Mitsui Symposium on Finance, University of Michigan, the UBC summer finance symposium, and the LBS 7th Transatlantic PhD conference for thoughtful comments. Address for correspondence: 518 Memorial Way, Stanford Graduate School of Business, Stanford, CA, 94305. Gorbenko: gorbenko@stanford.edu; Strebulaev: istrebulaev@stanford.edu. 


\title{
Temporary Versus Permanent Shocks: Explaining Corporate Financial Policies
}

\begin{abstract}
We investigate corporate financial policies in the presence of both temporary and permanent shocks to firms' cash flows. In our framework firms can experience negative cash flows, changes in and levels of cash flows are imperfectly correlated with firm value, and earnings volatility differs from asset volatility. These results are consistent with empirical stylized facts and are contrary to the implications of existing dynamic capital structure models that allow only for permanent shocks to cash flows. Temporary shocks increase the importance of financial flexibility and may provide an intuitively simple and realistic explanation of empirically observed financial conservatism and low leverage phenomena. The theoretical framework developed in this paper is general enough to be used in various corporate finance applications.
\end{abstract}

Keywords: Leverage, debt financing, capital structure, financing decisions, temporary and permanent shocks, mean-reversion, finance substitution JEL Classification Numbers: G12, G32, G33 
On September 15, 2006, all spinach-based food products were taken from the U.S. market as the result of an outbreak of spinach-borne E.coli. A few days later, quoting Joe Pezzini, chairman of the Grower-Shipper Association of Central California: "Right now, the spinach business is closed. It's stopped." 1 This scary case illustrates a class of typical shocks that may affect a firm's fortunes and that share the following features: Their timing is largely unexpected, their initial magnitude can be substantial, and their effect is felt over a limited time (indeed, about two weeks later, spinach was back in most consumers' baskets). Our paper claims that temporary shocks of this nature are crucial to our understanding of capital structure decisions and can provide a quantitative, natural explanation of well-known empirical patterns, such as financial flexibility and conservatism.

Indeed, according to empirical evidence, financial managers consider financial flexibility, earnings and cash flow volatility, and insufficient internal funds the most important factors influencing financing decisions by their firms (e.g., survey evidence by Graham and Harvey (2001)). Although intuitively appealing, these factors puzzle corporate finance theorists, who find it hard to pin down the exact mechanism of their influence. We may know the nature of economic frictions that lead firms to follow more cautious financing behavior, but existing attempts to quantify their effects leave a lot to be desired. In this paper we address this problem by proposing an economic mechanism and building a novel dynamic contingent-claims framework to study its implications. Importantly, our findings also help explain why traditional models appear incapable of fitting the data.

Our starting observation is that the nature of shocks driving the distribution of corporate cash flows can be summarized by the shocks' magnitude and persistence over time. Some shocks change the long-term prospects of an enterprize and thus influence cash flows permanently. The impact of other shocks instead is temporary and subsides over time. Indeed, most shocks, whether firm- and industry-specific or macroeconomic, can be viewed as temporary shocks. This simple observation helps explain why existing dynamic contingent-claims models of firm behavior exhibit so many features that contradict empirically observed stylized facts. In standard models (e.g., EBIT cash flow models by Goldstein, Ju, and Leland (2001), Morellec (2001), and Strebulaev (2007)), current period cash flow is proportional to the total value of assets. In other words, the value of assets is effectively a perpetuity with a payment equal to the current cash flow. The critical, though often overlooked, implication of these models is that all innovations to the value process have a permanent nature: A unit increase or a unit decrease in the current cash flow increases or decreases the expected value of each future cash flow by exactly this unit adjusted for the growth rate.

Although this critical feature dramatically simplifies such models, it induces several undesirable implications, all of which reflect the assumption of a permanent nature of cash flow shocks. First, the non-negativity of value implies that cash flows can never be negative. However, between 1987

\footnotetext{
${ }^{1}$ Washington Post, September 20 2006, p. D01.
} 
and 2005, approximately $17 \%$ to $25 \%$ of all quarterly cash flows for the full COMPUSTAT sample are negative. ${ }^{2}$ On a broader level, standard contingent claims models of capital structure ignore that firms that are highly profitable today may experience negative cash flows in the near future. ${ }^{3}$ In other words, firms may value financial flexibility to sustain them when cash flows are very low, even though the future is bright. To give an example in the context of the trade-off model, consider the economic marginal tax rate that Scholes and Wolfson (1992) define to account for the present value of the current and future taxes on an extra dollar of income earned. Profitable firms, according to existing models would be predicted to sustain their profitability in the future and therefore assigned high tax rates even though in reality their profitability will be less persistent and their true marginal tax rate should be lower, which would also lower their inclination to issue debt.

Second, the volatilities of cash flow and asset value growth rates are equal in existing models. ${ }^{4}$ Because the asset volatilities for most firms are relatively low, ${ }^{5}$ it becomes difficult to explain the importance of earnings volatility for financing decisions. To rationalize existing capital structure we would need substantially higher implied asset volatilities, which are unlikely to be observed or justified in practice. Third, in the existing models, both changes in and levels of current cash flow and asset value are perfectly correlated, which is inconsistent with both intuition and evidence.

Alas, all these problematic features are caused by the permanent nature of cash flow shocks in standard models. Consider the effect of introducing the temporary component to an otherwise standard cash flow process. The exact nature or sources of these shocks is irrelevant because this intuition is generic. For example, these shocks may affect the demand for a firm's product or the production cost structure. Because their impact is of limited duration, these transitory shocks affect future cash flows disproportionately over the time horizon. The consequences are many: The total realized current cash flow can turn negative (even if asset values are large), earnings and asset volatilities differ, and levels and innovations in current cash flows are imperfectly (though positively) correlated with those in asset values. Overall then, introducing temporary shocks makes the model's behavior patterns consistent with stylized facts about corporate earnings along many dimensions.

More importantly, what is the contribution of this mechanism to explanations of corporate behavior? Intuitively, for any given level of leverage, the expected advantage to debt is likely to be of lower value with more volatile and more frequently lower cash flows. For example, because we expect

\footnotetext{
${ }^{2}$ The frequency of negative cash flows depends on the definition of the underlying accounting variable. For EBITDA (COMPUSTAT item 13) and cash flow from operations (COMPUSTAT item 308), 17.5\% and 25.4\% of observations were negative, respectively. The sample is based on the full quarterly COMPUSTAT/CRSP merged file with the book value minimum cut-off at $\$ 10$ million dollars. See also Givoly and Hayn (2000).

${ }^{3}$ One way to address the non-negativity shortcoming is to introduce operating leverage by subtracting fixed costs of production from gross earnings. To the extent that these costs are also permanent, this approach does not address the root of the problem.

${ }^{4}$ For technical simplicity, these models usually assume a constant interest rate. The presence of a stochastic discount rate would lead to a lesser correlation between current cash flows and their future expectations, but the effect is likely to be minuscule.

${ }^{5}$ For example, Schaefer and Strebulaev (2008) estimate annualized asset volatility for an average firm with an existing investment-grade rating to be approximately $23 \%$.
} 
cash flow to be more often lower than the level of contractual financial obligations, the expected tax benefits of debt should fall in the absence of full loss tax offset provisions. In other words, incentives to use debt decrease with the probability that a firm will experience nontaxable states of the world (Kim (1989), Graham (2003)).

At a first glance, equityholders seemingly could borrow against future earnings, in which case temporary negative shocks are unlikely to exert any material influence. Two features, however, challenge this view: the limited liability option of residual claimants and costly external financing in distress. Limited liability gives residual claimants a real option of abandoning the firm if the present value of a negative shock is large enough, which in turn gives rise to an asymmetry between negative and positive shocks. In particular, equityholders benefit disproportionately from positive shocks, whereas debtholders bear the worst negative shocks and thus demand ex ante compensation, which reduces the equityholders' desire to rely on debt in the first place. In addition, the presence of financing frictions that affects firms asymmetrically across the states of nature further exacerbates the disadvantage of debt financing. In reality, firms could find it difficult to raise funds frictionlessly to finance a temporary shortfall for information, liquidity, or institutional reasons. Firms that find themselves in financial distress situations, often raise expensive external financing or sell assets at a liquidity discount (Asquith, Gertner, and Scharfstein (1994), Pulvino (1998)). As the 2008 financial crisis demonstrates, these frictions can be remarkably large and out of the control of any individual firm. Financing frictions effectively extend the notion of financial distress to asset value levels for which, under the assumption of a perfect correlation of asset values and cash flows, the firm should not experience any financing difficulties.

To quantify the impact of permanent and temporary shocks, we build a dynamic financing model with both types. For comparison purposes, we employ the trade-off model, a standard workhorse of the contingent claims framework. We find that the value of financial flexibility may indeed increase dramatically when firms face prospects of immediate adverse temporary shocks of large magnitude. For the benchmark set of parameters, the optimal leverage ratio decreases from $58 \%$ to $37 \%$ with the introduction of temporary shocks, conditional on retaining the same total asset volatility. Such a remarkably large difference is quantitatively robust to wide variation in the parameters. It is important to emphasize that this result is obtained under the static capital structure assumption: as well known, allowing firms to manage their capital structure dynamically will lower the leverage even further. Moreover, if managers (but not investors) are myopic and take into account only a limited number of shocks, their remaining desire to issue debt rapidly decreases. For the same set of parameters, if the manager expects only one large shock in the future, optimal leverage falls to $20 \%$, similar to the quasi-market leverage ratio of a typical public U.S. firm. To underline the economic message behind our results, we find that the impact of temporary shocks on financial decisions can be disproportionately large compared to their relatively small contribution to the unlevered firm value.

Although the economic intuition underlying temporary shocks to cash flows is straightforward, 
building a framework that fully incorporates both types of shocks entails formidable technical challenges. The lack of perfect correlation between permanent and temporary shocks gives rise to two sources of dynamic uncertainty that makes all financing decisions intrinsically complicated. To see this clearly, consider a firm whose cash flows are driven by two stochastic processes: one responsible for the long-term prospects (e.g., a geometric Brownian motion) and another constitutes the short-term deviations from long-term cash flow (e.g., any process than mean-reverts to long-term cash flow levels). In traditional models (which only include the long-term component) the default decision consists of finding a certain low cash flow level (or, equivalently, asset value) threshold that warrants default when reached for the first time. Importantly, with transitory shocks, the knowledge of either total asset value or total realized cash flow by itself is insufficient to make a well-informed default decision. The current cash flow can be low because firm's future is bleak (and it is optimal to default) or because the future prospects are bright conditional on the firm surviving a temporary period of losses (it is optimal to make debt payments). Only by decomposing the shock into the permanent and temporary components can equityholders make the optimal default decision.

This problem is very difficult to solve though, because the default boundary is now a curve in a two-dimensional permanent-temporary shock space and mathematical problems related to the first passage to such a boundary have not been satisfactorily solved even for simplest cases. In this light, our contribution becomes clearer. In a nutshell, we build a simplified framework that incorporates all these intuitive features. Specifically, we assume that the temporary component is driven by Poisson jump shocks that arrive in discrete time and then fade in expectation over time because of their mean-reversion to the permanent cash flow. Transitory shocks are characterized by their longevity (or speed of mean-reversion), their arrival intensity, and their magnitude. To compare our results to the permanent-only scenario, we introduce a standard trade-off model based on the interplay of taxes and bankruptcy costs and solve for optimal default and capital structure. We would like to stress that, although there is nothing special about the trade-off model, it presently enjoys a certain reputation as the only structurally quantified approach. To this extent, we model the permanent component of the cash flow process as in the standard contingent claims models (e.g.,Fischer, Heinkel, and Zechner (1989) and Leland (1994)). Because temporary shocks of the same magnitude should have larger impact on smaller firms, we assume the additivity structure of total cash flow, which leads to an empirically observed negative relation between asset values and volatilities.

We surely have to make a number of heroic assumptions and ignore some important avenues (such as optimal investment and cash holdings decisions). Nevertheless, stylized facts produced by our model, pertaining to both earnings and financial decisions, are consistent with empirical observations and therefore suggest the strong influence of temporary shocks. In particular, we reconcile the evidence that indicates observed asset volatilities are not high enough to justify financial conservatism, but earnings volatility is an important determinant of firms' financial decisions.

Our paper relates to a burgeoning field that tries to extend the contingent claims models to a 
broader set of corporate finance issues. Recent examples include Hackbarth and Morellec (2008), Sundaresan and Wang (2007), and Subramanian (2008). These papers only consider the case of permanent shocks. Hackbarth, Miao, and Morellec (2006) and Bhamra, Kühn, and Strebulaev (2009a, 2009b) model corporate financial policy in the presence of business cycles, which also give rise to the second state variable. For example, Hackbarth et al. are the first to study the impact of macro shocks. In their setup, the change in the macroeconomic state (boom to recession) leads to a jump to the cash flow level of a known size. Therefore, the default decision depends on the state of the economy. However, their study does not allow for shocks of larger variability, which might lead to negative cash flows. In our framework, temporary shocks could be thought of as both firmspecific and industry- or macro-wide. Our paper is also close in spirit to recent work that investigates the importance of financial flexibility and external financing costs in firms' financial and investment decisions (Hennessy and Whited (2005, 2007), Whited (2006), Gamba and Triantis (2008a, 2008b)).

Sarkar and Zapatero (2003) study financial decisions in a contingent claims framework, in which earnings are mean-reverting. Their cash flow process cannot turn negative, though, and does not allow for jumps in earnings. Moreover, their setup leads to perfect correlation between cash flows and asset values and to a positive relation between asset values and volatilities. In the same fashion, any cash flow process driven by a one-state variable cannot distinguish between permanent and temporary shocks and explain a variety of empirical facts. Some recent studies justify using the double exponential jump diffusion process (a variation of which we use to model temporary shocks) in asset pricing models. In particular, Kou (2002) and Kou and Wang (2004) study option pricing when values are affected by this type of jumps, though again, the shocks they consider are permanent.

The rest of the paper is organized as follows. The following section presents motivating examples

and introduces the notation and initial intuition. Section II presents our benchmark model and Section III contains the main results. Section IV concludes. All proofs appear in Appendix A. Appendix B contains the details of the numerical procedure.

\section{Motivating examples}

Consider a firm with access to a cash flow-generating investment project. At any time $t$, the realized cash flow, $\pi_{t}$, is the sum of two components: the cash flow generated by the permanent component, $\delta_{t}$, which reflects the long-term prospects of project returns, and the mean-reverting cash flow, $\epsilon_{t}$, which is generated by deviations from the permanent component caused by shocks of shorter duration:

$$
\pi_{t}=\delta_{t}+\epsilon_{t}
$$

We thus model the total realized cash flow as the sum of permanent and temporary shocks, which implies that shocks of the same magnitude matter more for smaller firms. Empirical evidence demonstrates that large firms are much less likely to experience negative cash flows than are small 
firms, an observation that supports the additivity assumption. ${ }^{6}$ Coles, Lemmon, and Meschke (2007) also show that the magnitude of the total shock's impact on the firm's cash flows is approximately proportional to the square root of the firm's size. One potential explanation is that large firms may be more likely to be involved in various unrelated lines of business so that the impact of independent temporary shocks gets dampened.

To give the flavor and intuition of the results of our benchmark model presented in Section II, the next two subsections consider simple and somewhat naive versions of permanent-only and temporary-only shocks scenarios, respectively.

\section{I.A Example A: Only permanent shocks}

An example of a model with only permanent shocks $\left(\epsilon_{t} \equiv 0\right.$, so $\delta_{t} \equiv \pi_{t}$ for any $\left.t\right)$ is any traditional contingent claims model in which $\delta_{t}$ is governed, under the risk-neutral probability measure, by a lognormal process,

$$
d \delta_{t}=\mu \delta d t+\sigma \delta d W_{t}
$$

where $\mu$ is the instantaneous growth rate, $\sigma$ is the instantaneous volatility of the growth rate, and $d W_{t}$ is a Brownian motion defined on a filtered probability space $\left(\Omega, \mathcal{F}, \mathbb{Q},\left(\mathcal{F}_{t}\right)_{t \geq 0}\right)$. This modelling framework is the workhorse of the burgeoning field in corporate finance research. The trade-off model in its basic form, which allows only for static capital structure decisions, is by Leland (1994) and the one that allows for dynamic financing decisions is by Fischer, Heinkel, and Zechner (1989) and Goldstein, Ju, and Leland (2001). This model has been extended to incorporate, among other dimensions, investment decisions (e.g., Mauer and Triantis (1994)), strategic behavior (Fan and Sundaresan (2000)), asset liquidity (Morellec (2001)), empire-building by managers (Morellec (2003)), imperfect competition (Zhdanov (2004)), managerial risk aversion (Ju et al. (2005)), macroeconomic fluctuations (Hackbarth, Miao, and Morellec (2006), Bhamra, Kühn, and Strebulaev (2009a, 2009b)), private and public debt (Hackbarth, Hennessy, and Leland (2007)), distressed asset sales (Strebulaev (2007)), and strategic mergers (Hackbarth and Morellec (2008)).

The results of the basic trade-off model are well known, so we will not replicate them here. This scenario constitutes our benchmark for comparisons in the next section, where it is a partial case. For now, it suffices to make the important observation that any innovation to the cash flow process in (2) is permanent, a feature of the log-normal assumption. As a consequence, if we define asset value as the present value of all future cash flows, then the asset value is proportional to the current cash flow:

$$
V_{t}=\mathbb{E}_{t} \int_{t}^{\infty} e^{-r(s-t)} \delta_{s} d s=\frac{\delta_{t}}{r-\mu}
$$

\footnotetext{
${ }^{6}$ For example, for a COMPUSTAT non-financial sample over the 1987-2005 period, 16\% of firm-years have negative operating cash flows among the sample of firms in the largest size tertile (as defined by book assets), but this number increases to $53 \%$ of firm-years for firms in the smallest size tertile.
} 
where all expectations here and throughout the paper are taken under the risk-neutral probability measure, and $r$ is the interest rate which is assumed constant for the remainder of the paper. Therefore, this framework implies that asset values and cash flows are perfectly correlated and their growth rate volatilities are equal. In addition, because cash flows are non-negative, firms never suffer losses. Clearly, all these implications are inconsistent with both economic intuition and stylized facts.

\section{I.B Example B: Only transitory shocks}

\section{I.B.1 Modeling transitory shocks}

Assume now that the cash flow generated by long-term prospects is constant. Because it serves as a numeraire in this example, we let $\delta_{t}=1$. The only uncertainty comes from exogenous and transitory shocks to firm's fortunes in the form of a jump deviation from the long-term cash flow. The transitory feature of the shock, which intuitively relates to any event that is felt only for a limited time, plays a crucial role, so it is important to have an appropriate discussion of how we model the concept. Several relevant sources of uncertainty about the shock include the random timing of the shock's arrival, the initial magnitude of the shock, and its persistence. For illustration, in this example we allow for only one transitory shock. Specifically, the shock arrives at a random moment $T_{s}$ ( $s$ refers to the shock's arrival); its size $\epsilon_{T_{s}}$ is also random and determined at $T_{s}$. The left-hand graph in Figure 1 shows the evolution of cash flows in the model.

The transitory nature of the shock is reflected in the degree of persistence: That is, the cash flow mean reverts from $\delta_{t}+\epsilon_{T_{s}}$ to $\delta_{t}$ at a random time $T_{r}$ ( $r$ indicates the shock's reversal). The presence of this mean-reversion is what distinguishes our model from previous asset pricing models of cash flow/asset value processes with jumps, where all shocks are of permanent nature (e.g., Merton (1976), Kou and Wang (2004), Dao and Jeanblanc (2006)). It also has tremendous consequences for modelling, economic intuition, and quantitative implications.

Both the timing of the shock arrival $T_{s}$ and its persistence $T_{r}-T_{s}$ follow a Poisson process with intensity $\lambda$ with the following probability density function:

$$
\phi(w)=\lambda_{w} e^{-\lambda_{w} w}, \quad w=\{s, r\} .
$$

The intuition offered by this framework is as follows. Starting with a state when the temporary shock is absent, the probability that it will occur in the next short interval of time $d t$ is $\lambda_{s} d t$, and when the temporary shock is present, the corresponding probability that it will revert to the permanent cash flow is $\lambda_{r} d t$. Two apparently similar parameters, $\lambda_{s}$ and $\lambda_{r}$, play distinctly different economic roles, such that $\lambda_{s}$ reflects the frequency of "big" transitory shocks hitting the firm, and higher values of $\lambda_{s}$ imply the firm is more often "in the news." In contrast, $\lambda_{r}$ reflects the speed of the shock's mean-reversion. Indeed, the expected value of the shock size attenuates exponentially with the speed $\lambda_{r}$ after the occurrence date $T_{s}$ (if the shock has not disappeared yet). To see this 

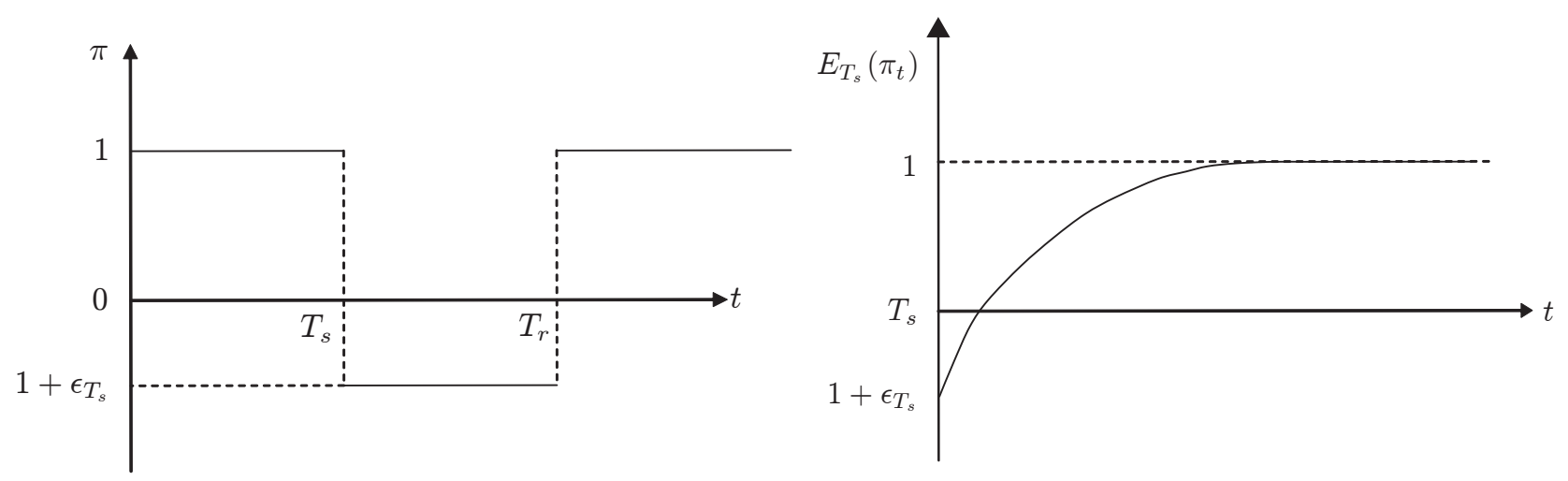

Figure 1: A model with only one transitory shock and constant permanent cash flow. The figure shows the properties of the cash flow process for a motivating example with only one stochastic temporary shock. The permanent cash flow is assumed to be 1. The left graph shows the time-series of the firm's cash flows. At random time $T_{s}$, shock $\epsilon_{T_{s}}$ occurs. The cash flow reverts to permanent cash flow at random time $T_{r}$. The right graph shows the expected value at time $T_{s}$ of future cash flows, given the realization of the transitory cash flow of $\epsilon_{T_{s}}$.

clearly, note that at any date $t$, the expected value of the transitory shock to the cash flow process at any future date $\tau>t$ can be written as

$$
\mathbb{E}_{t}\left[\epsilon_{\tau}\right]= \begin{cases}0, & t<T_{s} \text { and } t \geq T_{r} \\ \epsilon_{T_{s}} e^{-\lambda_{r}(\tau-t)}, & T_{s} \leq t<T_{r}\end{cases}
$$

The right-hand graph in Figure 1 shows the shock's expected value for any time $T_{s}+\tau$ at date $T_{s}$. Permanent shocks, of course, represent a partial case in this example if the mean-reversion speed, $\lambda_{r}$, is zero. In general, transitory shocks may have two economically similar interpretations. First, the shock is finitely lived and dies according to the Poisson death rate. Second, the shock might have an infinite life, but its effect exponentially decays over time. These two scenarios yield the same present value in the absence of financial frictions. Although we choose to model only the first case (which turns out to be the simpler of the two), the economic intuition is more general.

The realized transitory shock to the cash flow similarly can be written for any date $t$ as

$$
\epsilon_{t}= \begin{cases}0, & t<T_{s} \text { and } t \geq T_{r} \\ \epsilon_{T_{s}}, & T_{s} \leq t<T_{r}\end{cases}
$$

The initial size of the jump is distributed according to the symmetric double exponential distribution with the following probability density function:

$$
f\left(\epsilon_{T_{s}}\right)=\frac{1}{2} \gamma e^{-\gamma\left|\epsilon_{T_{s}}\right|} .
$$

The double exponential distribution has been used in the models of option pricing with (perma- 
nent) jumps (e.g., Kou (2002) and Kou and Wang (2004)). One advantage of modelling shocks in this way is that the expected value of the shock is zero and its positive and negative realizations are symmetric. ${ }^{7}$ Parameter $\gamma$ drives the volatility of the temporary shock, such that smaller $\gamma$ leads to shocks of larger magnitude.

To emphasize the difference with the traditional contingent claims model of Section I.A, which allows only for permanent shocks, note that in the model with temporary shocks, the expected cash flow volatility differs from asset value volatility, and the expected time-series correlation between asset value and cash flows is positive but less than one. Finally, this setup naturally accommodates the possibility of negative cash flows. Thus, even the naive model with temporary shocks satisfies all the empirical criteria for the firm's cash flows outlined in the introduction.

\section{I.B.2 Unlevered asset value}

Although the symmetric shock distribution guarantees that both negative and positive realizations are equally possible and the expected value of the future shock is zero, the asset value at any time before the shock occurrence, $V_{t}$, is affected by future shocks in the presence of limited liability. In particular, firm owners find it in their interest to abandon the firm if the total remaining present value of cash flows from asset ownership is negative. Note an important difference between the definition of abandonment which is introduced here and its counterpart in a number of financing models where it is equal to abandonment by equityholders who default and transfer their ownership rights to debtholders. In the presence of lognormal shocks, cash flows never turn negative and therefore the residual claimants never find it optimal to abandon. ${ }^{8}$ In reality, projects get scrapped and firms dissolve routinely, which can be explained by negative net profits and, thus, negative net value. Although abandonment may involve costs, it would not change the intuition of what follows, and therefore we assume that owners may abandon immediately and without cost. ${ }^{9}$

The threshold level of abandonment is denoted by $\epsilon_{A}$, at which firm owners are indifferent between abandonment and continuation, and which is found from the indifference condition by equating the

\footnotetext{
${ }^{7}$ The reasons we use the double exponential distribution function (rather than the normal distribution that has been used extensively in corporate finance to model shocks) are purely technical and anticipate our modeling of both permanent and temporary shocks in Section II. We also numerically solved the case with normal shocks with similar results, which are available upon request.

${ }^{8}$ Abandonment can be optimal only in the presence of negative free cash flows. In real option models, the abandonment decision is introduced by modelling $\delta$ as the revenue stream and adding production costs (e.g., Dixit and Pindyck (1994)). Thus, our modelling of abandonment is close to its counterpart in real option models.

${ }^{9}$ The introduction of abandonment costs makes residual claimants of the firm willing to hold on to the firm's assets for a longer time, because exit is costly and a continuation strategy is more profitable even if cash flows are lower.
} 
residual firm value to zero: ${ }^{10}$

$$
\mathbb{E}_{T_{s}}\left[\int_{T_{s}}^{T_{r}}\left(1+\epsilon_{A}\right) e^{-r\left(s-T_{s}\right)} d s+e^{-T_{r}} \int_{T_{r}}^{\infty} e^{-r\left(s-T_{s}\right)} d s\right]=0 .
$$

The abandonment level that satisfies (8) is

$$
\epsilon_{A}=-\frac{\lambda_{r}+r}{r}
$$

The transitory nature of the shock dictates that the abandonment level is always lower than the negative value of the permanent cash flow, $\epsilon_{A}<-\delta_{t}=-1$. Shorter-lived shocks yield lower abandonment threshold, because they are likely to have a marginal impact on the asset value. Lower interest rates also lead to less abandonment, for they render the bright future more valuable after the negative shock is over.

The asset value (which we define as the present value of all future cash flows streaming from asset's cash flow rights) is the sum of the perpetuity paying a permanent cash flow and the present value of transitory deviations, which equals

$$
V_{t}=\frac{\delta_{t}}{r}+\mathbb{E}_{t} \int_{t}^{\infty} e^{-r(s-t)} \epsilon_{s} d s=\frac{1}{r}+\frac{1}{2} \frac{\lambda_{s}}{r+\lambda_{s}} \frac{1}{\gamma\left(r+\lambda_{r}\right)} e^{\gamma_{A}}, \quad t<T_{s}
$$

The second term is always positive and reflects the asymmetric option-like nature of limited liability. As might be expected, asset value increases with the variance of the shock's size, the intensity of the shock's occurrence, and its persistence.

\section{I.B.3 Canonic securities}

To derive the value of any contingent claim security (such as equity and debt) in an intuitive way, we first introduce simple securities in this economy that pay off upon the shock's arrival with the payoff value depending on the region in which the temporary shock falls. Because all other securities are combinations of these, we call them canonic securities. The canonic security is an Arrow-Debreu security $A\left(g\left(\epsilon_{T}\right), \lambda, b\right)$ that pays $g\left(\epsilon_{T}\right)$ at time $T$ of the shock's arrival if the size of the shock $\epsilon_{T}$ is at least as large as $b$. Note that, importantly, these securities do not assume limited liability - their payoffs, and therefore values, can be negative. For our purposes, we require canonic securities with triplets of parameters $\left(1, \lambda_{s},-\infty\right),\left(1, \lambda_{s}, b\right)$, and $\left(\epsilon_{T_{s}}, \lambda_{s}, b\right)$. The first one pays $\$ 1$ at time $T_{s}$ for any value of the shock. The second and third securities pay correspondingly $\$ 1$ and $\epsilon_{T_{s}}$ if the size of the shock is at least as large as $b$.

\footnotetext{
${ }^{10}$ All results in this subsection can be proven easily by a simple adjustment of the proofs in Appendix A for Section II and therefore we omit all proofs here. Specifically, the intuitive fact that the value of the unlevered firm is monotonically increasing in $\epsilon$ is established in Section II for a more general case.
} 
The values of these securities at time $t, t<T_{s}$, are as follows:

$$
\begin{aligned}
A\left(1, \lambda_{s},-\infty\right)=\mathbb{E}_{t}\left[e^{-r\left(T_{s}-t\right)}\right] & =\frac{\lambda_{s}}{r+\lambda_{s}}, \\
A\left(1, \lambda_{s}, b\right)=A\left(1, \lambda_{s},-\infty\right) \mathbb{E}_{t}\left[1 \mid \epsilon_{T_{s}}>b\right] & =\frac{\lambda_{s}}{r+\lambda_{s}}\left(1-\frac{1}{2} e^{\gamma b}\right), \\
A\left(\epsilon_{T\left(\lambda_{s}\right)}, \lambda_{s}, b\right)=A\left(1, \lambda_{s},-\infty\right) \mathbb{E}_{t}\left[\epsilon_{T_{s}} \mid \epsilon_{T_{s}}>b\right] & =\frac{\lambda_{s}}{r+\lambda_{s}} \frac{1}{2 \gamma} e^{\gamma b}(1-\gamma b) .
\end{aligned}
$$

Although the particular values of the last two securities depend on the nature of the distribution of the shock size, the same securities can be defined similarly for any distribution, such as normal.

\section{I.B.4 Equity valuation and optimal default boundary}

At date 0, the firm issues perpetual debt that promises interest payments of $c$ per year. The firm's equityholders make two decisions over the life of the firm. At date 0 they choose an optimal coupon rate to maximize the firm's value (i.e., the sum of equity and debt values), and at some subsequent date of their choice they can optimally default. In standard models of debt financing (e.g., Leland (1994)) equityholders optimally choose the default boundary, which is the cash flow or asset value threshold, with default occurring when the state variable reaches the threshold for the first time from above. In our example, equityholders may optimally choose to default only at the time of the jump. Indeed, cash flow is a known constant before the shock occurs and, conditional on no default at the time of the jump, it is not optimal to default afterward, because the present value of the shock's effect is constant. The default boundary condition is thus equivalent to specifying the magnitude of the jump such that, if the shock is at least of this size or more severe (meaning more negative), equityholders optimally default. In Section II, we show how this default condition is transformed when permanent shocks follow a familiar lognormal process.

The default boundary, to be optimally determined by equityholders, is denoted by $\epsilon_{B}$,

$$
\epsilon_{B}=\pi_{B}-\delta_{B}=\pi_{B}-1
$$

For all values of the shock below $\epsilon_{B}$, equityholders transfer the ownership to debtholders. The equity value at any time $t$ before the shock occurs can therefore be written as:

$$
\begin{aligned}
E_{t}= & \mathbb{E}_{t}\left[\int_{t}^{T_{s}}\left(1-\tau_{e}\right)(1-c) e^{-r(s-t)} d s\right] \\
& +\mathbb{E}_{t}\left[\int_{\epsilon_{B}}^{\infty} \int_{T_{s}}^{\infty}\left(1-\tau_{e}\right)\left(1+\epsilon_{T_{s}} \cdot \mathbb{I}_{\left\{s<T_{r}\right\}}-c\right) e^{-r(s-t)} d s f\left(\epsilon_{T_{s}}\right) d \epsilon_{T_{s}}\right] .
\end{aligned}
$$

The first expectation is the present value of equity cash flows before the shock. The second term gives the present value of cash flows in the no default case, which again can be decomposed into the 
permanent and temporary components. The equity value can be intuitively represented in terms of canonic securities introduced above as

$$
E_{t}=\left(1-\tau_{e}\right)\left(\frac{1-c}{r}\left(1-A\left(1, \lambda_{s},-\infty\right)\right)+A\left(1, \lambda_{s}, \epsilon_{B}\right) \frac{1-c}{r}+A\left(\epsilon_{T_{s}}, \lambda_{s}, \epsilon_{B}\right) \frac{1}{r+\lambda_{r}}\right) .
$$

The last term is the present value of short-term deviations, which is strictly positive given equity's limited liability. The expected shock has thus an impact on equity value opposite to that on debt value: Equity value increases with the shock's frequency, persistence, and magnitude.

To determine the default boundary $\epsilon_{B}$, the equityholders evaluate the continuation value of their equity ownership rights at time $T_{s}$ and decide to forfeit them if the continuation value is lower than their promised payment to debtholders. They are indifferent exactly at the negative shock size when the value of equity is zero: ${ }^{11}$

$$
E_{T_{s}}=\mathbb{E}_{T_{s}}\left[\int_{T_{s}}^{\infty}\left(1+\epsilon_{B} \cdot \mathbb{I}_{\left\{s<T_{r}\right\}}-c\right) e^{-r\left(s-T_{s}\right)} d s\right]=0
$$

which gives us the optimal default boundary $\epsilon_{B}$ as a function of the coupon rate:

$$
\epsilon_{B}=-(1-c) \frac{\lambda_{r}+r}{r}
$$

The default boundary is always negative and increases with the coupon rate. In particular, if the coupon level is equal to the permanent cash flow, $c=1$, then default happens at any negative shock. Conversely, if the firm is unlevered, $c=0$, the default condition coincides with the abandonment rule, $\epsilon_{B}=\epsilon_{A}$. The default boundary increases in shock persistence because adverse shocks of longer duration imply that the firm continues to be in financial distress (i.e., $\pi_{t}<c$ ) longer. It is interesting to observe that $\lambda_{r}$ in the value of debt can be thought of as another type of liquidation costs. A lower $\lambda_{r}$ implies that negative shocks are longer lived and more of the firm's positive cash flows are going to be eroded. However, unlike traditional liquidation costs $\alpha$, these costs do enter the default boundary condition of equityholders, because equityholders do not internalize the bankruptcy costs incurred by the residual claimants ex-post but instead partially internalize temporary negative shocks to earnings.

\footnotetext{
${ }^{11}$ In Section II, we show (for a more general case) that Equation (17) has only one negative root and is thus an appropriate bankruptcy condition at the time of a discrete jump, an analogue of smooth-pasting conditions for continuous processes.
} 


\section{I.B.5 Corporate debt valuation}

Analogous to equity value, the debt value can be written as follows:

$$
\begin{aligned}
D_{t}= & \mathbb{E}_{t}\left[\int_{t}^{T_{s}}\left(1-\tau_{i}\right) c e^{-r(s-t)} d s\right] \\
& +\mathbb{E}_{t}\left[\int_{\epsilon_{B}}^{\infty} \int_{T_{s}}^{\infty}\left(1-\tau_{i}\right) c e^{-r(s-t)} d s f\left(\epsilon_{T_{s}}\right) d \epsilon_{T_{s}}\right] \\
& +(1-\alpha)\left(1-\tau_{e}\right) \mathbb{E}_{t}\left[\int_{\epsilon_{A}}^{\epsilon_{B}}\left(\int_{T_{s}}^{\infty}\left(1+\epsilon_{T_{s}} \cdot \mathbb{I}_{\left\{s<T_{r}\right\}}\right) e^{-r(s-t)} d s\right) f\left(\epsilon_{T_{s}}\right) d \epsilon_{T}\right], t<T_{s} .
\end{aligned}
$$

The first term is the after-tax present value of coupon payments prior to the shock, where $\tau_{i}$ is the marginal tax rate on interest payments. The second term is the present value of coupon payments after the shock occurs if equityholders do not default. Finally, the third term in Equation (19) is the residual value of the firm in default that debtholders receive in lieu of future coupon payments by defaulted equityholders. Debtholders may immediately and costlessly abandon the firm, which they do if the total remaining asset value is negative. This occurs at the values of the shock of $\epsilon_{A}$, given in (9), and lower. The post-default value also declines with the proportional liquidation/bankruptcy costs $\alpha$ and corporate taxes incurred at the proportional corporate tax rate $\tau_{e}{ }^{12}$

Using the canonic securities, we can re-write the value of debt in (19) as

$$
\begin{aligned}
D_{t}= & \frac{\left(1-\tau_{i}\right) c}{r}\left(1-A\left(1, \lambda_{s},-\infty\right)\right)+A\left(1, \lambda_{s}, \epsilon_{B}\right) \frac{\left(1-\tau_{i}\right) c}{r} \\
& +(1-\alpha)\left(1-\tau_{e}\right)\left(\left(A\left(1, \lambda_{s}, \epsilon_{A}\right)-A\left(1, \lambda_{s}, \epsilon_{B}\right)\right) \frac{1}{r}+\left(A\left(\epsilon_{T_{s}}, \lambda_{s}, \epsilon_{A}\right)-A\left(\epsilon_{T_{s}}, \lambda_{s}, \epsilon_{B}\right)\right) \frac{1}{r+\lambda_{r}}\right) .
\end{aligned}
$$

The first term gives the riskless bond value if the shock does not happen. It can be alternatively thought of as an annuity paid until the shock arrives. The second term shows that in case of no default at the time of the shock, the bondholders are entitled to a perpetuity (because it is a single shock-economy). The last term shows that in the case of bankruptcy, the value stems from the perpetuity generated by the permanent cash flow (first component of the third term) and the present value of deviations from the long-term cash flow. To understamd the intuition behind this representation, we can think of the complex security $A\left(\epsilon_{T_{s}}, \lambda_{s}, \epsilon_{A}\right)-A\left(\epsilon_{T_{s}}, \lambda_{s}, \epsilon_{B}\right)$ as the present value of the size of the shock if the debtholders incur all of the shock's cost (i.e., the shock is large enough to default but not severe enough to abandon the firm) which debtholders must pay until the shock mean-reverts, as is taken into account by the perpetuity formula $\frac{1}{r+\lambda_{r}}$.

Because default and abandonment can happen only at negative shocks (i.e., $\epsilon_{B}$ and $\epsilon_{A}$ are less than zero), the value of $A\left(\epsilon_{T_{s}}, \lambda_{s}, \epsilon_{A}\right)-A\left(\epsilon_{T_{s}}, \lambda_{s}, \epsilon_{B}\right)$ is negative, and therefore the debt value is always

\footnotetext{
${ }^{12}$ Here and throughout, we assume, following the literature, that debtholders do not lever up the firm in case of default and are thus liable for the corporate tax. This assumption is for technical simplicity and its quantitative impact for reasonable debt levels is negligible.
} 
lower in the presence of temporary shocks for a given coupon rate and other model parameters. This is a fundamental observation, because, as Equation (10) demonstrates, the total value of the firm is larger in the presence of temporary shocks. This apparent inconsistency results from an ex-post conflict of interest between equity and debt. Debtholders incur costs in bad states of the world but do not share in the benefits from good states. It follows naturally that debt value is a decreasing function of a temporary shock's frequency, its persistence, and its magnitude. This important mechanism only becomes exacerbated in the benchmark model and yields a higher reliance on financial flexibility and preoccupation with cash flow, as opposed to asset value, volatility.

\section{I.B.6 Optimal financial policy}

Firm owners decide on the optimal capital structure at date $0 .{ }^{13}$ Specifically, equityholders maximize the total firm value with respect to the coupon level, given the optimal default boundary:

$$
\max _{c} D_{0}+E_{0} \quad \text { s.t. eq. (18), }
$$

Although there is no analytic formula for $c$, the strict convexity of the maximization program implies a single solution for a given set of parameters, and the numerical solution is readily obtainable. Moreover, many of its properties can be determined in the absence of an explicit formula. The economic implications are nontrivial because the preferences of debtholders and equityholders diverge with respect to the parameters that govern temporary shocks.

To understand the implications of this simple model, note that in the absence of temporary shocks, the optimal coupon level is equal to the permanent cash flow, $c=\delta=1$, which maximizes the tax benefits of debt if $\tau_{i}<\tau_{e}$ (an assumption supported empirically by, e.g., Graham (2000)). What happens if we add the temporary shock? Figure 2 shows how the optimal coupon rate and optimal leverage generally behave as functions of the shock's frequency, its magnitude, and its persistence.

Debtholders face the asymmetric treatment by bearing the cost of bad shocks without participating in the upside of good shocks. As the expected time of the future shock arrival becomes shorter, they require higher compensation, which implies low debt levels and lower leverage. We delegate all quantitative discussions to Section III, in which we calibrate the parameters to replicate several stylized empirical facts in a more general model, but it is worth mentioning here that optimal financing is convex in $\lambda_{s}$ even for very low values of $\lambda_{s}$ (i.e., when the shock arrives with very low frequency and thus cash flows are rarely negative), and thus the effect of temporary shocks on the financial policy can be substantial.

The right-hand graph in Figure 2 shows that the effects of the shock's magnitude and persistence on the optimal coupon rate are not monotonic. When persistence is very high (value of $\lambda_{r}$ is low and so shocks mean-revert very slowly) or the expected size of the shock is very large (value of $\gamma$

\footnotetext{
${ }^{13}$ We assume a static capital structure decision for simplicity of exposition. What is important here is that debt is issued before the shock occurs.
} 

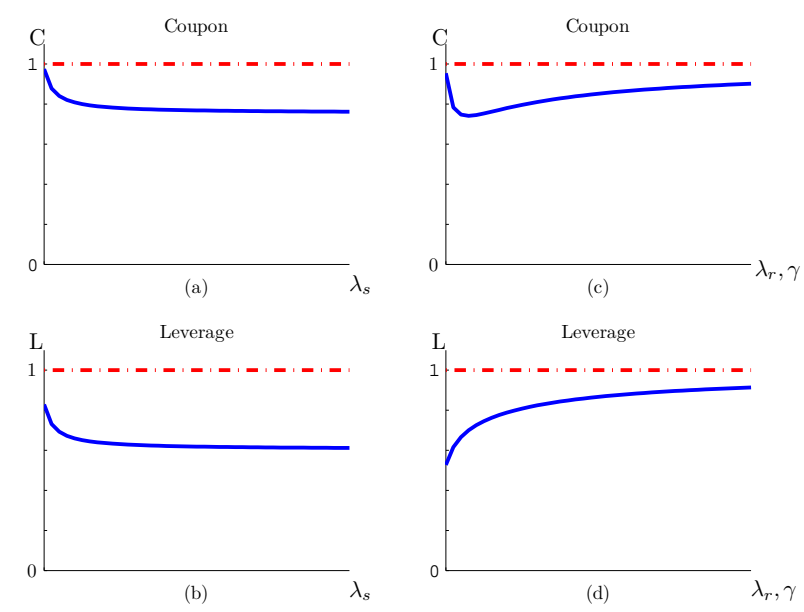

Figure 2: Optimal leverage ratio and coupon as a function of $\lambda_{s}, \lambda_{r}$, and $\gamma$ for a case with only one transitory shock. The figure shows the optimal leverage ratio and optimal coupon level as a function of the shock's arrival intensity, $\lambda_{s}$, (left graph) and speed of mean reversion, $\lambda_{r}$, as well as its dispersion, $\gamma$, (right graph), when the permanent cash flow component is a constant and the transitory component consists of one shock.

is low), equityholders may be tempted to lever up, maximize their value before the shock hits, and default with very high chances if the shock is negative. This short-sighted behavior is similar to the asset substitution phenomenon in which equityholders choose high-risk investment projects if their firm is highly levered. It can thus be thought of as finance substitution, where equityholders lever up to generate the substantial option value induced by the transitory shocks. In fact, not shown in Figure 2, for very low (high) values of $\gamma\left(\lambda_{r}\right)$, which are unlikely to occur in reality, shareholders may prefer to issue a coupon above the permanent cash level. In other words, they prefer to put the firm in financial distress from the very start, because in the case of a positive shock (about which they care most), the benefits are asymmetrically large.

However, when persistence is lower (i.e., the value of $\lambda_{r}$ is large and so shocks mean-revert quickly) or the expected size of the shock is relatively small (i.e., the value of $\gamma$ is large), transitory shocks matter less relative to the permanent cash flow component. Therefore, the optimal coupon level increases.

The leverage ratio generally increases as the temporary shock becomes less important (except in the unusual and less interesting cases in which the optimal coupon is greater than one). In the first effect, equity value grows disproportionately to debt value; in the second effect, the larger coupon level offsets the lower default probability. The leverage ratio is concave in these two parameters and even for relatively low persistency scenarios we expect a non-negligible decrease in the optimal leverage ratio. 


\section{Model of permanent and transitory shocks}

After considering simple models with either temporary or permanent shocks, we now develop a general framework that includes shocks of both types.

\section{II.A Modeling cash flows}

To relate the framework to the existing literature, we might think of the firm's cash flow process following the lognormal process, as in the standard model (the first motivating example), but the firm is now also subject to repeated short-term fluctuations in cash flow of the type introduced in the second motivating example. For convenience, we continue to use all the notation introduced previously; for completeness, we also briefly review the nature of the shocks introduced in Section I. The firm's earnings, $\pi_{t}$, now depend on two sources of uncertainty and can be written as

$$
\pi_{t}=\delta_{0} e^{\left(\mu-\frac{1}{2} \sigma^{2}\right) t+\sigma t\left(W_{t}-W_{0}\right)}+\epsilon_{t}, \quad \delta_{0} \geq 0, t \geq 0
$$

where $\delta_{0}$ is the initial value of the permanent component of earnings, and $\epsilon_{t}$ is the current value of short-term deviations. We denote the volatility of the permanent cash flow's growth rate $\sigma$ and stress that in the presence of the transitory shocks it is lower than the total asset volatility, $\sigma_{V}$. At random times $T_{s}$, either a positive or a negative shock of size $\epsilon_{T_{s}}$ to the permanent cash flow level can occur with the Poisson intensity $\lambda_{s}$. The short-term nature of shocks can be captured by the assumption that the realized deviation from the long-term cash flow level disappears at times $T_{r}$, which also follow the Poisson process with intensity $\lambda_{r}$. Temporary cash flows $\epsilon_{T_{s}}$ are distributed doubly exponentially with intensity $\gamma$. To describe the economic intuition, we start by considering the case of a single temporary shock in Sections II.B-II.F, for which closed-form solutions are available. We then consider the general case of multiple temporary shocks in Section II.G.

\section{II.B Canonic securities}

In the next several subsections, we derive the values of all assets in the economy, assuming that only one temporary shock is expected in the future, and we investigate the economic intuition behind optimal decisions. We start by introducing two basic and intuitive securities, of which all the other securities are linear combinations. Similarly to our terminology in Section I.B, we call them canonic securities.

The first security pays off at default or abandonment if these events occur prior to the jump caused by the transitory shock. Specifically, denote by $X\left(\delta_{t}, \lambda, b_{t}\right)$ a security that pays $\$ 1$ at the moment $\tau$ when $\delta_{t}$ reaches or crosses $b_{t}$ for the first time, such that $\tau<T$, where $T$ is the random time of temporary shock arrival $\left(T_{s}\right)$ or mean-reversion $\left(T_{r}\right)$. In our setting, $b_{t}$ can be either the 
default or the abandonment boundary. The value of this security can be written as

$$
X\left(\delta_{t}, \lambda, b_{t}\right)=\mathbb{E}_{t}\left[e^{-r(\tau-t)} \mathbb{I}_{\tau<T}\right]
$$

The second security pays off at the moment of a jump, conditional on the firm not exiting previously. We can denote the value of this security as $A\left(\delta_{t}, g\left(\delta_{T}\right), \lambda, b_{t}\right)$, which shows that it pays the expected value of $g\left(\delta_{T}\right)$ at time $T$ if $\tau \geq T$. Function $g(\cdot)$ can represent any corporate claim. We then can write the value of this security at time $t$ as

$$
A\left(\delta_{t}, g\left(\delta_{T}\right), \lambda, b_{t}\right)=\mathbb{E}_{t}\left[e^{-r(T-t)} g\left(\delta_{T}\right) \mathbb{I}_{\tau \geq T}\right]
$$

These claims are Arrow-Debreu-type securities, which are related via the following relationship:

$$
A\left(\delta_{t}, g\left(\delta_{T}\right), \lambda, b_{t}\right)=A\left(\delta_{t}, g\left(\delta_{T}\right), \lambda, 0\right)-X\left(\delta_{t}, \lambda, b_{t}\right) A\left(b_{t}, g\left(\delta_{T}\right), \lambda, 0\right)
$$

The analytic values of these two securities are given in Appendix A.

\section{II.C The value of an unlevered firm}

We start by deriving the unlevered firm value, $V\left(\delta_{t}, \epsilon_{t}\right)$ and $V\left(\delta_{t}\right)$, in the presence and absence of temporary shocks, respectively, which is useful because it provides a benchmark in comparisons with the levered firm value and debtholders' liquidation value. Proposition 1 derives this value:

Proposition 1 (Unlevered VAlue) The unlevered after-tax asset value $V_{t}$ is:

1. For $t \geq T_{r}$,

$$
V\left(\delta_{t}\right)=\left(1-\tau_{e}\right) \frac{\delta_{t}}{r-\mu} .
$$

2. For $T_{s} \leq t<T_{r}$, for any given realization of $\epsilon_{t}$,

$$
\begin{aligned}
\frac{V\left(\delta_{t}, \epsilon_{t}\right)}{1-\tau_{e}}= & \frac{\epsilon_{t}}{r}\left(1-X\left(\delta_{t}, \lambda_{r}, \delta_{A, t}\right)-A\left(\delta_{t}, 1, \lambda_{r}, \delta_{A, t}\right)\right) \\
& +\frac{\delta_{t}}{r-\mu}-\frac{\delta_{A, t}}{r-\mu} X\left(\delta_{t}, \lambda_{r}, \delta_{A, t}\right) \\
& -A\left(\delta_{t}, \frac{\delta_{T_{r}}}{r-\mu}, \lambda_{r}, \delta_{A, t}\right)+A\left(\delta_{t}, \frac{V\left(\delta_{T_{r}}\right)}{1-\tau_{e}}, \lambda_{r}, \delta_{A, t}\right),
\end{aligned}
$$

where $\delta_{A, t}$ is the level of cash flow at which the firm is abandoned. 
3. For $t<T_{s}$,

$$
\begin{aligned}
\frac{V\left(\delta_{t}\right)}{1-\tau_{e}}= & \frac{\delta_{t}}{r-\mu}-A\left(\delta_{t}, \frac{\delta_{T_{s}}}{r-\mu}, \lambda_{s}, 0\right) \\
& +\int_{\epsilon} A\left(\delta_{t}, \frac{V\left(\delta_{T_{s}}, \epsilon_{T_{s}}\right.}{1-\tau_{e}}, \lambda_{s}, 0\right) d F(\epsilon)
\end{aligned}
$$

To understand the intuition behind these formulas, consider the asset value when the shock is present, given in (27). The first line gives the present value of the transitory shocks (the effect of which is present until either abandonment or shock mean-reversion). The remaining lines show the valuation of permanent cash flows. In the case of abandonment, firm holders lose the right to all future cash flows (the second term on the second line shows the expected present value of these rights). Finally, the last line shows that in case of the shock's mean-reversion, firmholders exchange the expected pre-jump firm value for the expected post-jump firm value.

With only permanent shocks and costless production, the project is never abandoned, which implies that the firmholders would be willing to liquidate the firm only if the transitory shock were present and sufficiently negative, such that the present value of the permanent positive cash flows would be offset by expected losses from the transitory shock. To find the threshold level $\delta_{A, t}$, for every $\epsilon_{t}$, we apply a standard smooth-pasting condition to the unlevered firm value. Proposition 2 derives $\delta_{A, t}$ :

Proposition 2 (Abandonment Decision) The abandonment level $\delta_{A, t}$ is

$$
\delta_{A, t}= \begin{cases}0, & \text { for } t<T_{s}, t \geq T_{r} \text { and } T_{s} \leq t<T_{r} \text { if } \epsilon_{t} \geq 0 \\ -\frac{r-\mu}{r+\lambda_{r}} \frac{\vartheta_{\lambda_{r}}^{+}}{1+\vartheta_{\lambda_{r}}^{+}} \epsilon_{t}, & \text { for } T_{s} \leq t<T_{r} \text { if } \epsilon_{t}<0\end{cases}
$$

where $d_{w}$ is

$$
d_{w}=\frac{\vartheta_{w}^{+}-\vartheta_{w}^{-}}{2}
$$

and $\vartheta_{w}^{+}$, and $\vartheta_{w}^{-}$are positive and negative roots of the quadratic equation

$$
\frac{\sigma^{2}}{2} \vartheta_{w}^{2}-\left(\mu-\frac{\sigma^{2}}{2}\right) \vartheta_{w}-(r+w)=0
$$

As Figure 3 shows, the abandonment boundary is a linear function of transitory shock, because there is a constant marginal rate of substitution between the present value of negative temporary shock and the present value of permanent cash flows that keeps the firm indifferent between abandonment and continuation. If $\mu$ is positive, the slope of the abandonment boundary is always negative, but greater than -1 , because one unit of temporary shock is less valuable than one unit of permanent shock. 


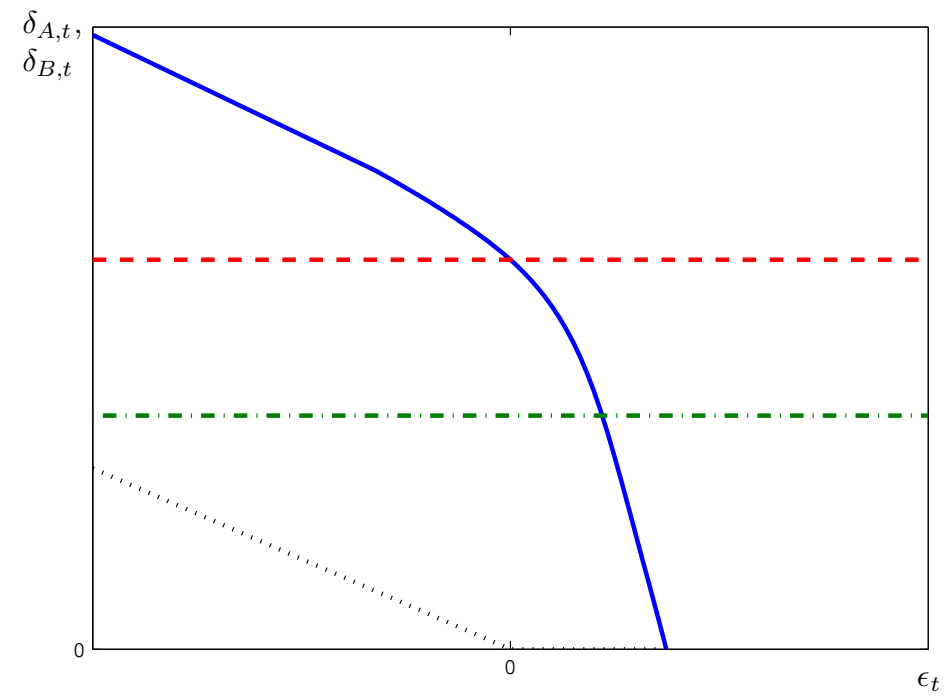

Figure 3: Optimal default and abandonment boundaries for fixed coupon in the benchmark model with both permanent and temporary shocks. The figure shows the optimal default boundaries for $t \leq T_{s}$ (dotted and dashed line), $T_{s} \leq t<T_{r}$ (solid line), and $t \geq T_{r}$ (dashed line), as well as the optimal abandonment level (dotted line) for the benchmark model with permanent and temporary shocks.

\section{II.D Equity valuation and optimal default decision}

The value of equity also consists of both transitory and permanent components. For example, during a period in which transitory shock is present, equity value can be written as follows:

$$
E\left(\delta_{t}, \epsilon_{t}\right)=\mathbb{E}_{t}\left[\left(1-\tau_{e}\right) \int_{t}^{\min \left(\tau, T_{r}\right)}\left(\delta_{s}+\epsilon_{t}-c\right) e^{-r(s-t)} d s+e^{-r\left(T_{r}-t\right)} \mathbb{I}_{\tau \geq T_{r}} E\left(\delta_{T_{r}}\right)\right]
$$

where $\min \left(\tau, T_{r}\right)$ is the first time either the default or the shock's mean-reversion occurs. The two components of the integral are the expected present value of dividends before and after the shock's mean-reversion, respectively. Similarly, at any time prior to the transitory shock occurrence, the value of equity is the sum of the present value of payout accruing to shareholders before the shock hits and the properly discounted continuation value:

$$
E\left(\delta_{t}\right)=\mathbb{E}_{t}\left[\left(1-\tau_{e}\right) \int_{t}^{\min \left(\tau, T_{s}\right)}\left(\delta_{s}-c\right) e^{-r(s-t)} d s+e^{-r\left(T_{s}-t\right)} \mathbb{I}_{\tau \geq T_{s}} E\left(\delta_{T_{s}}, \epsilon_{T_{s}}\right)\right] .
$$

Proposition 3 gives an intuitive way to write the equity value using the values of canonic securities:

Proposition 3 (Equity value) Let $\delta_{B, t}$ be the default boundary at time $t$. The value of equity, $E_{t}$, can be written as: 
1. For $t \geq T_{r}$,

$$
\frac{E\left(\delta_{t}\right)}{1-\tau_{e}}=\frac{\delta_{t}}{r-\mu}-\frac{\delta_{B, t}}{r-\mu} X\left(\delta_{t}, 0, \delta_{B, t}\right)-\frac{c}{r}\left(1-X\left(\delta_{t}, 0, \delta_{B, t}\right)\right)
$$

2. For $T_{s} \leq t<T_{r}$, the value of equity for any given realization of $\epsilon_{t}$ is,

$$
\begin{aligned}
\frac{E\left(\delta_{t}, \epsilon_{t}\right)}{1-\tau_{e}}= & \left(\frac{\epsilon_{t}}{r}-\frac{c}{r}\right)\left(1-X\left(\delta_{t}, \lambda_{r}, \delta_{B, t}\right)-A\left(\delta_{t}, 1, \lambda_{r}, \delta_{B, t}\right)\right) \\
& +\frac{\delta_{t}}{r-\mu}-\frac{\delta_{B, t}}{r-\mu} X\left(\delta_{t}, \lambda_{r}, \delta_{B, t}\right) \\
& -A\left(\delta_{t}, \frac{\delta_{T_{r}}}{r-\mu}, \lambda_{r}, \delta_{B, t}\right)+A\left(\delta_{t}, \frac{E\left(\delta_{T_{r}}\right)}{1-\tau_{e}}, \lambda_{r}, \delta_{B, t}\right)
\end{aligned}
$$

3. For $t<T_{s}$,

$$
\begin{aligned}
\frac{E\left(\delta_{t}\right)}{1-\tau_{e}}= & \frac{\delta_{t}}{r-\mu}-\frac{\delta_{B, t}}{r-\mu} X\left(\delta_{t}, \lambda_{s}, \delta_{B, t}\right) \\
& \left.-A\left(\delta_{t}, \frac{\delta_{T_{s}}}{r-\mu}, \lambda_{s}, \delta_{B, t}\right)+\int_{\epsilon} A\left(\delta_{t}, \frac{E\left(\delta_{T_{s}}\right.}{1-\tau_{e}}, \epsilon_{T_{s}}\right), \lambda_{s}, \delta_{B, t}\right) d F(\epsilon) \\
& -\frac{c}{r}\left(1-X\left(\delta_{t}, \lambda_{s}, \delta_{B, t}\right)-A\left(\delta_{t}, 1, \lambda_{s}, \delta_{B, t}\right)\right)
\end{aligned}
$$

The intuition is straightforward. For example, the first line of (36) is the pre-tax unlevered firm value, adjusted for the possibility of default prior to shock's arrival. The second line is the adjustment at the time of the shock's arrival, whereby equityholders forego the unlevered firm value and receive a new shock-specific contingent claim. Finally, the third line adjusts for a coupon that equityholders pay until either the default or the shock's arrival.

For any given level of interest payments to debtholders, $c$, the manager chooses the default boundary to maximize equityholders' value. An important distinction between the default decisions of equityholders in this and earlier models is that the default boundary is time-varying and depends on the temporary shock's expectations. ${ }^{14}$ The next proposition derives the optimal default boundary:

\section{Proposition 4 (Default Boundary)}

1. If either (i) $t \geq T_{r}$ or (ii) $T_{s} \leq t<T_{r}$ and $\epsilon_{t}=0$, then

$$
\delta_{B, t}=c \frac{r-\mu}{r} \frac{\vartheta_{0}^{+}}{\vartheta_{0}^{+}+1} .
$$

\footnotetext{
${ }^{14}$ The optimal default boundaries in Hackbarth, Miao, and Morellec (2006) and Bhamra, Kühn, and Strebulaev (2009a) are also state-dependent, reflecting the change in macroeconomic regimes.
} 
2. If $T_{s} \leq t<T_{r}$ and $\epsilon_{t}<0$, then $\delta_{B, t}$ is a solution to the following equation:

$$
\omega_{B, 1}+\omega_{B, 2} \delta_{B, t}+\omega_{B, 3} \delta_{B, t}^{-\vartheta_{0}^{+}}=0
$$

where $\omega_{B, 1}, \omega_{B, 2}$ and $\omega_{B, 3}$ are constants (see Appendix A for their values).

3. If $T_{s} \leq t<T_{r}$ and $\epsilon_{T_{s}} \geq c$, then the firm does not default, $\delta_{B, t}=0$.

4. If $T_{s} \leq t<T_{r}$ and $0<\epsilon_{T_{s}}<c$, then $\delta_{B, t}$ is a positive solution to the following equation:

$$
\chi_{B, 1}+\chi_{B, 2} \delta_{B, t}+\chi_{B, 3} \delta_{B, t}^{-\vartheta_{\lambda_{r}}^{-}}=0,
$$

where $\chi_{B, 1}, \chi_{B, 2}$, and $\chi_{B, 3}$ are constants (see Appendix A for their values).

For the period before shock's arrival, the time-varying default boundary can be easily found numerically and many of its properties can be shown analytically. Consider first the optimal default decision when transitory shock is present. When the realization of temporary shock is zero, managers expect a permanent-only cash flow world, and thus, both the equity value and the default boundary are equal to their permanent-only counterparts after the shock mean-reverts. This is shown on Figure 3 , in which the default boundaries for these periods intersect at the zero value of the shock.

Negative values of temporary shocks alternatively might be considered an additional fixed coupon, costs of production, or lump-sum tax penalty temporarily imposed on equityholders. A temporary reduction in the dividend payout for the duration of the shock decreases the benefits of cash flow rights, resulting in a higher default boundary level. Analogously, positive realizations of temporary shocks are similar to a temporary coupon reduction or lump-sum tax subsidy for the duration of the shock, which diminishes the desire to default earlier. When the temporary cash flow component is high enough, it is never optimal for equityholders to default for the duration of the shock. Even if permanent cash flow falls to zero, equityholders will optimally wait until the shock's mean reversion before defaulting. For the value of the shock larger than the level of coupon, the optimal default level therefore is zero in Proposition 4 and Figure 3.

An interesting and, as it turns out, economically important feature of the default boundary is its concavity (for values of the shock lower than the coupon level). The default boundary $\delta_{B, t}$ can be thought of as the indifference curve, such that for every pair of $\epsilon_{t}$ and $\delta_{B, t}\left(\epsilon_{t}\right)$, equityholders are indifferent between default and continuation. The slope of default boundary at each point is the marginal rate of substitution between one unit of temporary shock and one unit of permanent cash flows that keeps the present value of payoffs to equity equal to zero. To realize the implications of this intuition, consider the values of $\delta$ close to the default boundary, $\delta_{B, t}\left(\epsilon_{t}\right)$. If $\epsilon_{t}$ is close to $c$, the future shock's reversion almost inevitably makes equity worthless, and thus, the present value of all permanent cash flows accruing to equity is low. Therefore, along the indifference curve, equityholders 
trade one unit of temporary cash flows at a high price relative to one unit of permanent cash flows, as reflected in the slope of default boundary for $\epsilon_{t}$ close to $c$. For positive permanent cash flow growth $\mu$, this slope is always above -1 . For lower values of $\epsilon_{t}, \delta_{B, t}\left(\epsilon_{t}\right)$ increases, so equityholders' survival after the shock's reversion is more likely. Because permanent cash flows extend into the future, equityholders trade a unit of temporary shock at a lower price relative to a unit of permanent cash flows. The slope that reflects this trade-off decreases in absolute value. Finally, as $\epsilon_{t} \rightarrow-\infty$, default never occurs after shock's reversion, which implies the lowest relative price for each unit of temporary cash flows. Also, the value of equity becomes linear in $\delta_{t}$, so that the trade-off between temporary and permanent cash flows is equal for the levered and unlevered firms.

Empirical evidence suggests that firms often default "too late", after most of the value is dissipated and bondholders' recovery rate is too low. In other words, firms frequently default when their net worth is substantially lower than the promised value of debtholders' payments (e.g., Davydenko (2007)). Standard contingent-claim models have difficulty explaining this stylized fact, as well as the wide distribution of bondholders' recovery rates in cross-section. In our model, this is exactly what may happen upon default. It also easily accommodates cases of zero recovery rates. Moreover, empirical evidence shows that debt covenants can be of both net-worth (i.e., firm is in violation if its value is lower than a certain threshold) and cash-flow (firm is in violation if, say, the interest coverage ratio is lower than a certain threshold) types. While standard models cannot distinguish between two types of covenants (in a permanent-only case, these covenants coincide), our model may allow for an investigation of which type of firms find cash-flow or net-worth covenants more beneficial.

The next proposition summarizes the properties of default and abandonment thresholds:

Proposition 5 Let $\delta_{B, t}$ and $\delta_{A, t}$ be optimal default and abandonment boundaries, respectively. Then:

1. $\delta_{B, t}$ is a continuous function of $\epsilon_{t}$ for any $T_{s} \leq t<T_{r}$;

2. $\delta_{A, t}<\delta_{B, t}$ for any $T_{s} \leq t<T_{r}$;

3. $\delta_{B, t}-\delta_{A, t}$ converges to a constant as $\epsilon_{T_{s}}$ goes to $-\infty$ for any $T_{s} \leq t<T_{r}$;

4. $\delta_{B, t}$ is a decreasing and concave function of $\epsilon_{t}$ for any $T_{s} \leq t<T_{r}$ and $\epsilon_{T_{s}}<c$;

5. $\delta_{B, t}>\delta_{B, s}$ for any $t \geq T_{r}$ and any $s \leq T_{s}$.

Figure 4 shows how the default boundary behaves with respect to the speed of mean-reversion or longevity of shocks, $\lambda_{r}$; the volatility of the permanent component, $\sigma$; and the coupon level, $c$, ceteris paribus. Higher coupon payments reduce the equityholders' residual value and thus increase the optimal default boundary. Note that the graph of the optimal default boundary for the period when temporary shock exists moves to the right so that the new default boundary is zero for exactly the value of the shock equal to the new coupon payment. 
As $\lambda_{r}$ increases, shocks should be of shorter duration, and their adverse effect should damage equityholders' payoffs less. As a result, equityholders prefer to default at uniformly lower levels of permanent cash flows for negative shocks. Conversely, for positive values of temporary shocks, equityholders expect to obtain lower values of benefits for low $\lambda_{r}$, and thus, default boundaries increase.
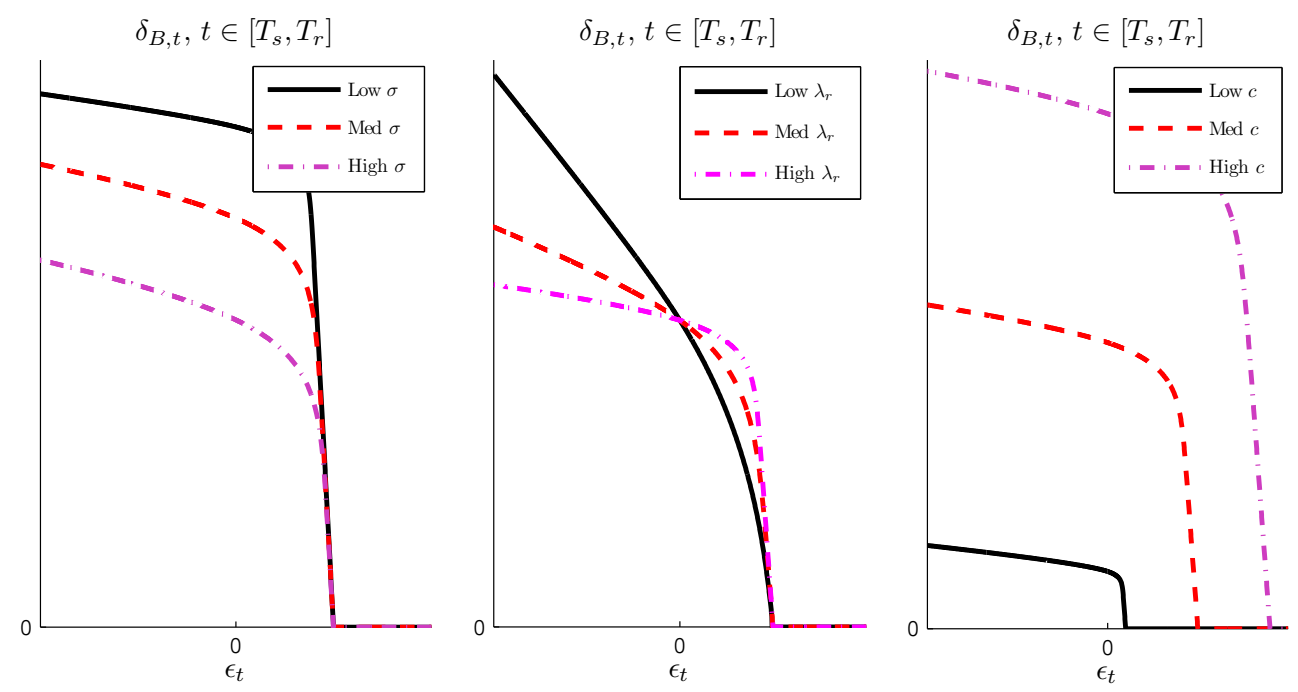

Figure 4: Comparative statics for the benchmark case of both permanent and temporary shocks with respect to $\sigma, \lambda_{r}$, and $c$. The figure shows optimal default boundaries at $t \in\left[T_{s}, T_{r}\right)$ for the benchmark model of both permanent and temporary shocks with respect to the volatility of the permanent cash flow growth rate, $\sigma$, speed of mean-reversion, $\lambda_{r}$, and coupon level, $c$.

Figure 4 also shows that a higher volatility of the permanent cash flow growth increases the optionality of equityholders' claim and, as in a model with permanent shocks only (e.g., Leland (1994)), makes them wait longer before defaulting, which lowers the default boundary.

\section{II.E Debt valuation}

In default, debtholders incur the bankruptcy costs of asset transfers. We assume that the asset value is reduced by a fraction $\alpha$ of all future permanent cash flows. Because default is more likely to be associated with negative transitory shocks, we assume that these shocks are unaffected by bankruptcy costs; otherwise, it would result in counterfactually mitigating debtholders' exposure. ${ }^{15}$ With this assumption, the next proposition gives the value of debt using canonic securities:

Proposition 6 (Debt Value) Debt value $D_{t}$ is given by:

\footnotetext{
${ }^{15}$ For simplicity, we do not treat the case when default happens at positive values of transitory shocks (our quantitative results show that these events are rare) differently. In reality, the ability of firms to reduce their tax exposure due to intertemporal tax provisions such as carry-forward provisions further complicates the treatment of negative cash flows.
} 
1. For $t \geq T_{r}$,

$$
D\left(\delta_{t}\right)=\frac{\left(1-\tau_{i}\right) c}{r}\left(1-X\left(\delta_{t}, 0, \delta_{B, t}\right)\right)+(1-\alpha)\left(1-\tau_{e}\right) \frac{\delta_{B, t}}{r-\mu} X\left(\delta_{t}, 0, \delta_{B, t}\right) .
$$

2. For $T_{s} \leq t<T_{r}$, the value of debt for any given realization of $\epsilon_{t}$ is,

$$
\begin{aligned}
D\left(\delta_{t}, \epsilon_{t}\right)= & \frac{\left(1-\tau_{i}\right) c}{r}\left(1-X\left(\delta_{t}, \lambda_{r}, \delta_{B, t}\right)-A\left(\delta_{t}, 1, \lambda_{r}, \delta_{B, t}\right)\right) \\
& +V\left((1-\alpha) \delta_{B, t}, \epsilon_{t}\right) X\left(\delta_{t}, \lambda_{r}, \delta_{B, t}\right)+A\left(\delta_{t}, D\left(\delta_{T_{r}}\right), \lambda_{r}, \delta_{B, t}\right) .
\end{aligned}
$$

3. For $t<T_{s}$,

$$
\begin{aligned}
D\left(\delta_{t}\right)= & \frac{\left(1-\tau_{i}\right) c}{r}\left(1-X\left(\delta_{t}, \lambda_{s}, \delta_{B, t}\right)-A\left(\delta_{t}, 1, \lambda_{s}, \delta_{B, t}\right)\right) \\
& +(1-\alpha) V\left(\delta_{B, t}\right) X\left(\delta_{t}, \lambda_{s}, \delta_{B, t}\right)+\int_{\epsilon} A\left(\delta_{t}, D\left(\delta_{T_{s}}, \epsilon_{T_{s}}\right), \lambda_{s}, \delta_{B, t}\right) d F(\epsilon) .
\end{aligned}
$$

It is easy to show that debtholders abandon the firm at the level of the permanent cash flow $\delta_{L, t}=\frac{\delta_{A, t}}{1-\alpha}$, where $\delta_{A, t}$ is the abandonment level of the unlevered firm derived in Proposition 2.

\section{II.F Financing constraints}

The model has not so far considered the impact of the asymmetric costs of financing, which usually are observed in reality. When firms pay interest out of their current cash flow, there are unlikely to be any additional penalties imposed. However, when cash flow is insufficient to pay interest and equityholders, in an attempt to stave off default, raise additional financing by other means, their action is usually costly, whether through payments of a higher interest rate on new financing, fixed costs of issuing new equity or debt, selling assets at fire-sale prices, or reducing financial slack. ${ }^{16}$

To explore to what extent financing constraints affect the conservative nature of the firm's financial behavior, we extend the model in the following way. If the firm lacks cash reserves to honor the current debt payments (i.e., if $\delta_{t}+\epsilon_{t}<c$ ), it must rely on costly outside financing. We assume that the cost of raising money in financial distress is proportional to the amount to be raised in excess of current cash flow, so that the final payout to shareholders can be written as:

$$
\phi(x)= \begin{cases}\left(1+q_{e}\right) x, & x=\delta_{t}+\epsilon_{t}-c<0, \quad q_{e} \geq 0 \\ x, & \delta_{t}+\epsilon_{t}-c \geq 0\end{cases}
$$

\footnotetext{
${ }^{16}$ Contingent claims models of capital structure usually assume this cost by allowing equityholders to restructure in good times but not allowing debt reduction in bad times (e.g., Goldstein, Ju, and Leland (2001)). These models, however, allow equityholders to issue new equity costlessly in financial distress. Strebulaev (2007) models the higher costs of financing in financial distress directly, in a way that is similar to our approach (he also assumes assets could be sold at fire-sale prices).
} 
In other words, if $\delta+\epsilon<c$, the firm is in financial distress, and it incurs distress costs that are proportional to the value of necessary additional financing. If $q_{e}=0$, the model with financing frictions simplifies to the benchmark case. Our modeling of distress costs represents a short cut and could reflect distressed asset fire-sales, the transaction costs of raising external equity or debt quickly, penalties for drawing on credit lines, reductions in investment expenditures, and so on.

To solve the model, the only expression that needs to be changed from the model of Section II is the value of equity. In the presence of temporary shock it equals

$$
E\left(\delta_{t}, \epsilon_{t}\right)=\mathbb{E}_{t}\left[\left(1-\tau_{e}\right) \int_{t}^{\min \left(\tau, T_{r}\right)} \phi\left(\delta_{s}+\epsilon_{t}-c\right) e^{-r(s-t)} d s+e^{-r\left(T_{r}-t\right)} \mathbb{I}_{\tau \geq T_{r}} E\left(\delta_{T_{r}}\right)\right]
$$

whereas in the absence of temporary shock it is

$$
E\left(\delta_{t}\right)=\mathbb{E}_{t}\left[\left(1-\tau_{e}\right) \int_{t}^{\min \left(\tau, T_{s}\right)} \phi\left(\delta_{s}-c\right) e^{-r(s-t)} d s+e^{-r\left(T_{s}-t\right)} \mathbb{I}_{\tau \geq T_{s}} E\left(\delta_{T_{s}}, \epsilon_{T_{s}}\right)\right]
$$

The model can be solved similarly to the benchmark model, taking into account an additional boundary $\delta_{c, t}=c-\epsilon_{t}$, which in the presence of frictions separates healthy and financially distressed firms. For a fixed coupon, a higher value of $q_{e}$ implies lower tolerance of equityholders with respect to losses, and thus a higher default boundary, more frequent and costly default, and lower debt value.

\section{II.G Multiple temporary shocks and optimal financing}

We finalize the model by extending it to cover an infinite number of temporary shocks. For simplicity, we continue to assume that at any point in time only one temporary shock may effect earnings. Specifically, we assume that the state of the economy follows a two-state continuous-time Markov chain. In the first state, the permanent cash flow is the only component of the cash flow, whereas in the second state, both shock types are present. The probability per unit of time of switching from the permanent-only state to a both-shock state is $\lambda_{s}$, and the probability of switching from a both-shock state to the permanent-only state is $\lambda_{r}$. Thus, on average, for a fraction $\lambda_{r} /\left(\lambda_{s}+\lambda_{r}\right)$ of the time, the firm's cash flow is affected by transitory shocks.

As before, $T_{s}$ denotes any date when the temporary shock hits, and $T_{r}$ is any date when the shock mean reverts. At any $T_{s}$, the magnitude of the shock is drawn randomly from the same double exponential distribution function in Equation (7). In other words, the expected magnitude of the new shock is the same, but its actual realization upon arrival generally differs. The firm expects an infinite number of shocks to arrive and get reversed in the future. ${ }^{17}$

\footnotetext{
${ }^{17}$ This is one of several potential "shock structures" that we could consider. For example, shocks also might be reversed by the arrival of a new shock. Alternatively, shocks can be reversed by only new shocks. All these models would lead to similar implications, but they do not in general allow us to disentangle two quantities with vastly different intuition: waiting times of shocks and their mean-reversion speed. In our model, $\lambda_{s}$ is responsible for the first effect,
} 
To value any security, note that the economy at any time is in one of two states, depending on whether current earnings are affected by the transitory shock. For the after-tax value of the unlevered firm, $V$, denote $V\left(\delta_{t}\right)$ to be the value in the no-shock state and $V\left(\delta_{t}, \epsilon_{t}\right)$ to be the value when a shock of size $\epsilon_{t}$ is present. Note that $V\left(\delta_{t}, 0\right)$ and $V\left(\delta_{t}\right)$ represent values in two different states of the world and generally are not equal. ${ }^{18}$

In both states these values can be written intuitively as a system of recursive equations:

$$
\begin{aligned}
V\left(\delta_{t}, \epsilon_{t}\right) & = \begin{cases}\mathbb{E}\left[\left(1-\tau_{e}\right) \int_{t}^{\min \left(\tau, T_{r}\right)}\left(\delta_{s}+\epsilon_{t}\right) e^{-r(s-t)} d s+e^{\left.-r T_{r} \mathbb{I}_{\tau \geq T_{r}} V\left(\delta_{T_{r}}\right)\right],}\right. & \delta_{t}>\delta_{A, t}\left(\epsilon_{t}\right), \\
0, & \delta_{t} \leq \delta_{A, t}\left(\epsilon_{t}\right),\end{cases} \\
V\left(\delta_{t}\right) & =\mathbb{E}\left[\left(1-\tau_{e}\right) \int_{t}^{T_{s}} \delta_{s} e^{-r(s-t)} d s+e^{-r T_{s}} V\left(\delta_{T_{s}}, \epsilon_{T_{s}}\right),\right]
\end{aligned}
$$

where $\delta_{A}$ derives from the smooth-pasting condition that the unlevered firm is abandoned, given a low enough realization of temporary shock:

$$
\left.\frac{\partial V\left(\delta_{t}, \epsilon_{t}\right)}{\partial \delta_{t}}\right|_{\delta_{t}=\delta_{A, t}\left(\epsilon_{t}\right)}=0
$$

In the formula for $V\left(\delta_{t}, \epsilon_{t}\right)$, the first term is the present value of cash flows until the shock reverts to the long-run mean and the second term is the present value of the firm at the moment of shock's mean reversion.

Analogous expressions can be written for equity and debt values. For example, the value of equity in two states can be written as:

$$
\begin{aligned}
E\left(\delta_{t}, \epsilon_{t}\right) & = \begin{cases}\mathbb{E}\left[\left(1-\tau_{e}\right) \int_{t}^{\min \left(\tau, T_{r}\right)} \phi\left(\delta_{s}+\epsilon_{s}-c\right) e^{-r(s-t)} d s+e^{-r T_{r}} \mathbb{I}_{\tau \geq T_{r}} E\left(\delta_{T_{r}}\right)\right] & \delta_{t}>\delta_{B, t}\left(\epsilon_{t}\right), \\
0, & \delta_{t} \leq \delta_{B, t}\left(\epsilon_{t}\right),\end{cases} \\
E\left(\delta_{t}\right) & =\mathbb{E}\left[\left(1-\tau_{e}\right) \int_{t}^{\min \left(\tau, T_{s}\right)} \phi\left(\delta_{s}-c\right) e^{-r(s-t)} d s+e^{-r T_{s}} \mathbb{I}_{\tau \geq T_{s}} E\left(\delta_{T_{s}}, \epsilon_{T_{s}}\right)\right] .
\end{aligned}
$$

In both expressions, the first term is the equity payout in the current state. Equityholders default optimally according to the following smooth-pasting conditions:

$$
\left.\frac{\partial E\left(\delta_{t}, \epsilon_{t}\right)}{\partial \delta_{t}}\right|_{\delta_{t}=\delta_{B, t}\left(\epsilon_{t}\right)}=0, \quad \text { and }\left.\quad \frac{\partial E\left(\delta_{t}\right)}{\partial \delta_{t}}\right|_{\delta_{t}=\delta_{B, t}}=0
$$

The value of debt can also be written in a similar system of recursive equations, using Equations (A21) and (A26) in the Appendix. Although these equations do not yield a closed-form solution, we

and $\lambda_{r}$ reflects the speed of mean-reversion. This distinction is helpful in understanding the economic intuition.

${ }^{18}$ Because a shock of size zero happens on a probability measure of zero, we do not consider informational aspects of the shock's existence, even though managers probably would not know for certain whether the firm is in the shock or no-shock state, when the realization of the shock is zero. 
can characterize the equilibrium properties of the model both qualitatively and quantitatively, and many of its intuitive properties can be established. ${ }^{19}$ Appendix B also provides the details of the numerical procedure used to find the solution of the general model.

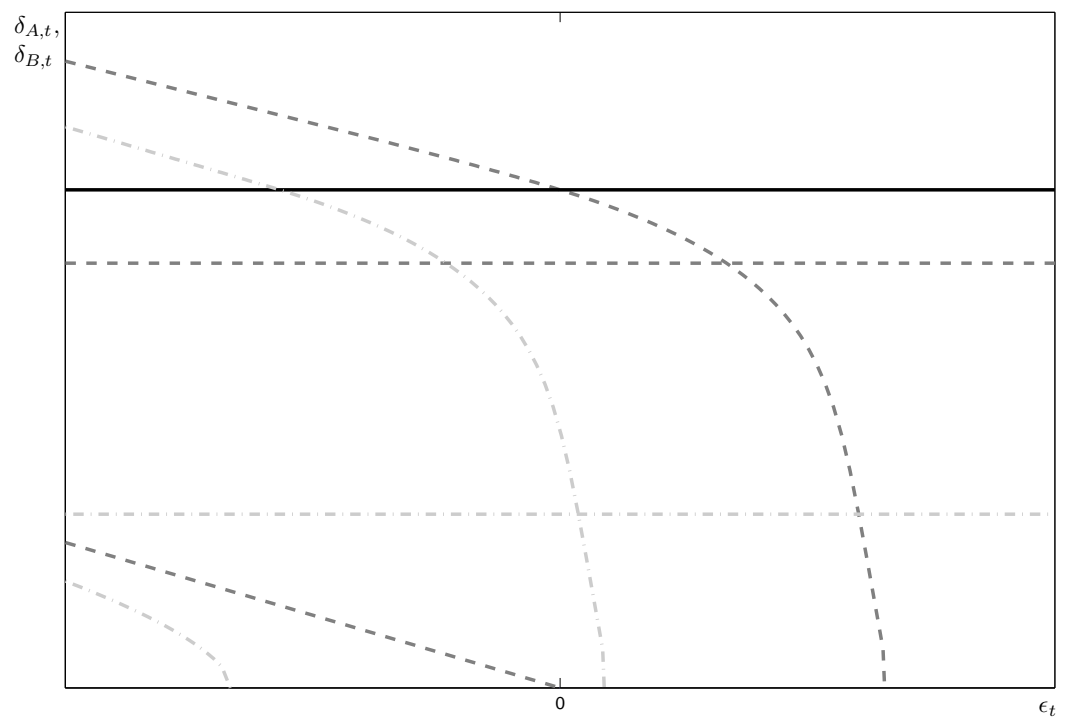

Figure 5: Optimal default boundaries. The figure shows the permanent shock-only optimal default boundary (solid line), the optimal default boundary before and during the shock, and the abandonment boundary during the shock in the model with single temporary shock (dashed line) and in the model with multiple temporary shocks (dashed and dotted line).

Figure 5 compares optimal abandonment and default boundaries for the models with single and multiple temporary shocks and shows that optimal decisions in both models are driven by the same economic forces. It also shows several differences between the models. First, in the case of multiple shocks, firm owners hold a call option on the future realizations of shocks, which creates additional convexity in their payoff and a desire to wait longer before abandoning the firm even for the value of $\delta=0$. For the same reason, equityholders do not default even for realizations of shocks slightly lower than the coupon level. Therefore, multiple shocks lead to further dissipation of the asset value prior to default and may further corroborate the need for net worth and cash flow covenants in debt contracts.

In addition, as the value of $\epsilon_{t}$ grows more negative, the slope of the abandonment boundary approaches that of the single-shock model, and the distance between the two thresholds converges to zero: conditional on a firm with strong fundamentals surviving an extremely negative shock, future realizations of temporary shocks should be relatively small and do not trigger the limited liability option of the firmholders. Similarly, the default boundary is uniformly below that of the benchmark

\footnotetext{
${ }^{19}$ For a special case with multiple temporary shocks and a constant permanent cash flow, we can find the closed-form solution, which dramatically simplifies the solution of the general problem. The details are available upon request.
} 
model, with the distance converging to zero as $\epsilon \rightarrow-\infty$.

The conflict of interest between equityholders and debtholders deepens because of the differential effect of short-term fluctuations on their respective value. When shocks are expected to last longer, equityholders are better off ex ante, and debtholders are worse off. In deciding on optimal financing, however, equityholders maximize the total value of the firm; it is easy to see how conflicting interests of equity and debt can lead to non-trivial implications.

For the optimal capital structure choice, we assume that the choice is made when there are no transitory shocks, such that equityholders solve the following optimization problem:

$$
\max _{c} D\left(\delta_{t}\right)+E\left(\delta_{t}\right)
$$

given the expressions for $\epsilon_{B}\left(\delta_{t}, c\right)$ and $\epsilon_{A}\left(\delta_{t}, c\right)$ obtained previously.

\section{Transitory shocks and optimal financing}

In this section, we calibrate and report the main implications of our model for optimal financing decisions. The basic quantitative question we are interested in is whether temporary shocks have a non-trivial impact on optimal leverage. We start by describing the benchmark choice of parameters and follow by presenting and discussing the results.

\section{III.A Model parameters}

In the choice of firm parameters for the benchmark model an important caveat is that for many parameters of interest, there is little empirical evidence permitting precise estimation of averages, sampling distributions, or in some cases even their ranges. In addition, the model requires that all parameters be estimated as time-invariant. Overall, any choice of parameters must inevitably be regarded as ad hoc and approximate. We deal with this problem in several ways. First, whenever possible (e.g., for tax rates), we use established empirical estimates. Second, and more importantly, we perform numerous robustness checks that show the economic implications of the model are not qualitatively affected by changing the parameters within a feasible range. Third, we calibrate and present the benchmark case, yet there is a substantial cross-sectional heterogeneity in the data, especially with regards to the importance of transitory shocks. We therefore carefully analyze various comparative statics. Table I summarizes the descriptive information for the parameters.

We assume a value of firm asset volatility, $\sigma_{V}$, of 0.30 . The average asset volatility from the distribution of the standard deviation of rates of return on firm assets, as reported by Schaefer and Strebulaev (2008), is somewhat lower at about 0.25, yet the sample used in that paper is confined to firms that issue public debt. Faulkender and Petersen (2006) show that for firms without access to public debt markets, implied volatility is non-trivially higher. For the proportional cost 
of restructuring in default, $\alpha$, we assume a value of 0.10 . Most empirical values reported in prior literature, such as Weiss (1990) and Altman (1984), are somewhat lower, though recent evidence by Andrade and Kaplan (1998) suggests somewhat higher values. Leland (1994) uses a similarly defined cost of 0.5, Leland (1998) uses 0.25, and Goldstein, Ju, and Leland (2001) use 0.05. Although the estimates of $q_{e}$ are difficult to pinpoint with precision, it is unlikely that the cost of raising funds in distress is lower than the cost of raising equity in good times, which is approximately $5-7 \%$ (Hansen (2001), Corwin (2003)), so we assume $q_{E}$ of 0.10 .

To choose the effective tax rate on equityholders (which includes both corporate and marginal personal tax rates on dividends) and the marginal personal tax rates on interest income, we follow recent evidence (e.g., Graham $(1999,2000)$ ) and assume that the effective tax rate on equityholders, $\tau_{e}$, is $40 \%$ and the marginal tax rate on interest income, $\tau_{i}$, is $30 \%$. The after-tax risk-free interest rate is assumed to be 0.055 . We also choose a risk-neutral growth rate of cash flows, $\mu$, of 0.01 , which is consistent with the average payout rate used in prior studies.

The rest of the benchmark parameters, which specify the behavior of transitory shocks (frequency $\lambda_{s}$, persistence $\lambda_{r}$, magnitude $\gamma$ ) and the volatility of permanent cash flows $\sigma$, are based on empirical evidence obtained from the COMPUSTAT sample of firms over the period 1987 to 2005, after we apply standard data filters. ${ }^{20}$ We assume that shock's persistence parameter $\lambda_{r}$ is 0.6 , so on average, the transitory shock mean reverts in 1.66 years, consistent with the empirical observation that small and large firms (based on tertiles sorted by the market value of assets) report, on average, 2.16 and 1.56 consecutive years of negative cash flows.

Shock's frequency parameter $\lambda_{s}$ is 1.2 , such that a new transitory shock arrives on average in 0.83 years. To calibrate this parameter, we use empirical evidence on the frequency (3-3.5 years) with which an average firm reports negative cash flows for the first time after experiencing losses in the past. For simplicity, we assume that each new transitory shock is equally likely to lead to losses or profits, then fit the simulated frequency of negative total cash flows to the empirical frequency. We then adjust the resulting estimate to account for a slight downward bias, because total cash flows do not become negative for each negative realization of the transitory shock. As we show in Section III.B, higher values of $\lambda_{s}$ (which account for the downward bias) only strengthen our results and intuition about temporary shock's importance.

We calibrate permanent cash flow volatility $\sigma$ and the temporary shock's magnitude $\gamma$ using two empirical moments. First, the total volatility of firm assets $\sigma_{V}$ should be equal to 0.30. Higher $\sigma$ and lower $\gamma$ increase the asset volatility $\sigma_{V}$. Second, we calibrate the probability of the negative cash flow realization to a conservative estimate of 0.15 (fraction of firm-years with negative cash flows for large firms in the empirical sample). Lower values of $\gamma$ increase the frequency of negative cash flows and fit the sample of smaller firms better. For the benchmark values, we also check that the total contribution of temporary shocks to the present value of the unlevered firm is lower than that of

\footnotetext{
${ }^{20}$ Details are omitted for brevity and available upon request.
} 
permanent shocks (approximately 20\%).

The parameters of the cash flow process, and in particular the temporary shock component, are calibrated using observed data under the actual probability measure, and therefore, we need to map between the actual measure and the risk-neutral measure, under which all the pricing and financial decisions are made. It is well known that for a compound Poisson process, the change of measure can affect both the intensity and the distribution of jump sizes (e.g., Shreve (2004)). We therefore assume that the actual and risk-neutral parameters of the temporary shock's process relate in the following way: $\lambda_{s}^{\mathbb{Q}}=\frac{1}{\zeta} \lambda_{s}^{\mathbb{P}}, \lambda_{r}^{\mathbb{Q}}=\zeta \lambda_{r}^{\mathbb{P}}$, and $\gamma^{\mathbb{Q}}=\zeta \gamma^{\mathbb{P}}$, where $\mathbb{Q}$ stands for the risk-neutral measure (the parameters we used previously to value securities), $\mathbb{P}$ denotes the actual measure (under which the parameter values are obtained in the data), and $\zeta$ is a constant. Intuitively, because investors are risk-averse to negative temporary shocks, a value of $\zeta$ between 0 and 1 leads to a larger magnitude, quicker arrival, and slower reversal of shocks in the risk-neutral world. ${ }^{21}$ We choose $\zeta$ to reflect empirically observed risk-adjustment (the ratio of risk-neutral to actual default probabilities). For example, Almeida and Philippon (2007) report a risk adjustment of 4.00 for BBB-rated bonds, whereas Berndt et al. (2005) report an average risk-adjustment of 2.76 . We therefore calibrate $\zeta$ so that the risk-adjustment at the horizon of five years is 3, which gives us a value of $\zeta$ equal to 0.65.

\section{III.B Results}

Can transitory shocks explain well-known stylized facts about corporate financial policies? The first set of predictions is presented in Table II, in which the first row represents the benchmark case of the standard model with permanent shocks only (e.g., Leland (1994)). For the asset volatility value of $30 \%$ and all other relevant parameters (including the cost of financial distress $q_{E}$ ) in Table I, the optimal leverage ratio is approximately $58 \%$. We compare this optimal leverage decision with the benchmark case of our model. Importantly, for this comparison to be viable, we must fix the total asset volatility of unlevered firm value at the same $30 \%$. In other words, even though the source of cash flow variability differs between these firms, empirical estimates of asset volatilities from the data for a firm with permanent shocks only and for a firm with both types of shocks should be equal. Otherwise, higher volatility in our benchmark case may lower the optimal leverage ratio and lead us to believe that a financial policy is more conservative, even if it is not. To match the values of total asset volatilities, we calibrate the implied value of the volatility of the permanent cash flow growth rate (reported in the last column); in the benchmark case, it is $15 \%$.

The second row of Table II demonstrates that for our benchmark calibration scenario, when tran-

\footnotetext{
${ }^{21}$ Alternatively, mapping between $\mathbb{P}$ and $\mathbb{Q}$ can be derived under the assumption that investors are risk-averse (e.g., have a CARA utility function). A resulting joint distribution of the shock's size and random times of arrival and reversion indicates that larger shocks have longer waiting times of arrival and shorter times of reversion and, therefore, the total volatility of negative jumps increases and that of positive jumps declines. Although this model is less technically tractable, compared with the assumption of mapping with the symmetric treatment of positive and negative shocks, the additional asymmetry between shocks of different size should further decrease the optimal leverage.
} 
sitory shocks are present, firms' optimal financial response is to follow a substantially more conservative financial policy. The optimal leverage ratio is $38 \%$, or $20 \%$ smaller than in the permanent-only case. This is a remarkable result and, given its startling magnitude, it is worth to understand its implications better. Empirical evidence generally reports low leverage ratios on the order of $25 \%$ for an average COMPUSTAT firm in the U.S. as well as similar levels world-wide (e.g., Rajan and Zingales (1995)), and a number of firms exhibit much smaller leverage ratios. This observation is often referred to as the "low leverage puzzle," emphasizing that standard trade-off models have difficulty explaining such low reliance on debt financing. The presence of transitory shocks, by making the present value of tax benefits lower relative to expected bankruptcy costs, changes the balance between debt and equity and effectively resolves most of the puzzle. Importantly, we obtain this result, for reasons of tractability, with the assumption of static capital structure. It is well known that if firms have an opportunity to refinance their debt obligations (as in models by Goldstein, Ju, and Leland (2001) and Strebulaev (2007)), the presence of future refinancing options reduces optimal leverage, because firms have a real option of increasing the leverage later, conditional on them experiencing higher cash flows. For example, the introduction of dynamic refinancing by Goldstein, $\mathrm{Ju}$ and Leland (2001) reduces the optimal leverage from 50\% (for their benchmark case, which is unlike ours due to the different tax assumptions) to $37 \%$. Intuitively, the presence of transitory shocks coupled with dynamic refinancing should explain the low leverage puzzle for an average firm.

An important concern with this result is that the presence of a real option inherent in the expectation of transitory shocks increases the levered equity value and may mechanically lead to a reduction in the quasi-market leverage measure, even if the firm has not reduced its reliance on debt, as would be manifest in, for example, an interest coverage ratio (we call this effect "finance substitution" in Section I). We address this concern by comparing the optimal coupon levels in both models. As the third column of Table II shows, the reduction of the coupon level actually is responsible for low leverage, not just the mechanical relationship between the market value of equity and leverage. The optimal coupon level (and therefore the interest coverage ratio, defined as the ratio of current total cash flow level to the coupon) decreases (increases) by roughly $26 \%$, from 1.74 to 1.28 (by $36 \%$, from 1.15 to 1.56 ).

As we stress in Section III.A, the precision of many parameters should be treated with caution. The remaining rows of Table II therefore consider the comparative statics and robustness of our basic result when we substantially vary the major parameters. Importantly, for each comparative statics exercise, we compare the results with the relevant permanent-only model. We require total asset volatility to remain at the same $30 \%$ level by calibrating the volatility of the permanent component (reported in the last column). For the last two rows, when we vary the total asset volatility, we also re-estimate the optimal financing decisions for the permanent-only case. The second and fourth columns show the difference in optimal leverage $(\Delta L)$ and coupon levels $(\Delta c)$ between the adjusted permanent-only case and the benchmark model, respectively. As the relative importance of transitory 
shocks decline, the optimal leverage ratio increases. For example, as the starting cash flow level increases, the relative magnitude of expected shock and thus its effect on financial policy declines. Our model suggests that, conditional on the same asset volatility, larger firms have higher leverage ratios. For sure, this effect is an artifact of our additivity assumption - in reality, we would expect the magnitude of temporary shocks to grow with size, dampening the size effect. However, the bottom line of this table is that, for a wide variation in all other parameters, the presence of transitory shocks clearly leads to a substantial adjustment in financing behavior, from a minimum decrease of $10 \%$ (when shocks are substantially less important) to a maximum reduction of $35 \%$. Almost all of the variation is caused by real changes in coupon levels. In other words, the main result of financial conservatism is robust to changes in the values of the parameters.

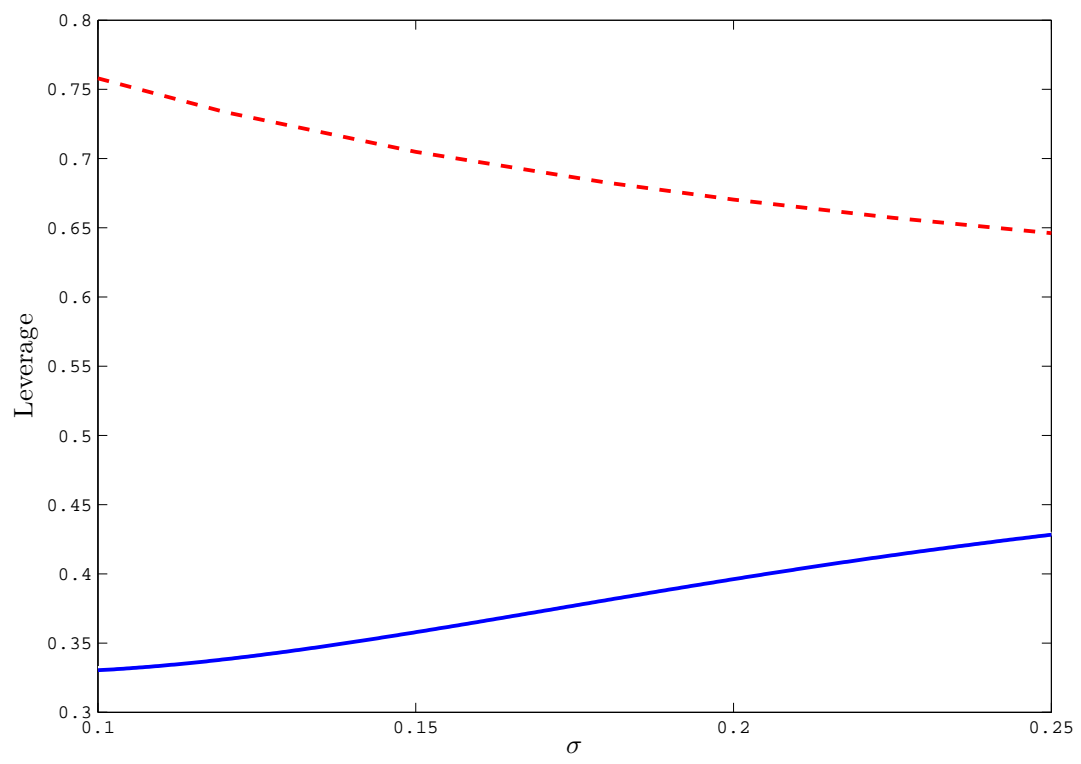

Figure 6: Leverage as a function of volatility. The figure shows the optimal leverage ratio as a function of volatility of the growth rate of the permanent component of cash flow, $\sigma$, for the model with permanent and temporary shocks (solid line) and for the model with permanent shocks only (dotted line). The asset volatility in the permanent-only model is chosen to match the total asset volatility of the benchmark model.

A standard result in capital structure models is a negative relation between optimal leverage and volatility. In our model, leverage actually may increase in total volatility if higher asset volatility is driven by the permanent component of cash flow, as shown in Figure 6. The asset volatility in the permanent-only model is chosen to match the total asset volatility of the benchmark model with temporary shocks for each value of $\sigma$. The intuition for this seemingly suprising result is straightforward: relative importance of temporary shocks affects optimal financing decisions. In the permanent-only model, higher asset volatility increases the limited liability option of eqityholders, causing the optimal leverage to fall. In our model, because low leverage is driven by aversion to 
temporary shocks, higher permanent cash flow volatility works to reduce the relative impact of temporary shocks and consequently can lead to higher leverage. Not shown on the figure, as $\sigma$ becomes larger, the two leverage ratios eventually converge. In reality, the cross-sectional variation in temporary shocks likely dominates that of permanent shocks, which explains why empirical results usually show that leverage is negatively related to asset volatility. To test our volatility conjecture, one must distinguish the two components of volatility in a cross-section.

Table III augments these main results by providing the comparative statics of optimal financial decisions with respect to major economic forces in the model. For this exercise, we allow total asset volatility $\sigma_{V}$ to vary as the parameters change. The table shows, for example, that as shocks occur less often (smaller values of $\lambda_{s}$ ), both coupon levels and the leverage ratio are optimally larger. In support of our prior results, financial decisions are relatively insensitive to the variation of benchmark parameters. For example, even if shocks occur substantially less often $\left(\lambda_{s}=0.8\right)$, the optimal coupon is higher only by $5 \%$ and the optimal leverage by $2 \%$. This result holds in general, and therefore suggests that the presence of temporary shocks induces a strong tendency toward financial conservatism.

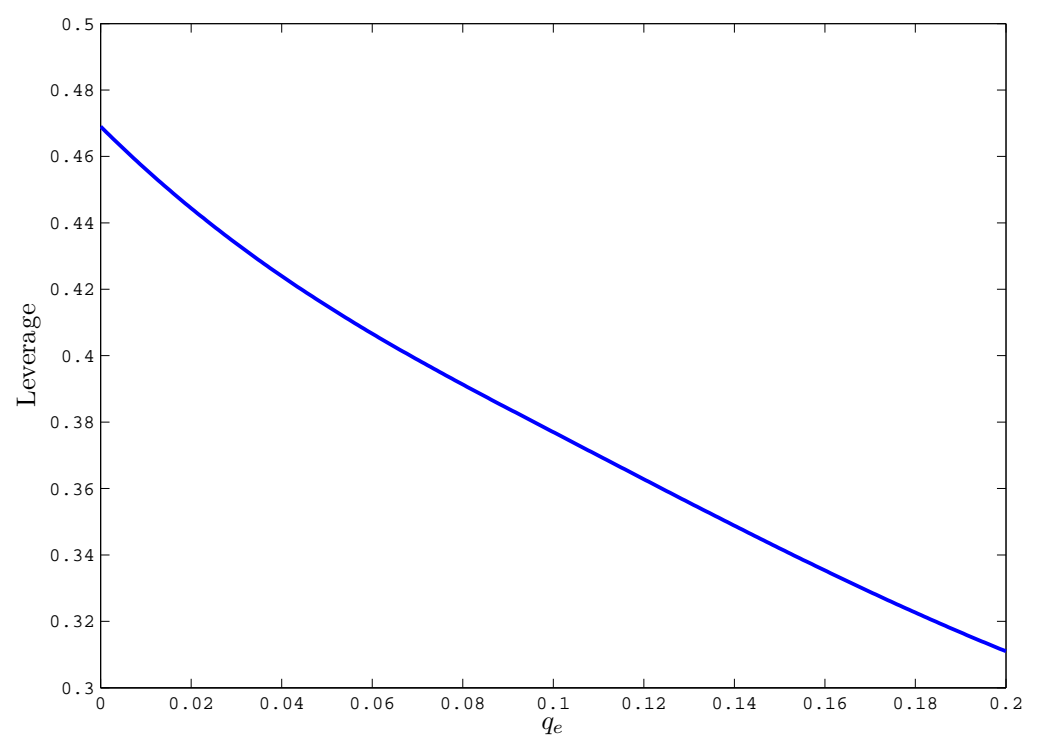

Figure 7: Leverage as a function of financing constraints. The figure shows the optimal leverage ratio as a function of financing constraints, $q_{e}$.

Table III also shows that though the costs of financial distress are important quantitatively, even when the costs are absent $\left(q_{E}=0\right)$, leverage remains substantially smaller than that of the benchmark model ( $47 \%$ vs $58 \%$ ). Figure 7 shows how the optimal leverage is affected by the magnitude of $q_{e}$. To understand why leverage is monotonically decreasing in $q_{e}$, note that for fixed coupon, higher values of $q_{e}$ imply lower tolerance by equityholders with respect to losses, - and thus a higher default boundary, 
more frequent and costly defaults, and lower debtholders' value. Taking into account the higher ex post bankruptcy losses, equityholders optimally reduce firm's debt levels. The convex nature of the dependence of leverage on distress costs is also intuitive: as $q_{e}$ increases, lower coupon levels imply higher initial distance to default (or, in other words, a higher interest coverage ratio). Marginal changes in coupon levels, therefore, affect the debtholders's value less, and the lower sensitivity of leverage results in a smaller curvature.

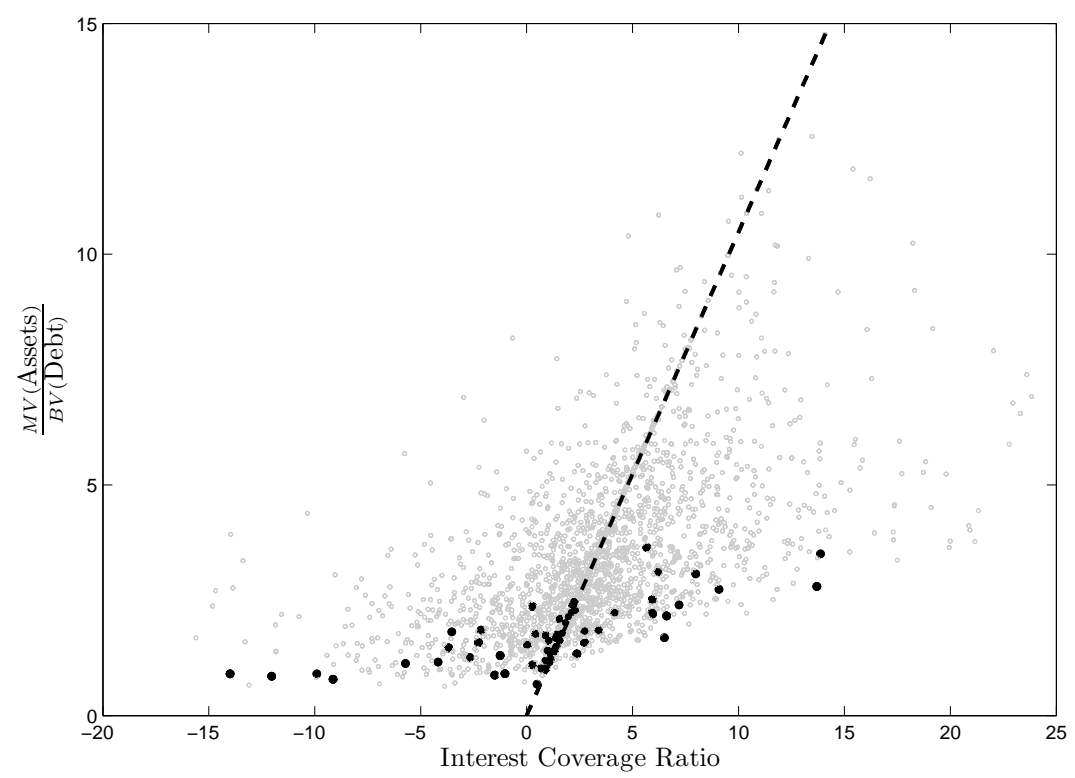

Figure 8: Interest coverage ratio, net worth, and default. The figure shows the model-simulated cross-section of the interest coverage ratio, $\frac{\delta_{t}+\epsilon_{t}}{c}$, and the ratio of market value of unlevered assets to the face value of riskless debt ("solvency" ratio) when the median of the interest coverage ratio across firms is 3 . The straight dotted line shows the relation between these two firm characteristics in the presence of permanent cash flows only. The firms that default over the next five years are identified by black dots.

The presence of both temporary and permanent shocks to cash flows allows us to relate our model to economic causes of defaults. Figure 8 shows the model-simulated cross-section of the interest coverage ratio, $\frac{\delta_{t}+\epsilon_{t}}{c}$, and the ratio of the market value of unlevered assets to the face value of riskless debt ("solvency" ratio) when the median of the interest coverage ratio across firms is 3, which roughly corresponds to the empirical median interest coverage ratio observed in the COMPUSTAT sample. These two firm characteristics appear in prior literature (e.g., Davydenko (2007)) as important proxies for firm's proximity to, correspondingly, financial distress (caused by lack of temporary liquidity) and economic distress (caused by fundamental unsoundness and the lack of long-term perspectives for the firm). The importance of their distinction also has been emphasized in studies of financially distressed firms that note the empirical challenge of identifying the cause of distress (Asquith, Gertner, and Scharfstein (1994), Andrade and Kaplan (1998)). Traditional 
dynamic contingent claims models, such as Leland (1994), have difficulty characterizing these two types of firm distress separately, as well as accounting for firms that do not default at substantially low (and negative) values of interest coverage ratio or asset values and those that default when the values of these characteristics are high, as illustrated by the straight dotted line on Figure 8 that shows the relation between the two firm characteristics in the presence of permanent cash flows only. Because in this case the interest coverage ratio and asset value are perfectly correlated, all firms are aligned along the straight line and there is no difference between financial and economic distress. Firms default when both characteristics cross the respective lower boundaries simultaneously.

In our model, asset value mainly shifts due to the variation in the permanent cash flow component, which proxies for the firm's long-term perspectives, whereas liquidity is influenced more by temporary shocks because of their large magnitude. As a result, the model implies richer causes of default, in line with empirical evidence (Davydenko (2007)), as shown by Figure 8, in which those firms that default over the next five years are identified by black dots. The figure suggests to the following conclusions. First, some firms are in both financial and economic distress (as indicated by their low interest coverage ratio and solvency ratio), and the fraction of such firms that defaults is much higher. Second, firms that are closer to economic insolvency are more prone to default given the realization of a negative temporary shock, as indicated by the clustering of defaults at the lower end and to the left of the straight line. Third, many firms are involved in "finance substitution", as illustrated on the right of the straight line; their long-term prospects are low, but these firms gamble by delaying their default due to the presence of positive temporary shocks. Such behavior results effectively in wealth transfer from bondholders to equityholders. Fourth, a substantial number of firms survive negative liquidity shocks if their solvency ratio is high enough.

These results indicate that optimal covenants in debt contracts should be based on a positive relation between net worth and the interest coverage ratio in an attempt to resolve the ex post trade off between, on the one hand, preventing equityholders from gambling in desperate situations and, on the other hand, reducing the incidence of inefficient renegotiations or liquidations in liquidity crises. Because equityholders are more prone to gamble when liquidity is high but the firm is fundamentally weak, higher net worth covenant controls their appetite for risk. Conversely, fundamentally strong firms should be given more opportunities to survive a temporary liquidity crunch.

Another set of predictions derived from our model relates to the pricing of corporate debt. Figure 9 shows the level of credit spreads for different values of temporary shocks and two values of leverage, 0.37 (proxying for investment-grade ratings such as BBB) and 0.5 (proxying for non-investment-grade ratings such as BB). Unlike in traditional models, such as Leland's (1994), in our model there is no one-to-one mapping between credit spreads and leverage, because the same level of leverage can correspond to different combinations of permanent and temporary cash flow components. This is consistent with empirical evidence that firms with similar leverage, as well as firms with the same credit rating, may have widely different credit spreads. As the figure shows, the credit spread is 


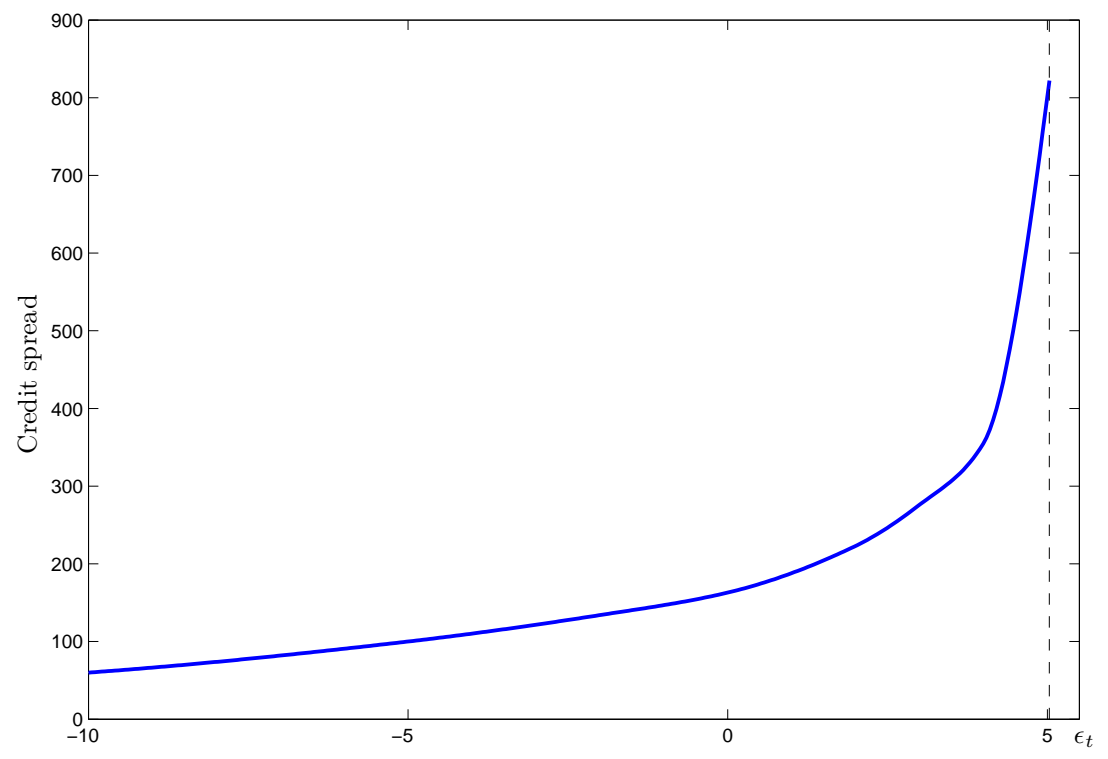

Figure 9: Credit spreads. The figure shows the model-implied credit spreads for two values of leverage, 0.37 (the straight line) and 0.5 (the dotted line), and for different values of temporary shocks. Credit spreads are in basis points.

higher for higher values of temporary shock, conditional on the same leverage. Intuitively, a higher value of shock implies a higher interest coverage ratio to keep leverage constant. Creditors realize the temporary nature of the shock and weaker fundamentals of the firm in the long run, which then lowers debt price. The magnitude of credit spreads is realistic: for example, for the average value of the shock, credit spreads are approximately 160-190bp.

\section{III.C Myopic managers and optimal financing}

Recent research studies various deviations from agents' rational behavior in making decisions and commonly finds that some economic agents can behave myopically. Intuitively, because myopic managers care less about long-term consequences, such as bankruptcy costs or financial distress, optimal leverage in our model would be higher if managers were myopic. Yet, this intuition is not correct. Consider the following modification of the model in Section II.G. The manager, who acts on behalf of shareholders, accounts for only one temporary shock when making abandonment and default decisions. In other words, the manager is myopic, i.e., he does not recognize the possibility of future shocks. Outside investors, however, incorporate all future temporary shocks in pricing their claims. The manager still maximizes the value of the firm in making optimal financing decision but does so under different default and abandonment conditions (which are equivalent to those described in Appendix A). 
The optimal leverage ratio in this model (with the same benchmark parameters) is 20\% (as opposed to $38 \%$ in the benchmark model) and the optimal coupon level is 0.60 (versus 1.28), which demonstrates that myopic managers are likely to behave much more conservatively. To understand the intuition behind this result, note that a single shock reduces the real option of the equityholders and uniformly shifts the default boundary up, as on Figure 5. A higher default probability reduces the market-implied values of debt and leads to an optimally lower coupon. Also, because default and abandonment boundaries uniformly decrease as the number of jumps expected by the manager increases, optimal leverage is an increasing function of the expected number of jumps and converges to the benchmark case as the number of jumps tends to infinity.

\section{Concluding Remarks}

Firms' earnings are affected by shocks of various duration. Although some shocks are long-term and can be thought of as permanent, most others, however great their impact in the short run, are of limited duration. In this paper we implement this simple intuition to investigate the impact of temporary shocks on corporate financial policies.

Our contributions at a theoretical level can be summarized as follows. By incorporating temporary deviations from permanent cash flows, our model can match empirical evidence along three dimensions. First, firms in the model may experience negative cash flows. Second, the correlation between both levels and changes in current cash flows and asset values is less than one. Third, earnings volatility in the model plays a different role from, and is larger than, asset volatility. These model implications are important because extant dynamic contingent claims models of financing decisions use only the permanent shock structure and so, cash flow in these models is proportional to asset values. In this case, cash flows are always positive, both levels and changes in cash flows and asset values are perfectly correlated, and earnings volatility is equal to asset volatility.

We show that temporary shocks likely make firms much more financially conservative than extant models would predict. For the benchmark set of parameters, the optimal leverage ratio is $38 \%$, as opposed to $58 \%$ in the model with permanent cash flows only, when we control for total asset volatility. Moreover, the convex relation between the arrival intensity of transitory shocks and the optimal coupon levels translates into substantially lower leverage ratios even for conservative parameters. We also model the scenario, in which managers behave myopically and do not take into account all future shocks, and find that this scenario may substantially exacerbate debt aversion.

For example, if the manager foresees only one jump in the future, the optimal leverage ratio falls from $38 \%$ to $20 \%$.

Our results allow us to explain empirically observed financial conservatism and the so-called low leverage puzzle. Overall, we show that accounting for short-term shocks is crucial for understanding the financial decisions of corporations; more work clearly is needed in this field. 


\section{Appendix A. Proofs: Benchmark model}

\section{I.A Derivation of values for $X\left(\delta_{t}, \lambda, b_{t}\right)$ and $A\left(\delta_{t}, g\left(\delta_{T}\right), \lambda, b_{t}\right)$}

Recall that $\vartheta_{w}^{+}$and $\vartheta_{w}^{-}$are defined in (31) as positive and negative roots of the quadratic equation $\frac{\sigma^{2}}{2} \vartheta_{w}^{2}-$ $\left(\mu-\frac{\sigma^{2}}{2}\right) \vartheta_{w}-(r+w)=0$. Also, $d_{w}=\frac{\vartheta_{w}^{+}-\vartheta_{w}^{-}}{2}$.

Using properties of first-passage times for the geometric Brownian motion, we price the canonic security $X\left(\delta_{t}, \lambda, b_{t}\right)$. This security pays $\$ 1$ at time $\tau$ when the process $\delta_{t}$ is below or reaches the lower boundary $b_{t}$ for the first time and $\tau<T$, where $T$ is the random $\lambda$-intensity Poisson time of temporary shock arrival $\left(T_{s}\right)$ or reversion $\left(T_{r}\right)$. Its price is

$$
X\left(\delta_{t}, \lambda, b_{t}\right)=\mathbb{E}_{t}\left[e^{-r(\tau-t)} \mathbb{I}_{\tau<T}\right]=\left(\frac{\delta_{t}}{\min \left(b_{t}, \delta_{t}\right)}\right)^{-\vartheta_{\lambda}^{+}}
$$

The price is bounded from above by 1 to account for the fact that $X\left(\delta_{t}, \lambda, b_{t}\right)$ pays off immediately if, at time $t, \delta_{t}$ is below $b_{t}$. Next, because the Poisson process of shock arrival and reversal has memoryless property, for every claim $g\left(\delta_{T}\right)$ that pays off conditional (i) on the realization of $\delta_{T}$ at time $T$ of shock arrival $\left(T_{s}\right)$ or reversal $\left(T_{r}\right)$ and (ii) on not crossing the lower boundary $b_{t}$ before $T$, the following expression holds:

$$
\begin{aligned}
\mathbb{E}_{t}\left[e^{-r(T-t)} g\left(\delta_{T}\right) \mathbb{I}_{\tau \geq T}\right] & =\mathbb{E}_{t}\left[e^{-r(T-t)} g\left(\delta_{T}\right)\right]-\mathbb{E}_{t}\left[e^{-r(T-t)} g\left(\delta_{T}\right) \mathbb{I}_{\tau<T}\right] \\
& =\mathbb{E}_{t}\left[e^{-r(T-t)} g\left(\delta_{T}\right)\right]-\mathbb{E}_{t}\left[e^{-r(\tau-t)} \mathbb{I}_{\tau<T}\right] \mathbb{E}_{t}\left[e^{-r(T-t)} g\left(\delta_{T}\right) \mid \delta_{t}=b_{t}\right]
\end{aligned}
$$

where $b_{t}$ is the lower boundary that is crossed at random time $\tau$. The left-hand side of (A2) defines $A\left(\delta_{t}, g\left(\delta_{T}\right), \lambda, b_{t}\right)$. The right-hand side therefore proves $(25)$, because $A\left(\delta_{t}, g\left(\delta_{T}\right), \lambda, 0\right)=\mathbb{E}_{t}\left[e^{-r(T-t)} g\left(\delta_{T}\right) \mathbb{I}_{\infty \geq T}\right]=$ $\mathbb{E}_{t}\left[e^{-r(T-t)} g\left(\delta_{T}\right)\right]: b_{t}=0$ means that the lower boundary is not reached by $\delta_{t}$ in finite time $\tau$ with positive probability.

Appendix I.B shows that $g\left(\delta_{T}\right)$ can take the form of piecewise polynomials:

$$
g\left(\delta_{T}\right)=\left\{\begin{array}{c}
\alpha_{1,1} \delta_{T}^{k_{1}}+\alpha_{1,2} \delta_{T}^{k_{2}}+\ldots+\alpha_{1, J} \delta_{T}^{k_{J}}, z_{0} \leq \delta_{T}<z_{1} \\
\alpha_{2,1} \delta_{T}^{k_{1}}+\alpha_{2,2} \delta_{T}^{k_{2}}+\ldots+\alpha_{2, J} \delta_{T}^{k_{J}}, z_{1} \leq \delta_{T}<z_{2} \\
\ldots \\
\alpha_{N, 1} \delta_{T}^{k_{1}}+\alpha_{N, 2} \delta_{T}^{k_{2}}+\ldots+\alpha_{N, J} \delta_{T}^{k_{J}}, z_{N-1} \leq \delta_{T}<z_{N}
\end{array}\right.
$$

where $z_{0} \equiv 0$ (lower boundary of the domain of $\delta_{T}$ ), $z_{N} \equiv \infty$ (upper boundary of the domain of $\delta_{T}$ ); any real-valued coefficients $\alpha_{i, j}$ can be equal to 0 , and $k_{j}, j \in 1, \ldots, N$ are real numbers. In addition, the functions $g\left(\delta_{T}\right)$ are smoothly connected at points $\left\{z_{i}\right\}_{i=1}^{N-1}$. In particular, continuation payoffs to equity, debt, and unlevered firm value at times $T_{s}, T_{r}$, as shown in Appendix I.B, are particular cases of the quasipolynomial function $g\left(\delta_{T}\right)$. For further convenience, rewrite $g\left(\delta_{T}\right)$ :

$$
g\left(\delta_{T}\right)=\sum_{i=1}^{N} \mathbb{I}_{z_{i-1} \leq \delta_{T}<z_{i}} \sum_{j=1}^{J} \alpha_{i, j} \delta_{T}^{j}
$$

Suppose first that $b_{t}=0$. Then, the present value of a security that promises to pay $g\left(\delta_{T}\right)$ at time $T$ of shock 
arrival $\left(T_{s}\right)$ or reversion $\left(T_{r}\right)$ is

$$
A\left(\delta_{t}, g\left(\delta_{T}\right), \lambda, 0\right)=\sum_{i=1}^{N} \sum_{j=1}^{J} \alpha_{i, j} A_{z_{i-1}}^{z_{i}}\left(\delta_{t}, \delta_{T}^{j}, \lambda, 0\right)
$$

where

$$
A_{z_{i-1}}^{z_{i}}\left(\delta_{t}, \delta_{T}^{j}, \lambda, 0\right)=\mathbb{E}_{t}\left[e^{-r(T-t)} \delta_{T}^{j} \mathbb{I}_{z_{i-1} \leq \delta_{T}<z_{i}}\right]
$$

Using the properties of geometric Brownian motion, we obtain

$$
\begin{aligned}
& A_{z_{i-1}}^{z_{i}}\left(\delta_{t}, 1, \lambda, 0\right)=\left\{\begin{array}{c}
-\frac{\lambda}{\sigma^{2} d_{\lambda} \vartheta_{\lambda}^{-}}\left(\frac{\delta_{t}}{z_{i-1}}\right)^{-\vartheta_{\lambda}^{-}}+\frac{\lambda}{\sigma^{2} d_{\lambda} \vartheta_{\lambda}^{-}}\left(\frac{\delta_{t}}{z_{i}}\right)^{-\vartheta_{\lambda}^{-}}, \delta_{t}<z_{i-1}, \\
\frac{\lambda}{r+\lambda}-\frac{\lambda}{\sigma^{2} d_{\lambda} \vartheta_{\lambda}^{+}}\left(\frac{\delta_{t}}{z_{i-1}}\right)^{-\vartheta_{\lambda}^{+}}+\frac{\lambda}{\sigma^{2} d_{\lambda} \vartheta_{\lambda}^{-}}\left(\frac{\delta_{t}}{z_{i}}\right)^{-\vartheta_{\lambda}^{-}}, \delta_{t} \in\left[z_{i-1}, z_{i}\right), \\
-\frac{\lambda}{\sigma^{2} d_{\lambda} \vartheta_{\lambda}^{+}}\left(\frac{\delta_{t}}{z_{i-1}}\right)^{-\vartheta_{\lambda}^{+}}+\frac{\lambda}{\sigma^{2} d_{\lambda} \vartheta_{\lambda}^{+}}\left(\frac{\delta_{t}}{z_{i}}\right)^{-\vartheta_{\lambda}^{+}}, \delta_{t} \geq z_{i},
\end{array}\right. \\
& A_{z_{i-1}}^{z_{i}}\left(\delta_{t}, \delta_{T}^{j}, \lambda, 0\right)=\left\{\begin{array}{c}
-\frac{\lambda \delta_{t}^{-\vartheta}{ }_{\lambda}^{-} z_{i-1}^{-}+j}{\sigma^{2} d_{\lambda}\left(\vartheta_{\lambda}^{-}+j\right)}+\frac{\lambda \delta_{t}^{-\vartheta}{ }_{\lambda}^{-} z_{i}^{-}+j}{\left.\sigma^{2} d_{\lambda} \vartheta_{\lambda}^{-}+j\right)}, \delta_{t}<z_{i-1}, \\
\frac{\lambda \delta_{t}^{j}}{\sigma^{2} d_{\lambda}}\left(\frac{1}{\vartheta_{\lambda}^{+}+j}-\frac{1}{\vartheta_{\lambda}^{-}+j}\right)-\frac{\lambda \delta_{t}^{-\vartheta_{\lambda}^{+}} z_{i-1}^{+}+j}{\sigma^{2} d_{\lambda}\left(\vartheta_{\lambda}^{+}+j\right)}+\frac{\lambda \delta_{t}^{-\vartheta}{ }_{\lambda}^{-} z_{i}^{-}+j}{\sigma^{2} d_{\lambda}\left(\vartheta_{\lambda}^{-}+j\right)}, \delta_{t} \in\left[z_{i-1}, z_{i}\right), \\
-\frac{\lambda \delta_{t}^{-\vartheta_{\lambda}^{+}} \vartheta_{\lambda-1}^{+}+j}{\sigma^{2} d_{\lambda}\left(\vartheta_{\lambda}^{+}+j\right)}+\frac{\lambda \delta_{t}^{-\vartheta} z_{\lambda}^{+} z_{\lambda}^{+}+j}{\sigma^{2} d_{\lambda}\left(\vartheta_{\lambda}^{+}+j\right)}, \delta_{t} \geq z_{i} .
\end{array}\right.
\end{aligned}
$$

An important particular case are the securities $A_{z_{N-1}}^{z_{N}}\left(\delta_{t}, \delta_{T}^{j}, \lambda, 0\right)$. Because $z_{N} \equiv \infty$, these securities' prices simplify to

$$
\begin{aligned}
& A_{z_{N-1}}^{z_{N}}\left(\delta_{t}, 1, \lambda, 0\right)=a_{z_{N-1}}^{\infty}\left(\delta_{t}, 1, \lambda, 0\right)=\left\{\begin{array}{c}
\frac{\lambda}{r+\lambda}-\frac{\lambda}{\sigma^{2} d_{\lambda} \vartheta_{\lambda}^{+}}\left(\frac{\delta_{t}}{z_{N-1}}\right)^{-\vartheta_{\lambda}^{+}}, \delta_{t} \geq z_{N-1}, \\
-\frac{\lambda}{\sigma^{2} d_{\lambda} \vartheta_{\lambda}^{-}}\left(\frac{\delta_{t}}{z_{N-1}}\right)^{-\vartheta_{\lambda}^{-}}, \delta_{t}<z_{N-1},
\end{array}\right. \\
& A_{z_{N-1}}^{z_{N}}\left(\delta, \delta_{T}^{j}, \lambda, 0\right)=a_{z_{N-1}}^{\infty}\left(\delta, \delta_{T}^{j}, \lambda, 0\right)=\left\{\begin{array}{c}
\frac{\lambda \delta_{t}^{j}}{\sigma^{2} d_{\lambda}}\left(\frac{1}{\vartheta_{\lambda}^{+}+j}-\frac{1}{\vartheta_{\lambda}^{-}+j}\right)-\frac{\lambda \delta_{t}^{-\vartheta_{\lambda}^{+}} z_{N-1}^{+}+j}{\sigma^{2} d_{\lambda}\left(\vartheta_{\lambda}^{+}+j\right)}, \delta_{t} \geq z_{N-1}, \\
-\frac{\lambda \delta_{t}^{-\vartheta_{\lambda}^{-}} z_{N-1}^{-}+j}{\sigma^{2} d_{\lambda}\left(\vartheta_{\lambda}^{-}+j\right)}, \delta_{t}<z_{N-1} .
\end{array}\right.
\end{aligned}
$$

The final step is to find closed form prices for $A\left(\delta_{t}, g\left(\delta_{T}\right), \lambda, b_{t}\right)$. Using (A5) and (25), we obtain

$$
A\left(\delta_{t}, g\left(\delta_{T}\right), \lambda, b_{t}\right)=\sum_{i=1}^{N} \sum_{j=1}^{J} \alpha_{i, j} A_{z_{i-1}}^{z_{i}}\left(\delta_{t}, \delta_{T}^{j}, \lambda, b_{t}\right)
$$

where

$$
A_{z_{i-1}}^{z_{i}}\left(\delta_{t}, \delta_{T}^{j}, \lambda, b_{t}\right)=A_{z_{i-1}}^{z_{i}}\left(\delta_{t}, \delta_{T}^{j}, \lambda, 0\right)-X\left(\delta_{t}, \lambda, b_{t}\right) A_{z_{i-1}}^{z_{i}}\left(b_{t}, \delta_{T}^{j}, \lambda, 0\right)
$$

The first term of the right-hand side expression is the present value of $\delta_{T}^{j}$ conditional on $\delta_{T}$ stopping in an interval $\left[z_{i}, z_{i-1}\right)$. The second term is subtracted from the first to reflect that those paths of $\delta_{t}$ that cross 
$b_{t}$ from above for some $\tau<T$ and end up in an interval $\left[z_{i}, z_{i-1}\right)$ should not add up to the price of security $A_{z_{i-1}}^{z_{i}}\left(\delta_{t}, \delta_{T}^{j}, \lambda, b_{t}\right)$. Two particular cases are important: (i) if $z_{i} \leq b_{t}$, i.e., a security pays off only is $\delta_{T}$ is below the threshold $b_{t}$, then (A12) equals 0 ; (ii) if $z_{i-1} \leq b_{t}<z_{t}$, i.e., a security pays off for realizations both below and above $b_{t}$, in which case (A12) can be rewritten as $A_{z_{i-1}}^{z_{i}}\left(\delta_{t}, \delta_{T}^{j}, \lambda, b_{t}\right)=A_{b_{t}}^{z_{i}}\left(\delta_{t}, \delta_{T}^{j}, \lambda, 0\right)-$ $X\left(\delta_{t}, \lambda, b_{t}\right) A_{b_{t}}^{z_{i}}\left(b_{t}, \delta_{T}^{j}, \lambda, 0\right)$.

Outside our model, any other function $g\left(\delta_{T}\right)$ that is not a quasipolynomial can be approximately priced using similar methods, if instead of $g\left(\delta_{T}\right)$ some quasipolynomial expansion $\hat{g}\left(\delta_{T}\right)$ of desirable precision is used, such as the Taylor expansion.

\section{I.B Proofs of Propositions 1-6}

Proposition 1. Proof. See the proof of Proposition 3; unlevered firm value is a particular case of equity value with no debt.

\section{Proposition 2. Proof.}

If $t>T_{r}$, the after-tax unlevered firm value is $V\left(\delta_{t}\right)=\left(1-\tau_{e}\right) \frac{\delta_{t}}{r-\mu}>0$ for every $\delta_{t}$, so it is never optimal to abandon the firm.

If $T_{s} \leq t<T_{r}$ and $\epsilon_{t}>0$, then the after-tax unlevered firm value is $V\left(\delta_{t}, \epsilon_{t}\right)=\left(1-\tau_{e}\right)\left(\frac{\delta_{t}}{r-\mu}+\frac{\epsilon_{t}}{r+\lambda_{r}}\right)>0$ for every $\delta_{t}$ and $\epsilon_{t}>0$, because it is never optimal to switch to the abandonment policy, which results in cash flows of 0 .

If $T_{s} \leq t<T_{r}$ and $\epsilon_{t} \leq 0$, then for $\delta_{t}>\delta_{A, t}$, using Proposition 1 and formulas from Appendix I.A, the after-tax unlevered firm value, $V\left(\delta_{t}, \epsilon_{t}\right)$, can be written as

$$
\begin{aligned}
\frac{V\left(\delta_{t}, \epsilon_{t}\right)}{1-\tau_{e}} & =\frac{\epsilon_{t}}{r+\lambda_{r}}-\frac{\epsilon_{t}}{r+\lambda_{r}}\left(\frac{\delta_{t}}{\delta_{A, t}}\right)^{-\vartheta_{\lambda_{r}}^{+}}+\left[\frac{\delta_{t}}{r+\lambda_{r}-\mu}-\frac{\delta_{A, t}}{r+\lambda_{r}-\mu}\left(\frac{\delta_{t}}{\delta_{A, t}}\right)^{-\vartheta_{\lambda_{r}}^{+}}\right. \\
& \left.+\frac{1}{r-\mu} \cdot \frac{\lambda_{r}}{\sigma^{2} d_{r}}\left(\left(\frac{1}{\vartheta_{\lambda_{r}}^{+}+1}-\frac{1}{\vartheta_{\lambda_{r}}^{-}+1}\right)-\delta_{t}^{-\vartheta_{\lambda_{r}}^{+}} \delta_{A, t}^{\vartheta_{\lambda_{r}}^{+}+1}\left(\frac{1}{\vartheta_{\lambda_{r}}^{+}+1}-\frac{1}{\vartheta_{\lambda_{r}}^{-}+1}\right)\right)\right]
\end{aligned}
$$

The optimal abandonment decision $\delta_{A, t}\left(\epsilon_{t}\right)$ is then found from the smooth-pasting condition $\left.\frac{\partial V\left(\delta_{t}, \epsilon_{t}\right)}{\partial \delta_{t}}\right|_{\delta_{t}=\delta_{A, t}}=$ 0 . Recombining terms,

$$
\delta_{A, t}\left(\epsilon_{t}\right)=-\frac{r-\mu}{r+\lambda_{r}} \frac{\vartheta_{\lambda_{r}}^{+}}{1+\vartheta_{\lambda_{r}}^{+}} \epsilon_{t}
$$

Proposition 3. Proof. Let $\min \left(\delta_{B, s}, \delta_{s}\right), s \geq t$ denote the path of the geometric Brownian motion at time $s$, which starts at initial value $\min \left(\delta_{B, t}, \delta_{t}\right)$ at time $t$. The after-tax value of equity for $t \geq T_{r}, E\left(\delta_{t}, \epsilon_{t}\right)$, is the standard result (e.g., Leland (1994)):

$$
\begin{aligned}
\frac{E\left(\delta_{t}, \epsilon_{t}\right)}{1-\tau_{e}} & =\mathbb{E}_{t}\left[\int_{t}^{\tau}\left(\delta_{s}-c\right) e^{-r(s-t)} d s\right]=\mathbb{E}_{t}\left[\int_{t}^{\infty}\left(\delta_{s}-c\right) e^{-r(s-t)} d s\right]-\mathbb{E}_{t}\left[\int_{t}^{\infty} \mathbb{I}_{s \geq \tau}\left(\delta_{s}-c\right) e^{-r(s-t)} d s\right] \\
& =\mathbb{E}_{t}\left[\int_{t}^{\infty}\left(\delta_{s}-c\right) e^{-r(s-t)} d s\right]-\mathbb{E}_{t}\left[e^{-r(\tau-t)}\right] \mathbb{E}_{t}\left[\int_{t}^{\infty}\left(\min \left(\delta_{B, t}, \delta_{t}\right)-c\right) e^{-r(s-t)} d s\right] \\
& =\frac{\delta_{t}}{r-\mu}-\frac{c}{r}-X\left(\delta_{t}, 0, \delta_{B, t}\right)\left(\frac{\min \left(\delta_{B, t}, \delta_{t}\right)}{r-\mu}-\frac{c}{r}\right)
\end{aligned}
$$


which is exactly (34). The value of equity in the time interval $\left[T_{s}, T_{r}\right)$ is

$$
\begin{aligned}
& \frac{E\left(\delta_{t}, \epsilon_{t}\right)}{1-\tau_{e}}=\mathbb{E}_{t}\left[\int_{t}^{\min \left(\tau, T_{r}\right)}\left(\delta_{s}+\epsilon_{s}-c\right) e^{-r(s-t)} d s+e^{-r\left(T_{r}-t\right)} \mathbb{I}_{\tau \geq T_{r}} \frac{E\left(\delta_{T_{r}}\right)}{1-\tau_{e}}\right] \\
& =\mathbb{E}_{t}\left[\int_{t}^{T_{r}}\left(\delta_{s}+\epsilon_{s}-c\right) e^{-r(s-t)} d s\right]-\mathbb{E}_{t}\left[\int_{t}^{T_{r}} \mathbb{I}_{s \geq \tau}\left(\delta_{s}+\epsilon_{s}-c\right) e^{-r(s-t)} d s\right]+\mathbb{E}_{t}\left[e^{-r\left(T_{r}-t\right)} \mathbb{I}_{\tau \geq T_{r}} \frac{E\left(\delta_{T_{r}}\right)}{1-\tau_{e}}\right] \\
& =\mathbb{E}_{t}\left[\int_{t}^{T_{r}}\left(\delta_{s}+\epsilon_{s}-c\right) e^{-r(s-t)} d s\right]-\mathbb{E}_{t}\left[e^{-r(\tau-t)} \mathbb{I}_{\tau<T}\right] \mathbb{E}_{t}\left[\int_{t}^{T_{r}}\left(\min \left(\delta_{B, s}, \delta_{s}\right)+\epsilon_{s}-c\right) e^{-r(s-t)} d s\right] \\
& +\mathbb{E}_{t}\left[e^{-r\left(T_{r}-t\right)} \mathbb{I}_{\tau \geq T_{r}} \frac{E\left(\delta_{T_{r}}\right)}{1-\tau_{e}}\right] \\
& =\left(\mathbb{E}_{t}\left[\int_{t}^{\infty}\left(\delta_{s}+\epsilon_{s}-c\right) e^{-r(s-t)} d s\right]-\mathbb{E}_{t}\left[e^{-r(\tau-t)} \mathbb{I}_{\tau<T}\right] \mathbb{E}_{t}\left[\int_{t}^{\infty}\left(\min \left(\delta_{B, s}, \delta_{s}\right)+\epsilon_{s}-c\right) e^{-r(s-t)} d s\right]\right) \\
& -\left(\mathbb{E}_{t} \mathbb{E}_{T_{r}}\left[\int_{T_{r}}^{\infty}\left(\delta_{s}+\epsilon_{s}-c\right) e^{-r(s-t)} d s\right]\right. \\
& \left.-\mathbb{E}_{t}\left[e^{-r(\tau-t)} \mathbb{I}_{\tau<T}\right] \mathbb{E}_{t} \mathbb{E}_{T_{r}}\left[\int_{T_{r}}^{\infty}\left(\min \left(\delta_{B, s}, \delta_{s}\right)+\epsilon_{s}-c\right) e^{-r(s-t)} d s\right]\right)+\mathbb{E}_{t}\left[e^{-r\left(T_{r}-t\right)} \mathbb{I}_{\tau \geq T_{r}} \frac{E\left(\delta_{T_{r}}\right)}{1-\tau_{e}}\right] \\
& =\frac{\delta_{t}}{r-\mu}-\frac{\min \left(\delta_{B, t}, \delta_{t}\right)}{r-\mu} X\left(\delta_{t}, \lambda_{r}, \delta_{B, t}\right)-A\left(\delta_{t}, \frac{\delta_{T_{r}}}{r-\mu}, \lambda_{r}, \delta_{B, t}\right) \\
& +\left(\frac{\epsilon_{t}}{r}-\frac{c}{r}\right)\left(1-X\left(\delta_{t}, \lambda_{r}, \delta_{B, t}\right)-A\left(\delta_{t}, 1, \lambda_{r}, \delta_{B, t}\right)\right)+A\left(\delta_{t}, \frac{E\left(\delta_{T_{r}}\right)}{1-\tau_{e}}, \lambda_{r}, \delta_{B, t}\right) .
\end{aligned}
$$

The last equality follows from the definition of $A\left(\delta_{t}, g\left(\delta_{T_{r}}\right), \lambda_{r}, \delta_{B, t}\right)$ given in (A2) and the application of the chain rule. Rearranging the terms, we get (35). Intuitively, the first part of (A16) can be thought of as a perpetuity that pays $\delta_{s}+\epsilon_{t}-c$ for every $s \geq t$, starting at $\delta_{t}$, stopped by either the endogenous default time $\tau$ or jump reversion at time $T_{r}$. Therefore, if $\tau<T_{r}$, the value of the perpetuity decreases by the value of a similar perpetuity starting at $\delta_{B, t}$ multiplied by the price of a security that pays $\$ 1$ at time $\tau$ if (i) $\delta_{t}$ is below or reaches the default boundary $\delta_{B, t}$ for the first time and (ii) $\tau<T$, which is exactly $\left(\frac{\delta_{B, t}}{r-\mu}+\frac{\epsilon_{t}}{r}-\frac{c}{r}\right) X\left(\delta_{t}, \lambda_{r}, \delta_{B, t}\right)$. If $\tau>T_{r}$, the value of the perpetuity further decreases by the value of a similar perpetuity starting at a random time $\delta_{T_{r}}$, conditional on $\delta_{t}$ not crossing the lower boundary $b_{t}$ in the time interval $\left[t, T_{r}\right]$. The amount of this decrease is equal to $A\left(\delta_{t},\left(\frac{\delta_{T_{r}}}{r-\mu}+\frac{\epsilon_{t}}{r}-\frac{c}{r}\right), \lambda, \delta_{B, t}\right)$. Finally, the second part of the expectation in (A16) is $A\left(\delta_{t}, \frac{E\left(\delta_{T_{r}}\right)}{1-\tau_{e}}, \lambda, \delta_{B, t}\right)$, by the definition of canonic security $A(\cdot)$.

For $t<T_{s}$,

$$
\frac{E\left(\delta_{t}\right)}{1-\tau_{e}}=\mathbb{E}_{t}\left[\int_{t}^{\min \left(\tau, T_{s}\right)}\left(\delta_{s}-c\right) e^{-r(s-t)} d t+e^{-r\left(T_{s}-t\right)} \mathbb{I}_{\tau \geq T_{s}} \int_{\epsilon} \frac{E\left(\delta_{T_{s}}, \epsilon_{T_{s}}\right)}{1-\tau_{e}} d F(\epsilon)\right] .
$$

Decomposing (A18) as we did (A16), we obtain (36). The only difference from (35) is that we must integrate over potential realizations of $\epsilon_{T_{s}}$ in the second part of the expectation in (A18). Note that, using Appendix I.A, (34)-(35) can be obtained in closed form. Also, for every future realization of shock size $\epsilon_{T_{s}}$, (36) can be obtained in closed form (to complete the calculation of equity value at time $t<T_{s}$, an additional numerical integration step over the distribution of shock size is needed).

To finish the derivation of equity value, using Appendix I.A, and in particular (A7)-(A10), we provide 
exact values of equity for each $t$. Let $z_{0 \ldots 3}=\left\{0, \delta_{B, T_{s}}, \delta_{B, T_{r}}, \infty\right\}$. Then,

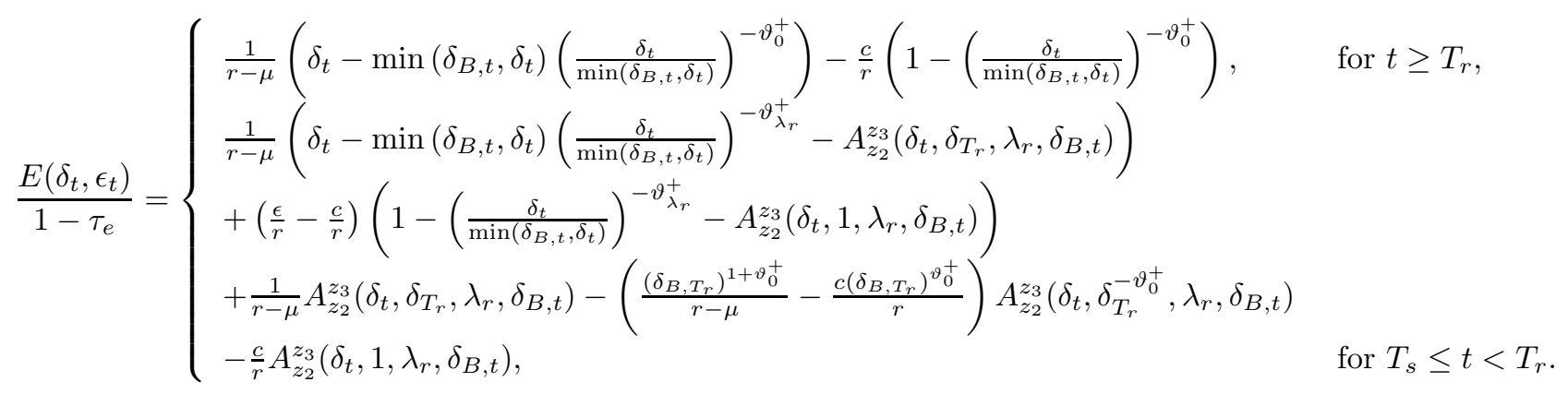

Also, define $J=5$ and $k_{1 \ldots J}=\left(0,1,-\vartheta_{0}^{+},-\vartheta_{\lambda_{r}}^{+},-\vartheta_{\lambda_{r}}^{-}\right)$. For any $t<T_{s}$ and given $\epsilon_{T_{s}}$ the value of equity is

$$
\frac{E\left(\delta_{t}, \epsilon_{t}\right)}{1-\tau_{e}}= \begin{cases}\frac{1}{r-\mu}\left(\delta_{t}-\min \left(\delta_{B, t}, \delta_{t}\right)\left(\frac{\delta_{t}}{\min \left(\delta_{B, t}, \delta_{t}\right)}\right)^{-\vartheta_{\lambda_{s}}^{+}}-A_{z_{1}}^{z_{3}}\left(\delta_{t}, \delta_{T_{s}}, \lambda_{s}, \delta_{B, t}\right)\right)- & \\
\frac{c}{r}\left(1-\left(\frac{\delta_{t}}{\min \left(\delta_{B, t}, \delta_{t}\right)}\right)^{-\vartheta_{\lambda_{s}}^{+}}-A_{z_{1}}^{z_{3}}\left(\delta_{t}, 1, \lambda_{s}, \delta_{B, t}\right)\right)+ & \text { for } t<T_{s} \text { and } \epsilon_{T_{s}} \geq 0, \\
& +\left\{\begin{array}{l}
\sum_{j=1}^{J}\left(\beta_{E, j} A_{z_{2}}^{z_{3}}\left(\delta_{t}, \delta_{T_{s}}^{k_{j}}, \lambda_{s}, \delta_{B, t}\right)+\gamma_{E, j} A_{z_{1}}^{z_{2}}\left(\delta_{t}, \delta_{T_{s}}^{k_{j}}, \lambda_{s}, \delta_{B, t}\right)\right), \\
\sum_{j=1}^{J} \zeta_{E, j} A_{z_{2}}^{z_{3}}\left(\delta_{t}, \delta_{T_{s}}^{k_{j}}, \lambda_{s}, \delta_{B, t}\right),
\end{array}\right.\end{cases}
$$

where the coefficients $\beta_{E, j}\left(c, \epsilon_{T_{s}}\right), \gamma_{E, j}\left(c, \epsilon_{T_{s}}\right)$, and $\zeta_{E, j}\left(c, \epsilon_{T_{s}}\right), j=1 \ldots J$, can be obtained by grouping together terms that have, correspondingly, $\left(1, \delta_{t}, \delta_{t}^{-\vartheta_{0}^{+}}, \delta_{t}^{\vartheta_{\lambda_{r}}^{+}}, \delta_{t}^{\vartheta_{\lambda_{r}}^{-}}\right)$in the expression for equity at time $T_{s}$. As follows from (A7)-(A10) and (A19), these terms differ with respect to both the temporary shock realization $\left(\epsilon_{T_{s}} \geq 0\right.$ or $\left.\epsilon_{T_{s}}<0\right)$ and the starting position of $\delta_{T_{s}}$ relative to the default boundary $\delta_{B, T_{r}}$. Specifically, (i) $E\left(\delta_{T_{s}}, \epsilon_{T_{s}}\right)=\sum_{j=1}^{J} \beta_{E, j} \delta_{T_{s}}^{k_{j}}$ if $\epsilon_{T_{s}} \geq 0$ and $\delta_{T_{s}} \geq \delta_{B, T_{r}}$, (ii) $E\left(\delta_{T_{s}}, \epsilon_{T_{s}}\right)=\sum_{j=1}^{J} \gamma_{E, j} \delta_{T_{s}}^{k_{j}}$ if $\epsilon_{T_{s}} \geq 0$ and $\delta_{T_{s}}<\delta_{B, T_{r}}$, and (iii) $E\left(\delta_{T_{s}}, \epsilon_{T_{s}}\right)=\sum_{j=1}^{J} \zeta_{E, j} \delta_{T_{s}}^{k_{j}}$ if $\epsilon_{t}<0$.

Technically, the coefficients $\beta_{E, j}\left(c, \epsilon_{T_{s}}\right)$, and $\gamma_{E, j}\left(c, \epsilon_{T_{s}}\right)$ and $\zeta_{E, j}\left(c, \epsilon_{T_{s}}\right)$ are functions of two variables: coupon $c$ and temporary shock $\epsilon_{T_{s}}$. However, they also depend on the optimal $\delta_{B, T_{s}}\left(c, \epsilon_{T_{s}}\right)$, which is a function of $c$ and $\epsilon_{T_{s}}$, and the optimal $\delta_{B, T_{r}}(c)$, which is a function of $c$. For example, to obtain the unlevered firm value $V\left(\delta_{t}, \epsilon_{t}\right)$ and prove Proposition 1 , we need to insert $c=0$ into the expressions for $\delta_{B, T_{r}}$ (which then equals 0 ) and $\delta_{B, T_{s}}$ (which then equals $\delta_{A, T_{s}}$ ), as well as into the set of coefficients. A variant of unlevered firm value $V\left((1-\alpha) \delta_{t}, \epsilon_{t}\right)$ completes calculations of the liquidation boundary $\delta_{L, T_{s}}$ following Proposition 2, and debt value from Proposition 6 . The exact values of the coefficients are not shown here to save space and are available upon request.

\section{Proposition 4. Proof.}

1. For $t \geq T_{r}$, the result is standard (e.g., Leland (1994)). If $t \in\left[T_{s}, T_{r}\right.$ ) and $\epsilon_{T_{s}}=0$, future shock reversion does not influence the state of the firm's temporary cash flows; therefore, the equity value is just $\left.E\left(\delta_{t}, 0\right)\right|_{T_{s} \leq t<T_{r}}=\left.E\left(\delta_{t}\right)\right|_{T_{r} \leq t}$. The smooth-pasting condition in this case also leads to (37).

2. If $t \in\left[T_{s}, T_{r}\right)$ and $\epsilon_{T_{s}}<0$, temporary cash flows act as a temporary increase in fixed coupon payments. Intuitively, a temporary increase in coupon payments puts a greater burden on shareholders and depletes their value; they optimally default at higher levels of permanent cash flows. Therefore, $\delta_{B, t}>\delta_{B, T_{r}}$ for $t \in\left[T_{s}, T_{r}\right.$ ). The derivative with respect to $\delta_{t}$ of the value of equity (A17) for $t \in\left[T_{s}, T_{r}\right.$ ), calculated 
at $\delta_{t}=\delta_{B, t}\left(\epsilon_{t}\right)$, yields the equation for $\delta_{B, t}: \omega_{B, 1}+\omega_{B, 2} \delta_{B, t}+\omega_{B, 3} \delta_{B, t}^{-\vartheta_{0}^{+}}=0$, where $\omega_{B, 1}=-\frac{\vartheta_{\lambda_{r}}^{+}\left(c-\epsilon_{t}\right)}{r+\lambda_{r}}-$ $\frac{c}{r} \frac{\lambda_{r} \vartheta_{\lambda_{r}}^{+}}{r+\lambda_{r}}, \omega_{B, 2}=\frac{1+\vartheta_{\lambda_{r}}^{+}}{r+\lambda_{r}-\mu}+\frac{\lambda_{r}}{\sigma^{2} d_{\lambda_{r}}}\left(1-\frac{\vartheta_{\lambda_{r}}^{+}+1}{\vartheta_{\lambda_{r}}^{-}+1}\right) \frac{1}{r-\mu}$, and $\omega_{B, 3}=-\frac{\lambda_{r}}{\sigma^{2} d_{\lambda_{r}}}\left(1-\frac{\vartheta_{\lambda_{r}}^{+}-\vartheta_{0}^{+}}{\vartheta_{\lambda_{r}}^{-}-\vartheta_{0}^{+}}\right)\left(\frac{\delta_{B, T_{r}}^{1+\vartheta_{0}^{+}}}{r-\mu}-\frac{c \delta_{B, T_{r}}^{\vartheta_{0}^{+}}}{r}\right)$.

3. If $t \in\left[T_{s}, T_{r}\right)$ and $\epsilon_{T_{s}} \geq c$, the current temporary shock dominates the negative effect of coupon payments on shareholders' value. As a result, shareholders receive positive total cash flows, regardless of the realization of permanent shock $\delta_{t}$, until the time of shock reversion $T_{r}$. Therefore, it is never optimal to default before $T_{r}$.

4. If $t \in\left[T_{s}, T_{r}\right)$ and $\epsilon_{T_{s}} \in(0, c)$, temporary cash flows act as a temporary reduction in fixed coupon payments. Intuitively, lower coupons make shareholders delay their default decision so that $\delta_{B, t}<\delta_{B, T_{r}}$ for $t \in\left[T_{s}, T_{r}\right)$. The derivative with respect to $\delta_{t}$ of the value of equity (A17) for $t \in\left[T_{s}, T_{r}\right.$ ), calculated at $\delta_{t}=\delta_{B, t}\left(\epsilon_{t}\right)$, yields the equation for $\delta_{B, t}: \chi_{B, 1}+\chi_{B, 2} \delta_{B, t}+\chi_{B, 3} \delta_{B, t}^{-\vartheta_{\lambda_{r}}^{-}}=0$ where $\chi_{B, 1}=-\frac{\vartheta_{\lambda_{r}}^{+}\left(c-\epsilon_{t}\right)}{r+\lambda_{r}}$, $\chi_{B, 2}=\frac{1+\vartheta_{\lambda_{r}}^{+}}{r+\lambda_{r}-\mu}$, and $\chi_{B, 3}=-\frac{\delta_{B, r}^{\vartheta_{\lambda_{r}}^{-}+1}}{r-\mu} \frac{\lambda_{r}}{\sigma^{2} d_{\lambda_{r}}} \frac{\vartheta_{\lambda_{r}}^{+}-\vartheta_{\lambda_{r}}^{-}}{\vartheta_{\lambda_{r}}^{-}+1}+\frac{c \delta_{B, T_{r}}^{-}}{r} \frac{\lambda_{r}}{\sigma^{2} d_{\lambda_{r}}} \frac{\vartheta_{\lambda_{r}}^{+}-\vartheta_{\lambda_{r}}^{-}}{\vartheta_{\lambda_{r}}^{-}}+\frac{\lambda_{r}}{\sigma^{2} d_{\lambda_{r}}} \frac{\left(\vartheta_{\lambda_{r}}^{+}-\vartheta_{\lambda_{r}}^{-}\right)_{B, T_{r}}^{\vartheta_{0}^{-}-\vartheta_{0}^{+}}}{\vartheta_{\lambda_{r}}^{-}-\vartheta_{0}^{+}}\left(\frac{\delta_{B, T_{r}}^{+1+\vartheta_{0}^{+}}}{r-\mu}-\frac{c \delta_{B, T_{r}}^{\vartheta_{0}^{+}}}{r}\right)$.

\section{Proposition 5.}

1. This result follows directly from the implicit function theorem applied to (38) and (39) for intervals $\epsilon_{T_{s}}<0$ and $\epsilon_{T_{s}}>0$. At point $\epsilon_{T_{s}}=0$, only solution $\delta_{B, t}=c \frac{r-\mu}{r} \frac{\vartheta_{0}^{+}}{\vartheta_{0}^{+}+1}$ satisfies both (38) and (39). Hence, $\delta_{B, t}$ is a continuous function of $\epsilon_{T_{s}}$. In addition, the implicit function theorem establishes the continuous differentiability of $\delta_{B, t}$ at any $\epsilon_{T_{s}}$ except $\epsilon_{T_{s}}=c$.

2. First, $\omega_{B, 2}>0, \omega_{B, 3}>0, \chi_{B, 2}>0$, and $\chi_{B, 3}<0$. As $\frac{d \delta_{B, t}}{d \epsilon}=\frac{-\frac{\vartheta_{\lambda r}^{+}}{r+\lambda_{r}}}{\omega_{B, 2}-\vartheta_{0}^{+} \omega_{B, 3} \delta_{B, t}^{-\vartheta_{0}^{+}-1}}$ if $\epsilon_{T_{s}}<0$ and $\frac{d \delta_{B, t}}{d \epsilon}=\frac{-\frac{\vartheta_{\lambda_{r}}^{+}}{r+\lambda_{r}}}{\chi_{B, 2}-\vartheta_{\lambda_{r}}^{-} \chi_{B, 3} \delta_{B, t}^{-\vartheta_{\lambda_{r}}^{+}}}$if $\epsilon_{T_{s}}>0, \delta_{B, t}$ is a decreasing function of $\epsilon$. Second, for any $\epsilon, \frac{d \delta_{B, t}}{d \epsilon}$ is below the constant slope of abandonment boundary $\frac{d \delta_{A, t}}{d \epsilon}=-\frac{\vartheta_{\lambda_{r}}^{+} \epsilon_{t}}{\omega_{B, 2}}$, so the default boundary decreases faster than the abandonment boundary. Third, because $\delta_{B, t}>\delta_{A, t}=0$ for $\epsilon_{T_{s}}=0, \delta_{B, t}>\delta_{A, t}$ for every $\epsilon_{T_{s}}$.

3. As $\epsilon_{T_{s}} \rightarrow-\infty$, the limit of $\frac{d \delta_{B, t}}{d \epsilon}$ is equal to the slope of the abandonment boundary. As a result, $\delta_{B, t}$ has an asymptote parallel to the abandonment boundary, and the supremum of distance between default and abandonment boundaries is the distance between the asymptote and the abandonment boundary for any $\epsilon_{T_{s}}<0$.

4. That $\delta_{B, t}$ is decreasing in $\epsilon_{T_{s}}$ is proven in item 3. Differentiating continuously differentiable $\frac{d \delta_{B, t}}{d \epsilon}$ with respect to $\delta_{B, t}$ at any $\epsilon_{T_{s}}<c$ yields concavity.

5. In the expression for equity (A17), for any fixed $\delta_{t}, \frac{\partial\left[X\left(\delta_{t}, \lambda_{r}, \delta_{B, t}\right)+A\left(\delta_{t}, 1, \lambda_{r}, \delta_{B, t}\right)\right]}{\delta_{B, t}}>0$. If it were the case that $\delta_{B, T_{s}}\left(\epsilon_{T_{s}}\right)=\delta_{B, T_{r}}$, i.e., a constant equal to the post-shock default boundary, then at $t<T_{s}$, the present value of future transitory shock would have been

$$
\int_{\epsilon} \frac{\epsilon}{r}\left(1-X\left(\delta_{t}, \lambda_{r}, \delta_{B, T_{r}}\right)-A\left(\delta_{t}, 1, \lambda_{r}, \delta_{B, T_{r}}\right)\right) d F(\epsilon)=0,
$$


because $\epsilon_{T_{s}}$ is distributed symmetrically around 0. However, Proposition 5.4 shows that for $\epsilon_{T_{s}}=0$, $\delta_{B_{t}}(0)=\delta_{B, T_{r}}$ and $\delta_{B_{t}}\left(\epsilon_{T_{s}}\right)$ is a decreasing function of $\epsilon_{T_{s}}$. Therefore,

$$
\begin{aligned}
& \left(1-X\left(\delta_{t}, \lambda_{r}, \delta_{B, T_{s}}\right)-A\left(\delta_{t}, 1, \lambda_{r}, \delta_{B, T_{s}}\right)\right)-\left(1-X\left(\delta_{t}, \lambda_{r}, \delta_{B, T_{r}}\right)-A\left(\delta_{t}, 1, \lambda_{r}, \delta_{B, T_{r}}\right)\right)>0, \epsilon_{T_{s}}>0, \\
& \left(1-X\left(\delta_{t}, \lambda_{r}, \delta_{B, T_{s}}\right)-A\left(\delta_{t}, 1, \lambda_{r}, \delta_{T_{s}}\right)\right)-\left(1-X\left(\delta_{t}, \lambda_{r}, \delta_{B, T_{r}}\right)-A\left(\delta_{t}, 1, \lambda_{r}, \delta_{B, T_{r}}\right)\right)<0, \epsilon_{T_{s}}<0 .
\end{aligned}
$$

Hence,

$$
\int_{\epsilon} \frac{\epsilon}{r}\left(\left(1-X\left(\delta_{t}, \lambda_{r}, \delta_{B, T_{r}}\right)-A\left(\delta_{t}, 1, \lambda_{r}, \delta_{B, T_{r}}\right)\right)-\left(1-X\left(\delta_{t}, \lambda_{r}, \delta_{B, T_{s}}\right)-A\left(\delta_{t}, 1, \lambda_{r}, \delta_{B, T_{s}}\right)\right)\right) d F(\epsilon)>0
$$

and, finally,

$$
\int_{\epsilon} \frac{\epsilon}{r}\left(1-X\left(\delta_{t}, \lambda_{r}, \delta_{B, T_{s}}\right)-A\left(\delta_{t}, 1, \lambda_{r}, \delta_{B, T_{s}}\right)\right) d F(\epsilon)>0 .
$$

Under the optimal default policy $\delta_{B, T_{s}}\left(\epsilon_{T_{s}}\right)$, the present value of future transitory shock is strictly above 0 . As a result, the value of equity at $t<T_{s}$ is strictly above the value of equity at $t>T_{r}$ for every realization of $\delta_{t}$. At time $t<T_{s}$, shareholders optimally default when $\delta_{t}$ reaches the lower boundary $\delta_{B, t}<\delta_{B, T_{r}}$.

\section{Proposition 6. Proof.}

It is useful to decompose the value of debt into two parts: the present value of all pre-bankruptcy coupon payments $C(\cdot)$ and the present value of all post-bankruptcy debt $L(\cdot)$ in every time interval.

The value of debt for $t>T_{r}$ is the standard result (e.g., Leland (1994)). The after-tax value of coupon payments, $C\left(\delta_{t}\right)$, is

$$
\begin{aligned}
\frac{C\left(\delta_{t}\right)}{1-\tau_{i}} & =\mathbb{E}_{t}\left[\int_{t}^{\tau} c e^{-r(s-t)} d t\right]=\mathbb{E}_{t}\left[\int_{t}^{\infty} c e^{-r(s-t)} d t\right]-\mathbb{E}_{t}\left[\int_{t}^{\infty} \mathbb{I}_{s \geq \tau}\left(1-\tau_{i}\right) c e^{-r(s-t)} d t\right] \\
& =\mathbb{E}_{t}\left[\int_{t}^{\infty} c e^{-r(s-t)} d t\right]-\mathbb{E}_{t}\left[e^{-r(\tau-t)}\right] \mathbb{E}_{t}\left[\int_{t}^{\infty} c e^{-r(s-t)} d t\right]=\frac{c}{r}-\frac{c}{r} X\left(\delta_{t}, 0, \delta_{B, t}\right),
\end{aligned}
$$

and the value of debt after bankruptcy, $L\left(\delta_{t}\right)$, is

$$
L\left(\delta_{t}\right)=\mathbb{E}_{t}\left[V\left((1-\alpha) \min \left(\delta_{B, t}, \delta_{\tau}\right)\right) e^{-r(\tau-t)}\right]=(1-\alpha)\left(1-\tau_{e}\right) \frac{\min \left(\delta_{B, t}, \delta_{t}\right)}{r-\mu} X\left(\delta_{t}, 0, \delta_{B, t}\right) .
$$

Writing $D\left(\delta_{t}\right)=C\left(\delta_{t}\right)+L\left(\delta_{t}\right)$ proves (40).

The value of debt in the time interval $\left[T_{s}, T_{r}\right)$ is

$$
\begin{aligned}
D\left(\delta_{t}, \epsilon_{t}\right)= & \mathbb{E}_{t}\left[\int_{t}^{\min \left(\tau, T_{r}\right)}\left(1-\tau_{i}\right) c e^{-r(s-t)} d t\right. \\
& \left.+e^{-r(\tau-t)} \mathbb{I}_{\tau<T_{r}} V\left((1-\alpha) \max \left(\delta_{L, t}, \min \left(\delta_{B, t}, \delta_{\tau}\right)\right), \epsilon_{t}\right)+e^{-r\left(T_{r}-t\right)} \mathbb{I}_{\tau \geq T_{r}} D\left(\delta_{T_{r}}\right)\right] \\
= & \mathbb{E}_{t}\left[\int_{t}^{\min \left(\tau, T_{r}\right)}\left(1-\tau_{i}\right) c e^{-r(s-t)} d t+e^{-r\left(T_{r}-t\right)} \mathbb{I}_{\tau \geq T_{r}} C\left(\delta_{T_{r}}\right)\right] \\
& +\mathbb{E}_{t}\left[e^{-r(\tau-t)} \mathbb{I}_{\tau<T_{r}} V\left((1-\alpha) \max \left(\delta_{L, t}, \min \left(\delta_{B, t}, \delta_{\tau}\right)\right), \epsilon_{t}\right)+e^{-r\left(T_{r}-t\right)} \mathbb{I}_{\tau \geq T_{r}} L\left(\delta_{T_{r}}\right)\right] \\
= & C\left(\delta_{t}, \epsilon_{t}\right)+L\left(\delta_{t}, \epsilon_{t}\right),
\end{aligned}
$$


where the pre-tax value of the coupon payments is

$$
\begin{aligned}
\frac{C\left(\delta_{t}, \epsilon_{t}\right)}{1-\tau_{i}}= & \mathbb{E}_{t}\left[\int_{t}^{\min \left(\tau, T_{r}\right)} c e^{-r(s-t)} d t+e^{-r\left(T_{r}-t\right)} \mathbb{I}_{\tau \geq T_{r}} \frac{C\left(\delta_{T_{r}}\right)}{1-\tau_{i}}\right] \\
= & \mathbb{E}_{t}\left[\int_{t}^{T_{r}} c e^{-r(s-t)} d t\right]-\mathbb{E}_{t}\left[\int_{t}^{T_{r}} \mathbb{I}_{s \geq \tau} c e^{-r(s-t)} d t\right]+\mathbb{E}_{t}\left[e^{-r\left(T_{r}-t\right)} \mathbb{I}_{\tau \geq T_{r}} \frac{C\left(\delta_{T_{r}}\right)}{1-\tau_{i}}\right] \\
= & \mathbb{E}_{t}\left[\int_{t}^{T_{r}} c e^{-r(s-t)} d t\right]-\mathbb{E}_{t}\left[e^{-r(\tau-t)} \mathbb{I}_{\tau<T}\right] \mathbb{E}_{t}\left[\int_{t}^{T_{r}} c e^{-r(s-t)} d t\right]+\mathbb{E}_{t}\left[e^{-r\left(T_{r}-t\right)} \mathbb{I}_{\tau \geq T_{r}} \frac{C\left(\delta_{T_{r}}\right)}{1-\tau_{i}}\right] \\
= & \left(\mathbb{E}_{t}\left[\int_{t}^{\infty} c e^{-r(s-t)} d t\right]-\mathbb{E}_{t}\left[e^{-r(\tau-t)} \mathbb{I}_{\tau<T}\right] \mathbb{E}_{t}\left[\int_{t}^{\infty} c e^{-r(s-t)} d t\right]\right) \\
& -\left(\mathbb{E}_{t} \mathbb{E}_{T_{r}}\left[\int_{T_{r}}^{\infty} c e^{-r(s-t)} d t\right]-\mathbb{E}_{t}\left[e^{-r(\tau-t)} \mathbb{I}_{\tau<T}\right] \mathbb{E}_{t} \mathbb{E}_{T_{r}}\left[\int_{T_{r}}^{\infty} c e^{-r(s-t)} d t\right]\right) \\
& +\mathbb{E}_{t}\left[e^{-r\left(T_{r}-t\right)} \mathbb{I}_{\tau \geq T_{r}} \frac{C\left(\delta_{T_{r}}\right)}{1-\tau_{i}}\right] \\
= & \frac{c}{r}\left(1-X\left(\delta_{t}, \lambda_{r}, \delta_{B, t}\right)-A\left(\delta_{t}, 1, \lambda_{r}, \delta_{B, t}\right)\right)+A\left(\delta_{t}, \frac{C\left(\delta_{T_{r}}\right)}{1-\tau_{i}}, \lambda_{r}, \delta_{B, t}\right) .
\end{aligned}
$$

The last equality follows from the definition of $A\left(\delta_{t}, g\left(\delta_{T_{r}}\right), \lambda_{r}, \delta_{B, t}\right)$ given in (A2) and the application of the chain rule. The value of debt after bankruptcy is

$$
\begin{aligned}
L\left(\delta_{t}, \epsilon_{t}\right) & =\mathbb{E}_{t}\left[e^{-r(\tau-t)} \mathbb{I}_{\tau<T_{r}} V\left((1-\alpha) \max \left(\delta_{L, t}, \min \left(\delta_{B, t}, \delta_{\tau}\right)\right), \epsilon_{t}\right)\right]+\mathbb{E}_{t}\left[e^{-r\left(T_{r}-t\right)} \mathbb{I}_{\tau \geq T_{r}} L\left(\delta_{T_{r}}\right)\right] \mathrm{A} \\
& =V\left((1-\alpha) \max \left(\delta_{L, t}, \min \left(\delta_{B, t}, \delta_{t}\right)\right), \epsilon_{t}\right) X\left(\delta_{t}, \lambda_{r}, \delta_{B, t}\right)+A\left(\delta_{t}, L\left(\delta_{T_{r}}\right), \lambda_{r}, \delta_{B, t}\right) .
\end{aligned}
$$

Therefore, writing $D\left(\delta_{t}, \epsilon_{t}\right)=C\left(\delta_{t}, \epsilon_{t}\right)+L\left(\delta_{t}, \epsilon_{t}\right)$ proves (41). For $t<T_{s}$,

$$
\begin{aligned}
D\left(\delta_{t}\right) & =\mathbb{E}_{t}\left[\int_{t}^{\min \left(\tau, T_{s}\right)}\left(1-\tau_{i}\right) c e^{-r(s-t)} d t+e^{-r(\tau-t)} \mathbb{I}_{\tau<T_{s}} V\left((1-\alpha) \min \left(\delta_{B, t}, \delta_{\tau}\right)\right)\right. \\
& \left.+e^{-r\left(T_{s}-t\right)} \mathbb{I}_{\tau \geq T_{s}} \int_{\epsilon} D\left(\delta_{T_{s}}, \epsilon_{T_{s}}\right) d F(\epsilon)\right] .
\end{aligned}
$$

Decomposing (A26) in the same way as (A21), we obtain (42). The only difference from (41) is that we must integrate over potential realizations of $\epsilon_{T_{s}}$ in the second part of the expectation in (A26). Using Appendix I.A, (40)-(41) can be obtained in closed form. Also, for every future realization of shock size $\epsilon_{T_{s}}$, (42) can be obtained in closed form (to complete the calculation of equity value at time $t<T_{s}$, an additional numerical integration step over the distribution of shock size is needed).

To finish the derivation of debt value, using Appendix I.A, and in particular (A7)-(A10), we provide exact values of debt for each $t$. Let $z_{0 \ldots 3}=\left\{0, \delta_{B, T_{s}}, \delta_{B, T_{r}}, \infty\right\}$.

Then, the after-tax present value of coupon payments, $C\left(\delta_{t}, \epsilon_{t}\right)$, is

$$
\frac{C\left(\delta_{t}, \epsilon_{t}\right)}{1-\tau_{i}}= \begin{cases}\frac{c}{r}\left(1-\left(\frac{\delta_{t}}{\min \left(\delta_{B, t}, \delta_{t}\right)}\right)^{-\vartheta_{0}^{+}}\right), & \text {for } t \geq T_{r}, \\ \frac{c}{r}\left(1-\left(\frac{\delta_{t}}{\min \left(\delta_{B, t}, \delta_{t}\right)}\right)^{-\vartheta_{\lambda_{r}}^{+}}-A_{z_{2}}^{z_{3}}\left(\delta_{t}, 1, \lambda_{r}, \delta_{B, t}\right)\right)-\frac{c\left(\delta_{B, T_{r}}\right)_{0}^{+}}{r} A_{z_{2}}^{z_{3}}\left(\delta_{t}, \delta_{T_{r}}^{-\vartheta_{0}^{+}}, \lambda_{r}, \delta_{B, t}\right) & \\ +\frac{c}{r} A_{z_{2}}^{z_{3}}\left(\delta_{t}, 1, \lambda_{r}, \delta_{B, t}\right), & \text { for } T_{s} \leq t<T_{r} .\end{cases}
$$


As in Proposition 3, define $J=5$ and $k_{1, \ldots, J}=\left(0,1,-\vartheta_{0}^{+},-\vartheta_{\lambda_{r}}^{+},-\vartheta_{\lambda_{r}}^{-}\right)$. For any $t<T_{s}$ and given $\epsilon_{T_{s}}$ the after-tax value of coupon payments, $C\left(\delta_{t}, \epsilon_{t}\right)$, is

$$
\frac{C\left(\delta_{t}, \epsilon_{t}\right)}{1-\tau_{i}}= \begin{cases}\frac{c}{r}\left(1-\left(\frac{\delta_{t}}{\min \left(\delta_{B, t}, \delta_{t}\right)}\right)^{-\vartheta_{\lambda_{s}}^{+}}-A_{z_{1}}^{z_{3}}\left(\delta_{t}, 1, \lambda_{s}, \delta_{B, t}\right)\right)+ & \\ + \begin{cases}\sum_{j=1}^{J}\left(\beta_{C, j} A_{z_{2}}^{z_{3}}\left(\delta_{t}, \delta_{T_{s}}^{k_{j}}, \lambda_{s}, \delta_{B, t}\right)+\gamma_{C, j} A_{z_{1}}^{z_{2}}\left(\delta_{t}, \delta_{T_{s}}^{k_{j}}, \lambda_{s}, \delta_{B, t}\right)\right), & \text { for } t<T_{s} \text { and } \epsilon_{T_{s}} \geq 0 \\ \sum_{j=1}^{J} \zeta_{C, j} A_{z_{2}}^{z_{3}}\left(\delta_{t}, \delta_{T_{s}}^{k_{j}}, \lambda_{s}, \delta_{B, t}\right), & \text { for } t<T_{s} \text { and } \epsilon_{T_{s}}<0,\end{cases} \end{cases}
$$

where the coefficients $\beta_{C, j}\left(c, \epsilon_{T_{s}}\right), \gamma_{C, j}\left(c, \epsilon_{T_{s}}\right)$, and $\zeta_{C, j}\left(c, \epsilon_{T_{s}}\right), j=1 \ldots J$, are obtained by grouping together terms that have, correspondingly, $\left(1, \delta_{t}, \delta_{t}^{-\vartheta_{0}^{+}}, \delta_{t}^{\vartheta_{\lambda_{r}}^{+}}, \delta_{t}^{\vartheta_{\lambda_{r}}^{-}}\right)$in the expression for the after-tax value of coupon payments at time $T_{s}$. As follows from (A7)-(A10) and (A27), these terms differ with respect to both temporary shock realization $\left(\epsilon_{T_{s}} \geq 0\right.$ or $\left.\epsilon_{T_{s}}<0\right)$ and the starting position of $\delta_{T_{s}}$ relative to the default boundary $\delta_{B, T_{r}}$. Specifically, (i) $\frac{C\left(\delta_{T_{s}}, \epsilon_{T_{s}}\right)}{1-\tau_{i}}=\sum_{j=1}^{J} \beta_{C, j} \delta_{T_{s}}^{k_{j}}$ if $\epsilon_{T_{s}} \geq 0$ and $\delta_{T_{s}} \geq \delta_{B, T_{r}}$, (ii) $\frac{C\left(\delta_{\left.T_{s}, \epsilon_{s}\right)}\right.}{1-\tau_{i}}=\sum_{j=1}^{J} \gamma_{C, j} \delta_{T_{s}}^{k_{j}}$ if $\epsilon_{T_{s}} \geq 0$ and $\delta_{T_{s}}<\delta_{B, T_{r}}$, and (iii) $\frac{C\left(\delta_{\left.T_{s}, \epsilon_{T_{s}}\right)}\right.}{1-\tau_{i}}=\sum_{j=1}^{J} \zeta_{C, j} \delta_{T_{s}}^{k_{j}}$ if $\epsilon_{t}<0$.

The coefficients $\beta_{C, j}\left(c, \epsilon_{T_{s}}\right), \gamma_{C, j}\left(c, \epsilon_{T_{s}}\right)$, and $\zeta_{C, j}\left(c, \epsilon_{T_{s}}\right)$ are functions of two variables: coupon $c$ and temporary shock $\epsilon_{T_{s}}$, though they also depend on the optimal $\delta_{B, T_{s}}\left(c, \epsilon_{T_{s}}\right)$, which is a function of $c$ and $\epsilon_{T_{s}}$, and optimal $\delta_{B, T_{r}}(c)$, which is a function of $c$. The exact values of the coefficients are not shown here to save space and are available upon request.

Finally, for any $t \geq T_{s}$, the after-tax present value of debt after bankruptcy, $L\left(\delta_{t}, \epsilon_{t}\right)$, is

$$
\frac{L\left(\delta_{t}, \epsilon_{t}\right)}{1-\tau_{e}}= \begin{cases}(1-\alpha) \frac{\min \left(\delta_{B, t}, \delta_{t}\right)}{r-\mu}\left(\frac{\delta_{t}}{\min \left(\delta_{B, t}, \delta_{t}\right)}\right)^{-\vartheta_{0}^{+}}, & \text {for } t \geq T_{r}, \\ V\left((1-\alpha) \max \left(\delta_{L, t}, \min \left(\delta_{B, t}, \delta_{t}\right)\right), \epsilon_{t}\right)\left(\frac{\delta_{t}}{\min \left(\delta_{B, t}, \delta_{t}\right)}\right)^{-\vartheta_{\lambda_{r}}^{+}} & \\ +(1-\alpha) \frac{\delta_{B, T_{r}}^{\vartheta_{+}^{+}}}{r-\mu} A_{z_{2}}^{z_{3}}\left(\delta_{t}, \delta_{T_{r}}^{-\vartheta_{0}^{+}}, \lambda_{r}, \delta_{B, t}\right) & \\ +(1-\alpha) \frac{1}{r-\mu} A_{\min \left(\delta_{B, t}, z_{2}\right)}^{z_{2}}\left(\delta_{t}, \delta_{T_{r}}, \lambda_{r}, \delta_{B, t}\right), & \text { for } T_{s} \leq t<T_{r} .\end{cases}
$$

For any $t<T_{s}$ and given $\epsilon_{T_{s}}$ the after-tax value of debt after bankruptcy, $L\left(\delta_{t}, \epsilon_{t}\right)$, is

$$
\frac{L\left(\delta_{t}, \epsilon_{t}\right)}{1-\tau_{e}}=\left\{\begin{aligned}
& V\left((1-\alpha) \min \left(\delta_{B, t}, \delta_{t}\right)\right)\left(\frac{\delta_{t}}{\min \left(\delta_{B, t}, \delta_{t}\right)}\right)^{-\vartheta_{\lambda_{s}}^{+}} \\
&+ \begin{cases}\sum_{j=1}^{J}(1-\alpha) \beta_{E, j}\left(0, \frac{\epsilon_{T_{s}}}{1-\alpha}\right) A_{\max \left(\delta_{L, T_{s}}, \min \left(\delta_{B, t}, z_{1}\right)\right)}^{z_{1}}\left(\delta_{t}, \delta_{T_{s}}^{k_{j}}, \lambda_{r}, \delta_{B, t}\right), & \text { for } t<T_{s} \text { and } \epsilon_{T_{s}} \geq 0 \\
\sum_{j=1}^{J}(1-\alpha) \zeta_{E, j}\left(0, \frac{\epsilon_{T_{s}}}{1-\alpha}\right) A_{\max \left(\delta_{L, T_{s}}, \min \left(\delta_{B, t}, z_{1}\right)\right)}^{z_{1}}\left(\delta_{t}, \delta_{T_{s}}^{k_{j}}, \lambda_{r}, \delta_{B, t}\right), & \text { for } t<T_{s} \text { and } \epsilon_{T_{s}}<0\end{cases} \\
&+ \begin{cases}\sum_{j=1}^{J}\left(\beta_{L, j} A_{z_{2}}^{z_{3}}\left(\delta_{t}, \delta_{T_{s}}^{k_{j}}, \lambda_{s}, \delta_{B, t}\right)+\gamma_{L, j} A_{z_{1}}^{z_{2}}\left(\delta_{t}, \delta_{T_{s}}^{k_{j}}, \lambda_{s}, \delta_{B, t}\right)\right), & \text { for } t<T_{s} \text { and } \epsilon_{T_{s}} \geq 0, \\
\sum_{j=1}^{J} \zeta_{L, j} A_{z_{2}}^{z_{3}}\left(\delta_{t}, \delta_{T_{s}}^{k_{j}}, \lambda_{s}, \delta_{B, t}\right), & \text { for } t<T_{s} \text { and } \epsilon_{T_{s}}<0,\end{cases}
\end{aligned}\right.
$$

where the coefficients $\beta_{E, j}\left(c, \epsilon_{T_{s}}\right)$, and $\zeta_{E, j}\left(c, \epsilon_{T_{s}}\right), j=1, \ldots, J$, provided in Proposition 3, are calculated at zero coupon and at the scaled shock size $\frac{\epsilon_{T_{s}}}{1-\alpha}$ instead of $\epsilon_{T_{s}}$, then multiplied by $(1-\alpha)$ (because debt receives unlevered equity value $V\left((1-\alpha) \delta_{t}, \epsilon_{t}\right)=(1-\alpha) V\left(\delta_{t}, \frac{\epsilon_{t}}{1-\alpha}\right)$ after bankruptcy). The coefficients $\beta_{L, j}\left(c, \epsilon_{T_{s}}\right)$, $\gamma_{L, j}\left(c, \epsilon_{T_{s}}\right)$, and $\zeta_{L, j}\left(c, \epsilon_{T_{s}}\right), j=1, \ldots, J$, are obtained by grouping together terms that have, correspondingly, $\left(1, \delta_{t}, \delta_{t}^{-\vartheta_{0}^{+}}, \delta_{t}^{\vartheta_{\lambda_{r}}^{+}}, \delta_{t}^{\vartheta_{\lambda_{r}}^{-}}\right)$in the expression for the before-tax value of debt after bankruptcy at time $T_{s}$. As follows from (A7)-(A10) and (A27), these terms differ with respect to both temporary shock realization $\left(\epsilon_{T_{s}} \geq 0\right.$ or $\left.\epsilon_{T_{s}}<0\right)$ and the starting position of $\delta_{T_{s}}$ relative to the default boundary $\delta_{B, T_{r}}$. Specifically, (i) $\frac{L\left(\delta_{T_{s}}, \epsilon_{T_{s}}\right)}{1-\tau_{e}}=\sum_{j=1}^{J} \beta_{L, j} \delta_{T_{s}}^{k_{j}}$ if $\epsilon_{T_{s}} \geq 0$ and $\delta_{T_{s}} \geq \delta_{B, T_{r}}$, (ii) $\frac{L\left(\delta_{\left.T_{s}, \epsilon_{T_{s}}\right)}\right.}{1-\tau_{e}}=\sum_{j=1}^{J} \gamma_{L, j} \delta_{T_{s}}^{k_{j}}$ if $\epsilon_{T_{s}} \geq 0$ and $\delta_{T_{s}}<\delta_{B, T_{r}}$, 
and (iii) $\frac{L\left(\delta_{T_{s}}, \epsilon_{T_{s}}\right)}{1-\tau_{e}}=\sum_{j=1}^{J} \zeta_{L, j} \delta_{T_{s}}^{k_{j}}$ if $\epsilon_{t}<0$.

Finally, the coefficients $\beta_{L, j}\left(c, \epsilon_{T_{s}}\right), \gamma_{L, j}\left(c, \epsilon_{T_{s}}\right)$, and $\zeta_{L, j}\left(c, \epsilon_{T_{s}}\right)$ are functions of two variables: coupon $c$ and temporary shock $\epsilon_{T_{s}}$, though they also depend on the optimal $\delta_{B, T_{s}}\left(c, \epsilon_{T_{s}}\right)$, which itself is a function of $c$ and $\epsilon_{T_{s}}$, and the optimal $\delta_{B, T_{r}}(c)$, which is a function of $c$. The exact values of the coefficients are not shown here to save space and are available upon request.

\section{Appendix B. Numerical procedure}

The model with both permanent and multiple transitory shocks of Section ?? allows us to characterize a solution of optimal abandonment and default boundaries as non-linear functions of the transitory shock size and coupon. To conserve space, we briefly outline the procedure used to obtain the solution and provide the detailed explanation in the Supplement, which is available upon request.

The functional form of the default boundary $\delta_{B}\left(c, \epsilon_{t}\right)$ is obtained by applying the standard smooth-pasting condition (49) to the Hamilton-Jacobi-Bellman (HJB) equation for equity value:

$\sum_{i=0}^{\infty}\left(a_{s, i}^{+} \delta_{B, t}^{-\vartheta_{\lambda_{r}}^{+}} \log ^{i} \delta_{B, t}^{-\vartheta_{\lambda_{r}}^{+}}+a_{s, i}^{-} \delta_{B, t}^{-\vartheta_{\lambda_{r}}^{-}} \log ^{i} \delta_{B, t}^{-\vartheta_{\lambda_{r}}^{-}}+b_{s, i}^{+} \delta_{B, t}^{-\vartheta_{\lambda_{s}}^{+}} \log ^{i} \delta_{B, t}^{-\vartheta_{\lambda_{s}}^{+}}+b_{s, i}^{-} \delta_{B, t}^{-\vartheta_{\lambda_{s}}^{-}} \log ^{i} \delta_{B, t}^{-\vartheta_{\lambda_{s}}^{-}}\right)+c_{s} \delta_{B, t}+d_{s}+e_{s} \epsilon_{t}=0$,

if the transitory shock is present, and

$\sum_{i=0}^{\infty}\left(a_{r, i}^{+} \delta_{B, t}^{-\vartheta_{\lambda_{r}}^{+}} \log ^{i} \delta_{B, t}^{-\vartheta_{\lambda_{r}}^{+}}+a_{r, i}^{-} \delta_{B, t}^{-\vartheta_{\lambda_{r}}^{-}} \log ^{i} \delta_{B, t}^{-\vartheta_{\lambda_{r}}^{-}}+b_{r, i}^{+} \delta_{B, t}^{-\vartheta_{\lambda_{s}}^{+}} \log ^{i} \delta_{B, t}^{-\vartheta_{\lambda_{s}}^{+}}+b_{r, i}^{-} \delta_{B, t}^{-\vartheta_{\lambda_{s}}^{-}} \log ^{i} \delta_{B, t}^{-\vartheta_{\lambda_{s}}^{-}}\right)+c_{r} \delta_{B, t}+d_{r}=0$,

if the transitory shock is absent. A similar functional form can be obtained for the abandonment boundary by solving the HJB Equation (46)-(47) for $V\left((1-\alpha) \delta_{t}, \epsilon_{t}\right)$.

However, the closed form representation of these functions in terms of model primitives does not exist: $\left.\left\{a_{s, i}^{+}, a_{s, i}^{-}, a_{r, i}^{+}, a_{r, i}^{-}, b_{s, i}^{+}, b_{s, i}^{-}, b_{r, i}^{+}, b_{r, i}^{-}, c_{s}, c_{r}, d_{s}, d_{r}, e_{s}\right\}\right|_{i=0} ^{\infty}$ are unknown functions of the coupon $c$ and the distribution of shock size. To solve for optimal abandonment and default boundaries approximately and then control for approximation quality, we develop the numerical procedure by considering the following functional form for both abandonment and default boundaries:

$$
\begin{aligned}
H_{s}^{-}\left(\epsilon_{t}, \delta_{X, t}\right) & =b_{s, 0}^{+} \delta_{X, t}^{-\vartheta_{\lambda_{s}}^{+}}+c_{s}^{+} \delta_{X, t}+d_{s}^{+}+\left(\epsilon_{t}-\tilde{\epsilon}\right)=0, \epsilon<\tilde{\epsilon}, \\
H_{s}^{+}\left(\epsilon_{t}, \delta_{X, t}\right) & =a_{s, 0}^{-} \delta_{X, t}^{-\vartheta_{\lambda_{r}}^{-}}+c_{s}^{-} \delta_{X, t}+d_{s}^{-}+\left(\epsilon_{t}-\tilde{\epsilon}\right)=0, \epsilon \geq \tilde{\epsilon}, \\
H_{r}\left(\delta_{X, t}\right) & =\delta_{X, t}-d_{r}=0,
\end{aligned}
$$

where $\delta_{X, t}$ is either the abandonment $\left(\delta_{L, t}\right)$ or the default $\left(\delta_{B, t}\right)$ boundary, and $\tilde{\epsilon}$ is the switching point. The first two equations define the approximate boundary in the presence of the transitory shock and therefore depend on the realization of temporary cash flows. The last equation defines the exact boundary in the absence of the transitory shock, which for the given coupon is a constant. We maximize the values of post-bankruptcy debt and levered equity over the set of parameters $\Omega_{X}=\left\{b_{s, 0}^{+}, c_{s}^{+}, d_{s}^{+}, a_{s, 0}^{-}, c_{s}^{-}, d_{s}^{-}, d_{r}\right\}$ and find approximate solutions $\hat{\delta}_{L, t}\left(\epsilon_{t}\right)$ and $\hat{\delta}_{B, t}\left(c, \epsilon_{t}\right)$.

The approximation works well, because true functional forms of both abandonment and default bound- 
aries are very similar to those in the model with single temporary shock. The approximate functional form (B3) exploits this similarity and obtains the same properties (continuous, decreasing, concave function with asymptotic behavior as $\left.\epsilon_{t} \rightarrow \infty\right)$ of $\delta_{L, t}, \delta_{B, t}$ as in the single-shock model, while still keeping the number of parameters small to achieve convergence to an optimum in reasonable time. In particular, $H_{s}^{-}\left(\epsilon_{t}, \delta_{X, t}\right)$ approximates a small curvature and asymptotic behavior as $\epsilon_{t} \rightarrow \infty$ of the boundary for sufficiently negative $\epsilon_{t}$, because the term with $\vartheta_{(\cdot)}^{+}$is included in its functional form. $H_{s}^{+}\left(\epsilon_{t}, \delta_{X, t}\right)$ approximates large curvature for positive and slightly negative $\epsilon_{t}$ due to the inclusion of the term with $\vartheta_{(\cdot)}^{-}$in its functional form. The restrictions imposed on the set of parameters for both boundaries, which help achieve these properties, are described in more detail in the Supplement (available upon request). We find optimal parameters in the final set by checking that the derivative with respect to $\delta_{t}$ of, correspondingly, the simulated value of post-bankruptcy debt and simulated equity, calculated at $\delta_{t}=\delta_{L, t}\left(\epsilon_{t}\right)$ or $\delta_{t}=\delta_{B, t}\left(c, \epsilon_{t}\right)$, is as close to 0 as possible for any $\epsilon_{t}$ and $c$. This approach emulates the theoretical solution to the smooth-pasting condition in a two-dimensional cash flow space $\left(\delta_{t}, \epsilon_{t}\right)$. The step-by-step maximization algorithm is described in the Supplement.

\section{References}

Almeida, Heitor and Thomas Philippon, 2007, The Risk-Adjusted Cost of Financial Distress, Journal of Finance, 62, 2557-2586.

Altman, Edward I., 1984, A Further Empirical Investigation of the Bankruptcy Cost Question, Journal of Finance, 39, 1067-1089.

Andrade, Gregor and Steven N. Kaplan, 1998, How Costly Is Financial (Not Economic) Distress? Evidence from Highly Leveraged Transactions that Became Distressed, Journal of Finance, 53, $1443-1493$.

Asquith, Paul, Robert Gertner, And David Scharfstein, 1994, Anatomy of Financial Distress: An Examination of Junk Bond Issuers, Quarterly Journal of Economics, 109, 625-658.

Berndt, Antje, Rohan Douglas, Darrell Duffie, Mark Ferguson, and David Schranz, 2005, Measuring Default Risk Premia from Default Swap Rates and EDFs, Working Paper, Stanford GSB.

Bhamra, Harjoat, Lars-Alexander Kühn, And Ilya A. Strebulaev, 2009a, The Levered Equity Risk Premium and Credit Spreads: A Unified Framework, Review of Financial Studies, forthcoming.

Bhamra, Harjoat, Lars-Alexander Kühn, and Ilya A. Strebulaev, 2009b, The Aggregate Dynamics of Capital Structure and Macroeconomic Risk, Review of Financial Studies, forthcoming.

Coles, Jeffrey, Michael Lemmon, And Felix Meschke, 2007, Structural Models and Endogeneity in Corporate Finance, Working Paper, University of Utah.

Corwin, Shane A., 2003, The Determinants of Underpricing for Seasoned Equity Offers, Journal of Finance, $58,2249-2279$.

Dao, B., And Monique Jeanblanc, 2006, Double Exponential Jump Diffusion Process: A Structural Model of Endogenous Default Barrier with Roll-Over Debt Structure, Working Paper, Universite Paris Dauphine.

Davydenko, Sergei, 2007, When Do Firms Default? A Study of the Default Boundary, Working Paper, University of Toronto.

Dixit, Avinash K., And Robert S. Pindyck, 1994, Investment under Uncertainty, Princeton, NJ: Princeton University Press.

Fan, Hua, And Suresh M. Sundaresan, 2000, Debt Valuation, Renegotiation, and Optimal Dividend Policy, Review of Financial Studies 13, 1057-1099.

Faulkender, Michael, And Mitchell A. Petersen, 2006, Does the Source of Capital Affect Capital Structure?, Review of Financial Studies, 19, 45-79. 
Fischer, Edwin O., Robert Heinkel, And Josef Zechner, 1989, Optimal Dynamic Capital Structure Choice: Theory and Tests, Journal of Finance, 44, 19-40.

Gamba, Andrea, And Alexander Triantis, 2008a, The Value of Financial Flexibility, Journal of Finance, $63,2263-2296$.

Gamba, Andrea, and Alexander Triantis, 2008b, Valuing Corporate Financing Strategies, Working Paper, University of Maryland.

Givoly, Dan, and Carla Hayn, 2000, The Changing Time-Series Properties of Earnings, Cash Flows and Accruals: Has Financial Reporting Become More Conservative?, Journal of Accounting and Economics, 29, $287-320$.

Goldstein, Robert, Nenguiu Ju, and Hayne E. Leland, 2001, An EBIT-Based Model of Dynamic Capital Structure, Journal of Business, 74, 483-512.

Graham, John R., 1999, Do Personal Taxes Affect Corporate Financing Decisions?, Journal of Public Economics, 73, 147-185.

Graham, John R., 2000, How Big Are the Tax Benefits of Debt, Journal of Finance, 55, 1901-1941.

Graham, John R., 2003, Taxes and Corporate Finance: A Review, Review of Financial Studies, 16, 10751129.

Graham, John R., and Campbell R. Harvey, 2001, The Theory and Practice of Corporate Finance: Evidence from the Field, Journal of Financial Economics, 60, 187-243.

Hackbarth, Dirk, C. A. Hennessy, and H. E. Leland, 2007, Can the Trade-Off Theory Explain Debt Structure, Review of Financial Studies, 20, 1389-1428.

Hackbarth, Dirk, Jianjun Miao, and Erwan Morellec, 2006, Capital Structure, Credit Risk, and Macroeconomic Conditions, Journal of Financial Economics, 82, 519-550.

Hackbarth, Dirk, and Erwan Morellec, 2008, Stock Returns in Mergers and Acquisitions, Journal of Finance, 63, 1213-1252.

Hansen, Robert S., 2001, Do Investment Banks Compete in IPOs: The Advent of the "7\% Plus Contract", Journal of Financial Economics, 59, 313-346.

Hennessy, Christopher A., And Toni M. Whited, 2005, Debt Dynamics, Journal of Finance, 60, 11291165 .

Hennessy, Christopher A., And Toni M. Whited, 2007, How Costly Is External Financing? Evidence from a Structural Estimation, Journal of Finance, 62, 1705-1745.

Ju, Nenguiu, Robert Parrino, Allen M. Poteshman, and Michael S. Weisbach, 2005, Horse and Rabbits? Optimal Dynamic Capital Structure from Shareholder and Manager Perspectives, Journal of Financial and Quantitative Analysis, 259-281.

KIM, E. H., 1989, Optimal Capital Structure in Miller's Equilibrium, Financial Markets and Incomplete Information, Rowman and Littlefield, NJ.

Kou, S.G., 2002, A Jump-Diffusion Model for Option Pricing, Management Science, 48, 1086-1101.

Kou, S.G., And H. WAng, 2004, Option Pricing Under a Double Exponential Jump Diffusion Model, Management Science, 50, 1178-1192.

Kurshev, Alexander, And Ilya A. Strebulaev, 2007, Firm Size and Capital Structure, Working Paper, Stanford Graduate School of Business.

Leland, Hayne E., 1994, Corporate Debt Value, Bond Covenants, and Optimal Capital Structure, Journal of Finance, 49, 1213-1252.

Leland, Hayne E., 1998, Agency Costs, Risk Management, and Capital Structure, Journal of Finance, 53, $1213-1243$. 
Mauer, David C. And Alexander J. Triantis, 1994, Interactions of Corporate Financing and Investment Decisions: A Dynamic Framework, Journal of Finance, 49, 1253-1277.

Merton, Robert C., 1976, Option Pricing when Underlying Stock Returns Are Discontinuous, Journal of Financial Economics, 3, 125-144.

Morellec, Erwan, 2001, Asset Liquidity, Capital Structure, and Secured Debt, Journal of Financial Economics, 61, 173-206.

Morellec, Erwan, 2003, Can Managerial Discretion Explain Observed Leverage Ratios?, Review of Financial Studies, 17, 257-294.

Nelder, John A., And Roger Mead, 1967, A Simplex Method for Function Minimisation, Computer Journal, 7, 308-313.

Pulvino, Todd C., 1998, Do Asset Fire Sales Exist? An Empirical Investigation of Commercial Aircraft Transactions, Journal of Finance, 53, 939-978.

Rajan, Raghuram G., and Luigi Zingales, 1995, What Do We Know about Capital Structure? Some Evidence from International Data, Journal of Finance, 50, 1421-1460.

Sarkar, Sudipto and Fernando Zapatero, 2003, The Trade-off Model with Mean Reverting Earnings: Theory and Empirical Tests, Economic Journal, 113, 834-860.

Schaefer, Stephen M. And Ilya A. Strebulaev, 2008, Structural Models of Credit Risk Are Useful: Evidence from Hedge Ratios on Corporate Bonds, Journal of Financial Economics, 90, 1-19.

Scholes, Miles, and Mark Wolfson, 1992, Taxes and Business Strategy: A Planning Approach, PrenticeHall, Englewood Cliffs, N.J.

Shreve, Steven E., 2004, Stochastic Calculus for Finance II: Continuous-Time Models, Springer.

Strebulaev, Ilya A., 2007, Do Tests of Capital Structure Theory Mean What They Say?, Journal of Finance, 62, 1747-1787.

Subramanian, Ajay, 2008, Managerial Flexibility, Agency Costs and Optimal Capital Structure, Working Paper, Georgia State University.

Sundaresan, Suresh M., And Neng Wang, 2007, Investment under Uncertainty with Strategic Debt Service, Americal Economic Review, 97, 256-261.

Weiss, Lawrence A., 1990, Bankruptcy Resolution Direct Costs and Violations of Priority of Claims, Journal of Financial Economics, 27, 285-314.

Whited, Toni M., 2006, External Finance Constraints and the Intertemporal Pattern of Intermittent Investment, Journal of Financial Economics, 81, 467-502.

Zhdanov, Alexei, 2008, Optimal Capital Structure in a Duopoly, Working Paper, Rochester University. 
This table reports parameter values used in the benchmark calibration.

\begin{tabular}{lll}
\hline \hline Variable & Description & Value \\
\hline$\lambda_{s}$ & Shock frequency & 1.2 \\
$\lambda_{r}$ & Shock persistence & 0.6 \\
$\gamma$ & Shock magnitude & 0.225 \\
$\zeta$ & Risk-neutral adjustment & 0.65 \\
$\delta_{0}$ & Initial value of permanent cash flow & 2 \\
$\sigma_{V}$ & Volatility of unlevered asset value & 0.30 \\
$\sigma$ & Volatility of growth rate of permanent cash flow & 0.15 \\
$\tau_{e}$ & Effective tax rate on dividends & 0.4 \\
$\tau_{i}$ & Marginal income tax rate & 0.3 \\
$\alpha$ & Bankruptcy costs & 0.1 \\
$r$ & Risk-free rate & 0.055 \\
$\mu$ & Risk-neutral growth rate & 0.01 \\
$q_{E}$ & Financial distress costs & 0.1 \\
\hline \hline
\end{tabular}




\section{Table II. Financial decisions and transitory shocks}

This table reports optimal financial decisions of the model with permanent and transitory shocks of Section II. For all cases, the volatility of unlevered asset value, $\sigma_{V}$, is 0.30 . The "Permanent only" case refers to the model without transitory shocks. The "Benchmark case" refers to the model in Section II.G. For both models, all the parameters are as reported in Table I. All other rows report results for the benchmark model and parameters with the change in one of the parameters and calibrating the volatility of the permanent cash flow, $\sigma$, so that the volatility of unlevered asset value, $\sigma_{V}$, is unchanged. In particular, $\delta_{0}$ is the initial value of the permanent cash flow, $\lambda_{s}$ is the shock frequency parameter, $\lambda_{r}$ is the shock persistence parameter, and $\gamma$ is the shock magnitude parameter. $L$ is the optimal leverage ratio and $c$ is the optimal coupon level. $\Delta L(\Delta c)$ is the differences between the permanent-only leverage ratio (coupon level) and the leverage ratio (coupon level) in the model with both permanent and temporary shocks. $\sigma$ is the volatility of the permanent cash flow growth rate.

\begin{tabular}{lccccc}
\hline & $L$ & $\Delta L$ & $c$ & $\Delta c$ & $\sigma$ \\
\hline Permanent only & 57.8 & & 1.74 & & 0.30 \\
Benchmark case & 37.7 & 20.1 & 1.28 & 0.46 & 0.15 \\
$\delta_{0}=1.5$ & 28.0 & 29.8 & 0.80 & 0.94 & 0.09 \\
$\delta_{0}=3$ & 54.8 & 3.00 & 2.68 & -0.94 & 0.21 \\
$\lambda_{r}=0.3$ & 33.4 & 24.4 & 1.34 & 0.40 & 0.09 \\
$\lambda_{r}=1.2$ & 46.2 & 11.6 & 1.44 & 0.30 & 0.22 \\
$\lambda_{s}=0.6$ & 44.8 & 13.0 & 1.52 & 0.22 & 0.18 \\
$\lambda_{s}=1.8$ & 32.7 & 25.1 & 1.09 & 0.65 & 0.14 \\
$\gamma=0.15$ & 24.0 & 33.8 & 0.98 & 0.76 & 0.05 \\
$\gamma=0.3$ & 48.6 & 9.2 & 1.57 & 0.17 & 0.20 \\
$\sigma_{V}=0.25$ & 33.3 & 24.5 & 1.05 & 0.69 & 0.11 \\
$\sigma_{V}=0.5$ & 47.1 & 10.7 & 2.07 & -0.33 & 0.33 \\
\hline
\end{tabular}




\section{Table III. Comparative statics of financial decisions}

This table reports comparative statics of optimal financial decisions of the benchmark model with permanent and transitory shocks of Section II.G with respect to a number of model parameters. Optimal financial decisions are $c$, the optimal coupon level, and $L$, the optimal leverage ratio. Model parameters are as follows: $\sigma$ is the volatility of the permanent cash flow growth rate; $\delta_{0}$ is the initial value of the permanent cash flow, $\lambda_{s}$ is the shock frequency parameter, $\lambda_{r}$ is the shock persistence parameter, $\gamma$ is the shock magnitude parameter; $\zeta$ is the risk-neutral adjustment; $q_{E}$ is the financial distress cost; $\alpha$ is the bankruptcy costs; and $\tau_{e}$ is the marginal corporate tax rate. The benchmark values of the parameters are shown in bold.

\begin{tabular}{lccccc}
\hline \hline & 1 & 2 & 3 & 4 & 5 \\
\hline \hline$\lambda_{r}$ & 0.40 & 0.50 & $\mathbf{0 . 6 0}$ & 0.70 & 0.80 \\
$\mathrm{c}$ & 1.33 & 1.30 & 1.28 & 1.28 & 1.27 \\
$\mathrm{~L}$ & 34.5 & 36.4 & 37.7 & 39.8 & 41.1 \\
\hline \hline$\lambda_{s}$ & 0.80 & 1.00 & $\mathbf{1 . 2 0}$ & 1.30 & 1.50 \\
$\mathrm{c}$ & 1.32 & 1.29 & 1.28 & 1.26 & 1.21 \\
$\mathrm{~L}$ & 39.8 & 38.8 & 37.7 & 37.1 & 35.7 \\
\hline \hline$\gamma$ & 0.17 & 0.20 & $\mathbf{0 . 2 2 5}$ & 0.25 & 0.30 \\
$\mathrm{c}$ & 1.14 & 1.17 & 1.28 & 1.32 & 1.43 \\
$\mathrm{~L}$ & 28.5 & 32.7 & 37.7 & 41.0 & 47.3 \\
\hline \hline$\zeta$ & 0.50 & 0.55 & $\mathbf{0 . 6 5}$ & 0.70 & 0.80 \\
$\mathrm{c}$ & 1.45 & 1.36 & 1.28 & 1.37 & 1.48 \\
$\mathrm{~L}$ & 32.2 & 33.9 & 37.7 & 42.8 & 50.1 \\
\hline \hline$\sigma$ & 0.10 & 0.12 & $\mathbf{0 . 1 5}$ & 0.20 & 0.25 \\
$\mathrm{c}$ & 1.04 & 1.07 & 1.28 & 1.41 & 1.64 \\
$\mathrm{~L}$ & 33.2 & 33.4 & 37.7 & 39.4 & 42.9 \\
\hline \hline$q_{E}$ & 0.00 & 0.05 & $\mathbf{0 . 1 0}$ & 0.15 & 0.20 \\
$\mathrm{c}$ & 1.59 & 1.41 & 1.28 & 1.17 & 1.08 \\
$\mathrm{~L}$ & 46.9 & 41.5 & 37.7 & 34.2 & 31.1 \\
\hline \hline$\alpha$ & 0.05 & $\mathbf{0 . 1 0}$ & 0.15 & 0.20 & 0.30 \\
$\mathrm{c}$ & 1.87 & 1.28 & 0.87 & 0.61 & 0.25 \\
$\mathrm{~L}$ & 52.3 & 37.7 & 26.4 & 18.5 & 7.0 \\
\hline \hline$\tau_{e}$ & 0.35 & $\mathbf{0 . 4 0}$ & 0.45 & 0.50 & 0.60 \\
$\mathrm{c}$ & 0.62 & 1.28 & 1.54 & 1.78 & 1.98 \\
$\mathrm{~L}$ & 18.3 & 37.7 & 46.1 & 53.2 & 61.6 \\
\hline & & & & &
\end{tabular}

